Prepared in cooperation with the Central Platte Natural Resources District and the Nebraska Environmental Trust

\title{
Quantification of Aquifer Properties with Surface Nuclear Magnetic Resonance in the Platte River Valley, Central Nebraska, Using a Novel Inversion Method
}

Scientific Investigations Report 2012-5189 
COVER: Collage showing multiple photographic images of surface nuclear magnetic resonance and aquifer-test data collection.

Center top, a broad view showing trailer-mounted hydraulic pump, used in constant-discharge aquifer test. Project staff shown for general scale.

Lower left, hydraulic head recording instrumentation in the observation wells, with wire reels (also shown in large photograph) approximately 25 centimeters in diameter.

Lower right, surface nuclear magnetic resonance instrument. Boxes contain electronic equipment and are about 60 centimeters by 60 centimeters in plan view.

Top and lower left photographs taken in November 2008 by Gregory V. Steele, U.S. Geological Survey, licensed under Creative Commons.

Lower right photograph was taken by David Walsh, Vista Clara Inc., Mukilteo, Wash., November 2008. 


\section{Quantification of Aquifer Properties with Surface Nuclear Magnetic Resonance in the Platte River Valley, Central Nebraska, Using a Novel Inversion Method}

By Trevor P. Irons, Christopher M. Hobza, Gregory V. Steele, Jared D. Abraham, James C. Cannia, and Duane D. Woodward

Prepared in cooperation with the Central Platte Natural Resources District and the Nebraska Environmental Trust

Scientific Investigations Report 2012-5189 


\title{
U.S. Department of the Interior \\ KEN SALAZAR, Secretary \\ U.S. Geological Survey \\ Marcia K. McNutt, Director
}

\author{
U.S. Geological Survey, Reston, Virginia: 2012
}

For more information on the USGS - the Federal source for science about the Earth, its natural and living resources, natural hazards, and the environment, visit http://www.usgs.gov or call 1-888-ASK-USGS.

For an overview of USGS information products, including maps, imagery, and publications, visit http://www.usgs.gov/pubprod

To order this and other USGS information products, visit http://store.usgs.gov

Any use of trade, firm, or product names is for descriptive purposes only and does not imply endorsement by the U.S. Government.

Although this information product, for the most part, is in the public domain, it also may contain copyrighted materials as noted in the text. Permission to reproduce copyrighted items must be secured from the copyright owner.

Suggested citation:

Irons, T.P., Hobza, C.M., Steele, G.V., Abraham, J.D., Cannia, J.C., Woodward, D.D., 2012, Quantification of aquifer properties with surface nuclear magnetic resonance in the Platte River valley, central Nebraska, using a novel inversion method: U.S. Geological Survey Scientific Investigations Report 2012-5189, 50 p. 


\section{Contents}

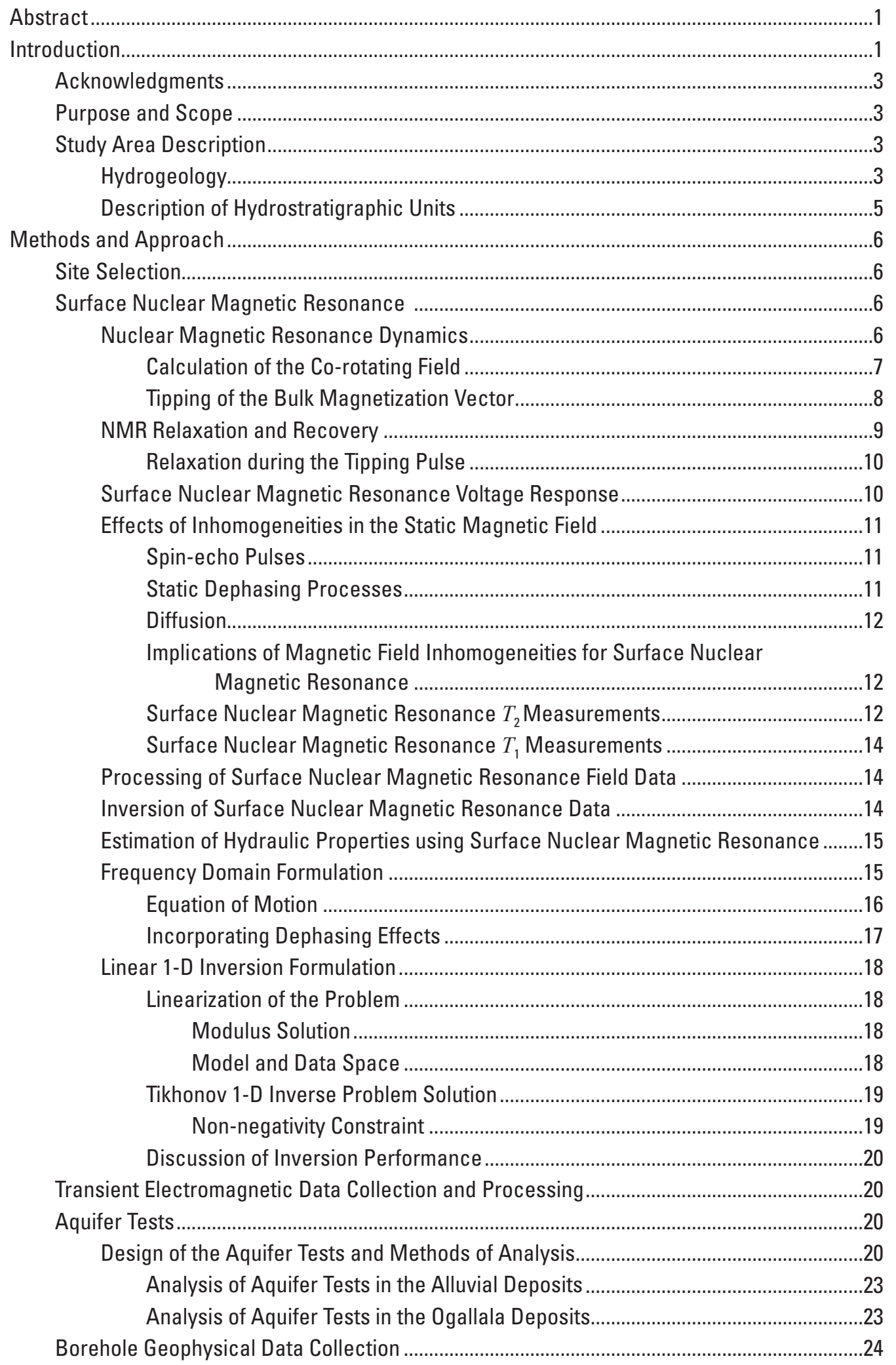




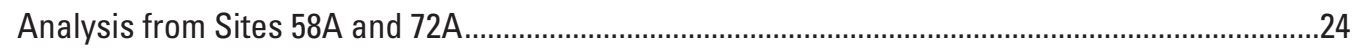

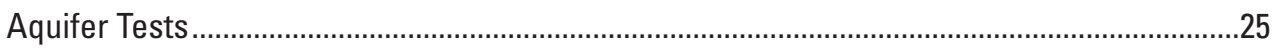

Uncertainty Analysis of SNMR Data Collection and Inversion Results.................................27

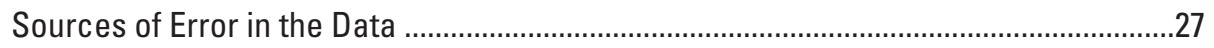

Inversion and Analysis Uncertainty and Error ……………..........................................28

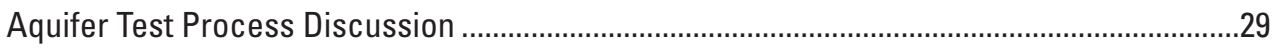

Analysis of Electromagnetic Flowmeter Tests.................................................................30

Surface NMR Inversions and Determination of the Cp Calibration Factor ...............................34

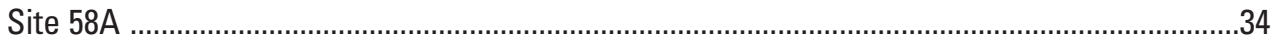

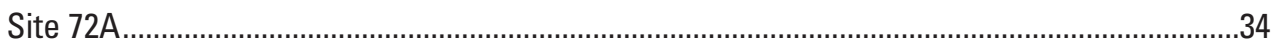

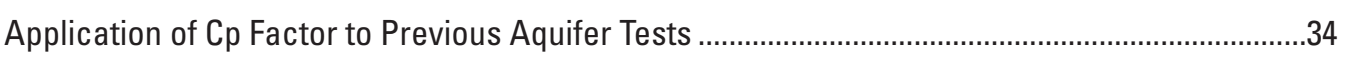

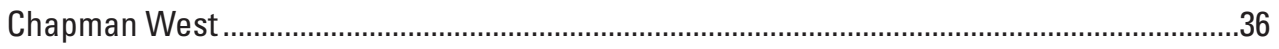

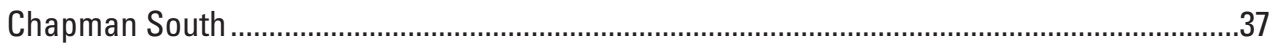

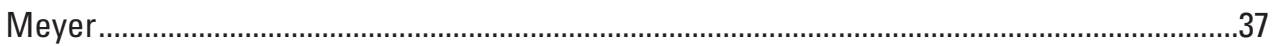

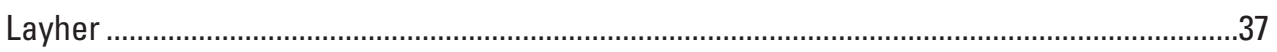

Management Systems Evaluation Area (MSEA) ………........................................................

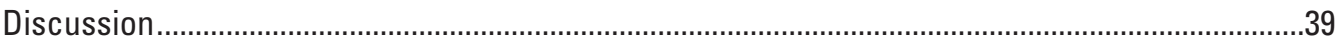

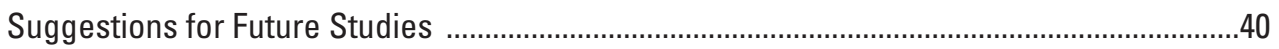

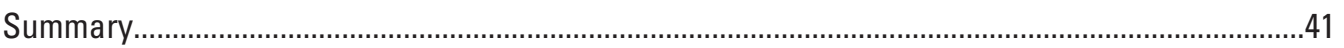

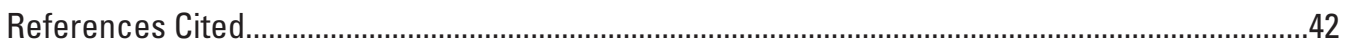

Appendix

\section{Figures}

1. Aquifer test locations and surface geophysical data-collection locations within the Central Platte Natural Resources District, Nebr.

2. Plot showing decomposition of an elliptically polarized time-varying magnetic field into counter-rotating components.

3. Series of plots showing spin dynamics of bulk magnetization before, during, and after the application of an electromagnetic tipping pulse...

4. Plot showing the tipping angle in a homogenous saturated water model for a single pulse moment.

5. Illustration after tipping of $A$, magnetization by applied transverse magnetic field, showing precession and recovery toward the equilibrium position; and $B$, a simulated nuclear magnetic resonance signal

6. Plot showing progression of an idealized surface nuclear magnetic resonance time series for a single transmitter pulse moment, with representation of the complex envelope of the data

7. Plots showing discrepancy between $T_{1}, T_{2}$, and $T_{2}^{*}$ measurements, with $A$, spins in phase immediately after a tipping pulse; and $B$, free induction decay shown as spins dephase. Application of a 180-degree pulse $(C)$ reverses motion and causes a refocusing Hahn echo, although with some diffusion loss. $D$, a series of Hahn echoes defines the $T_{2}$ parameter

8. Plots showing the free induction decay of a dephased signal

9. Comparison of the frequency-domain inversion using both $A$, strictly exponential, and $B$, dephased kernels, showing observed and predicted data. $C$, data misfit shown at the optimal trade-off parameter. 
10. Maps showing locations of aquifer tests at $A$, site $58 \mathrm{~A}$, and $B$, site $72 \mathrm{~A}$,

Dawson County, Nebr..

11. Plots showing composite analysis of results for aquifer tests for $A$, site $58 \mathrm{~A}$, and $B$, site 72A, Dawson County, Nebr.

12. Plots showing composite analysis of aquifer tests in the Ogallala Group for $A$, site $58 \mathrm{~A}$, and $B$, site $72 \mathrm{~A}$, Dawson County, Nebr.

13. Plot showing one-standard-deviation error bars of the surface nuclear magnetic resonance initial amplitude as a function of pulse moment across a single experiment.

14. Illustration of a typical surface nuclear magnetic resonance field record taken for a single pulse moment at site 58A, Dawson County, Nebr., using a square-loop transmitter (A). $B$, the last 10 milliseconds of data are shown, recording only the noise component..

15. Plot illustrating non-Gaussian surface nuclear magnetic resonance noise $(A)$, with $B$, a quantile-quantile plot of the late-time data from figure $14 B$.

16. A summary of the estimated noise levels for the surface nuclear magnetic resonance data taken at site 58A, Dawson County, Nebr..

17. A summary of the estimated noise levels for the surface nuclear magnetic resonance data taken at site 72A, Dawson County, Nebr.....

18. Two examples of the point-spread function of the surface nuclear magnetic resonance kernel, plotted from data taken at site 58A, Dawson County, Nebr.

19. Composite presentation of flow and fluid-property logs for observation well OW58A-430, Dawson County, Nebr.

20. Flowmeter-derived hydraulic conductivities for individual hydrostratigraphic units, aquifer-test hydraulic conductivities for observation wells with screened intervals plotted against depth, and composite hydraulic conductivity from aquifer tests in the Ogallala Group at site 58A, Dawson County, Nebr.

21. Flowmeter-derived hydraulic conductivities for individual hydrostratigraphic units, aquifer-test hydraulic conductivities for individual screened intervals, and composite hydraulic conductivity from an aquifer test in the Ogallala Group at site 72A, Dawson County, Nebr.

22. Results of surface nuclear magnetic resonance inversion at site $58 \mathrm{~A}$, Dawson County, Nebr.

23. Results of surface nuclear magnetic resonance inversion at site 72A, Dawson County, Nebr.

24. Comparison of surface nuclear magnetic resonance inversions at site 58A, Dawson County, Nebr., from data collected in 2009 and 2010 showing good repeatability.

25. Surface nuclear magnetic resonance inversion result for the Chapman West site, Central Platte Natural Resource District, Nebr.

26. Surface nuclear magnetic resonance inversion result from the Chapman South site, Central Platte Natural Resource District, Nebr.

27. Surface nuclear magnetic resonance inversion result from the Meyer site, Central Platte Natural Resource District, Nebr.

28. Surface nuclear magnetic resonance inversion result from the Layher site, Central Platte Natural Resource District, Nebr.

29. Surface nuclear magnetic resonance inversion result from the Management Systems Evaluation Area (MSEA) site, Central Platte Natural Resource District, Nebr.. 


\section{Tables}

1. Generalized geologic section of the principal geologic units of the High Plains aquifer in the Central Platte Natural Resources District, Nebr..

2. Primary assumptions used for analysis of aquifer tests, Dawson County, central Nebraska, 2008 and 2010

3. Dates of data acquisition, Central Platte Natural Resources District, Nebr.

4. Depth, screened interval, screen slot, and radial distance of observation wells from respective production wells, Dawson County, Nebr.

5. Depth, screened interval, screen slot, and radial distance of fully screened observation wells from respective production wells, Dawson County, Nebr..

6. Results of aquifer-test analyses, sites $58 \mathrm{~A}$ and $72 \mathrm{~A}$, Dawson County, central Nebraska, 2008 and 2010.

7. Primary investigator, reference date, site, well identifier, aquifer thickness, screened interval below land surface, and hydraulic conductivity of observation wells at selected aquifer-test sites in the Central Platte Natural Resources District, Nebr.

\section{Conversion Factors}

SI to Inch/Pound

\begin{tabular}{|c|c|c|}
\hline Multiply & By & To obtain \\
\hline \multicolumn{3}{|c|}{ Length } \\
\hline centimeter $(\mathrm{cm})$ & 0.3937 & inch (in.) \\
\hline meter $(\mathrm{m})$ & 3.281 & foot $(\mathrm{ft})$ \\
\hline kilometer $(\mathrm{km})$ & 0.6214 & mile (mi) \\
\hline \multicolumn{3}{|c|}{ Area } \\
\hline hectare (ha) & 2.471 & Acre \\
\hline square meter $\left(\mathrm{m}^{2}\right)$ & 10.76 & square foot $\left(\mathrm{ft}^{2}\right)$ \\
\hline hectare (ha) & 0.003861 & square mile $\left(\mathrm{mi}^{2}\right)$ \\
\hline square kilometer $\left(\mathrm{km}^{2}\right)$ & 0.3861 & square mile $\left(\mathrm{mi}^{2}\right)$ \\
\hline \multicolumn{3}{|c|}{ Volume } \\
\hline liter (L) & 0.2642 & gallon (gal) \\
\hline \multicolumn{3}{|c|}{ Flow rate } \\
\hline meter per day $(\mathrm{m} / \mathrm{d})$ & 3.281 & foot per day $(\mathrm{ft} / \mathrm{d})$ \\
\hline liter per minute $(\mathrm{L} / \mathrm{min})$ & 0.264 & gallon per minute $(\mathrm{gal} / \mathrm{min})$ \\
\hline \multicolumn{3}{|c|}{ Hydraulic conductivity } \\
\hline meter per day $(\mathrm{m} / \mathrm{d})$ & 3.281 & foot per day (ft/d) \\
\hline \multicolumn{3}{|c|}{ Transmissivity } \\
\hline meter squared per day $\left(\mathrm{m}^{2} / \mathrm{s}\right)$ & 930,000 & foot squared per day $\left(\mathrm{ft}^{2} / \mathrm{d}\right)$ \\
\hline
\end{tabular}

Temperature in degrees Celsius $\left({ }^{\circ} \mathrm{C}\right)$ may be converted to degrees Fahrenheit $\left({ }^{\circ} \mathrm{F}\right)$ as follows: ${ }^{\circ} \mathrm{F}=\left(1.8 x^{\circ} \mathrm{C}\right)+32$

Temperature in degrees Fahrenheit $\left({ }^{\circ} \mathrm{F}\right)$ may be converted to degrees Celsius $\left({ }^{\circ} \mathrm{C}\right)$ as follows: ${ }^{\circ} \mathrm{C}=\left({ }^{\circ} \mathrm{F}-32\right) / 1.8$

Vertical coordinate information is referenced to the North American Vertical Datum of 1988 (NAVD 88).

Horizontal coordinate information is referenced to the North American Datum of 1983 (NAD 83). Altitude, as used in this report, refers to distance above the vertical datum. 


\section{Abbreviations and Acronyms}

$\begin{array}{ll}\text { COHYST } & \text { Platte River Cooperative Hydrology Study } \\ \text { CPNRD } & \text { Central Platte Natural Resources District } \\ \text { EM } & \text { electromagnetic } \\ \text { FID } & \text { free induction decay } \\ \text { IMP } & \text { Integrated Water-Management Plan } \\ \text { NRD } & \text { Natural Resources District } \\ \text { NMR } & \text { nuclear magnetic resonance } \\ \text { SNMR } & \text { surface nuclear magnetic resonance }\end{array}$

\section{Mathematical Symbols}

\begin{tabular}{ll}
\hline Symbol & \multicolumn{1}{c}{ Meaning } \\
\hline$j$ & $\sqrt{-1}$ \\
$\mathbf{r}$ & position vector in 3D space \\
$t$ & Time \\
$e$ & Euler's number \\
$\mathbf{B}_{0}$ & NMR static magnetic field (Earth's field) \\
$\hat{\mathbf{B}}_{0}$ & unit vector aligned with static field \\
$B_{0}$ & magnitude of the static field \\
$\mathbf{M}_{\mathrm{N}}^{(0)}$ & steady state nuclear volume magnetization \\
$\mathbf{M}_{\mathrm{N}}$ & nuclear volume magnetization \\
$\mathbf{M}_{\mathrm{N}}^{\perp}$ & projection of nuclear volume magnetization onto the plane perpendicular to $\hat{\mathbf{B}}_{0}$ \\
$\boldsymbol{B}_{\mathrm{T}}$ & complex magnetic field produced by SNMR transmitter \\
$\boldsymbol{B}_{N}^{\perp}$ & projection of the complex transmitter field onto the plane perpendicular to the \\
& $\quad$ static field \\
$\mathbf{B}_{\mathrm{T}}^{+}$ & real co-rotating component of perpendicular transmitter field \\
$\mathbf{B}_{\mathrm{T}}^{-}$ & real counter-rotating component of perpendicular transmitter field \\
$\hat{\mathbf{b}}_{T}$ & static unit vector lying on the transverse plane of $\hat{\mathbf{B}}_{0}$ defining local NMR frame \\
& $\quad$ of reference \\
$\hat{\mathbf{b}}_{\mathrm{T}}^{\perp}$ & static unit vector lying on the perpendicular plane of $\hat{\mathbf{B}}_{0}$ also orthogonal to $\hat{\mathbf{b}}_{\mathrm{T}}$ \\
$\alpha_{T}$ & Scalar used in elliptic field decomposition \\
$\beta_{T}$ & Scalar used in elliptic field decomposition \\
$\boldsymbol{B}_{\mathrm{R}}$ & hypothetical complex adjoint receiver field \\
$\mathbf{B}_{\mathrm{R}}^{+}$ & real co-rotating hypothetical adjoint receiver field \\
$\mathbf{B}_{\mathrm{R}}^{-}$ & real counter-rotating hypothetical adjoint receiver field \\
$n_{\mathrm{H}} \mathrm{O}$ & number density of liquid water molecules \\
$\gamma_{\mathrm{H}}$ & gyromagnetic ratio of hydrogen nucleus \\
$\hbar$ & h-bar, Plank constant divided by $2 \pi$ \\
$k_{B}$ & Boltzmann constant \\
$T$ & absolute temperature, in Kelvin \\
$f$ & volume fraction of water \\
$\chi_{\mathrm{N}}$ & nuclear paramagnetic susceptibility \\
$v_{L}$ & Larmor frequency, in Hz \\
$\omega$ & angular frequency \\
$\omega_{L}$ & angular Larmor frequency \\
$\theta_{T}$ & nuclear tip angle \\
&
\end{tabular}




\section{Mathematical Symbols-Continued}

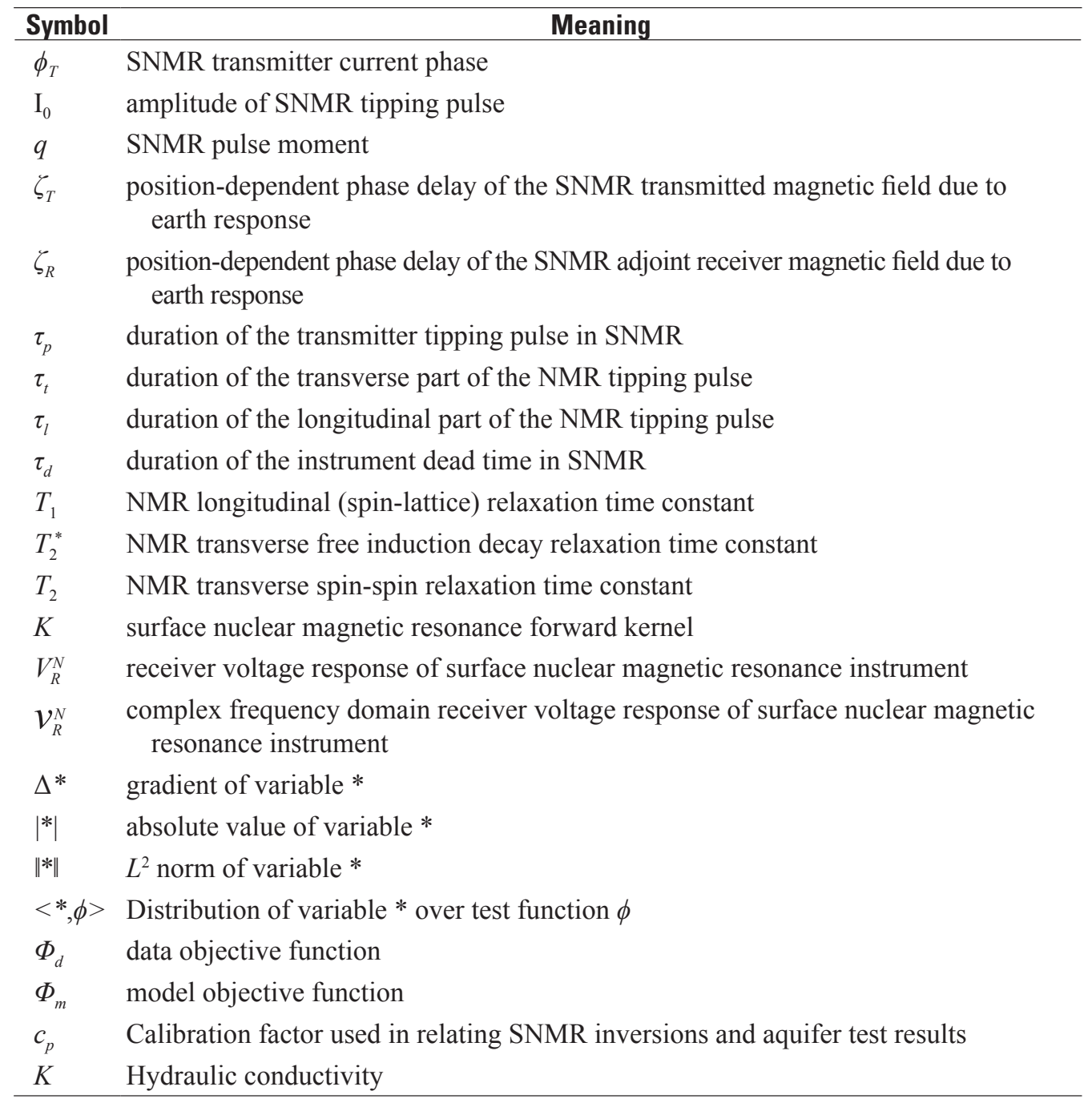

\section{Mathematical Operators}

\begin{tabular}{ll}
\hline \multicolumn{1}{c}{ Symbol } & \multicolumn{1}{c}{ Meaning } \\
\hline $\mathcal{F}\{*\}$ & Fourier transform of variable $*$ \\
$\mathbf{a} \times \mathbf{b}$ & Cross product between the two vectors $\mathbf{a}$ and $\mathbf{b}$ \\
$\mathbf{a} \cdot \mathbf{b}$ & Scalar product between the two vectors $\mathbf{a}$ and $\mathbf{b}$ \\
$\int_{V} x \mathrm{~d}^{3} \mathrm{r}$ & volume integral of $x$ over all space \\
\hline
\end{tabular}




\title{
Quantification of Aquifer Properties with Surface Nuclear Magnetic Resonance in the Platte River Valley, Central Nebraska, Using a Novel Inversion Method
}

\author{
By Trevor P. Irons, Christopher M. Hobza, Gregory V. Steele, Jared D. Abraham, James C. Cannia, \\ and Duane D. Woodward
}

\section{Abstract}

Surface nuclear magnetic resonance, a noninvasive geophysical method, measures a signal directly related to the amount of water in the subsurface. This allows for low-cost quantitative estimates of hydraulic parameters. In practice, however, additional factors influence the signal, complicating interpretation. The U.S. Geological Survey, in cooperation with the Central Platte Natural Resources District, evaluated whether hydraulic parameters derived from surface nuclear magnetic resonance data could provide valuable input into groundwater models used for evaluating water-management practices. Two calibration sites in Dawson County, Nebraska, were chosen based on previous detailed hydrogeologic and geophysical investigations. At both sites, surface nuclear magnetic resonance data were collected, and derived parameters were compared with results from four constant-discharge aquifer tests previously conducted at those same sites. Additionally, borehole electromagnetic-induction flowmeter data were analyzed as a less-expensive surrogate for traditional aquifer tests. Building on recent work, a novel surface nuclear magnetic resonance modeling and inversion method was developed that incorporates electrical conductivity and effects due to magnetic-field inhomogeneities, both of which can have a substantial impact on the data. After comparing surface nuclear magnetic resonance inversions at the two calibration sites, the nuclear magnetic-resonance-derived parameters were compared with previously performed aquifer tests in the Central Platte Natural Resources District. This comparison served as a blind test for the developed method. The nuclear magnetic resonance-derived aquifer parameters were in agreement with results of aquifer tests where the environmental noise allowed data collection and the aquifer test zones overlapped with the surface nuclear magnetic resonance testing. In some cases, the previously performed aquifer tests were not designed fully to characterize the aquifer, and the surface nuclear magnetic resonance was able to provide missing data. In favorable locations, surface nuclear magnetic resonance is able to provide valuable noninvasive information about aquifer parameters and should be a useful tool for groundwater managers in Nebraska.

\section{Introduction}

In 2004, the Nebraska State Legislature passed Legislative Bill 962 (LB962) requiring all Natural Resources Districts (NRDs) to develop an integrated water-management plan (IMP). The IMP requires a balance of surface water and groundwater supply and demand for areas within each NRD declared fully or over-appropriated with respect to water use by the Nebraska Department of Natural Resources (Ostdiek, 2009). The IMP created for the Central Platte Natural Resources District (CPNRD) needed to address concerns raised by prolonged drought and the effects of water-resources development on endangered species and the long-term water supply. Decrease in available surface-water and groundwater resources has affected substantially the local riparian ecosystem; moreover, several threatened and endangered species use the central Platte River valley for habitat. Changes in flow regime and land use have transformed the Platte River channel and altered adjacent wet meadows; the complexity of this system and interaction between the available surface-water and groundwater resources, however, is not fully understood (U.S. Geological Survey, 2010).

As part of their management plan, the CPNRD has been involved with ongoing groundwater flow-modeling efforts to understand the effects of specific groundwater-management decisions on streamflow. The Platte River Cooperative Hydrology Study (COHYST, http://cohyst.dnr.ne.gov/) was initiated as a major component of a three-state (Colorado, Nebraska, and Wyoming) cooperative agreement with the U.S. Department of the Interior. The COHYST was tasked to collect additional data and to create numerical groundwaterflow models for use in support of regulatory and management decisions. The COHYST is a cooperative effort to improve the understanding of hydrological conditions of the Platte River upstream of Columbus, Nebr., and to evaluate changes to existing and proposed water uses in the Platte River Basin (fig. 1).

For the COHYST groundwater-flow models, predictive accuracy depends upon the quality and quantity of hydrologic and geologic data available in a particular modeled area. 


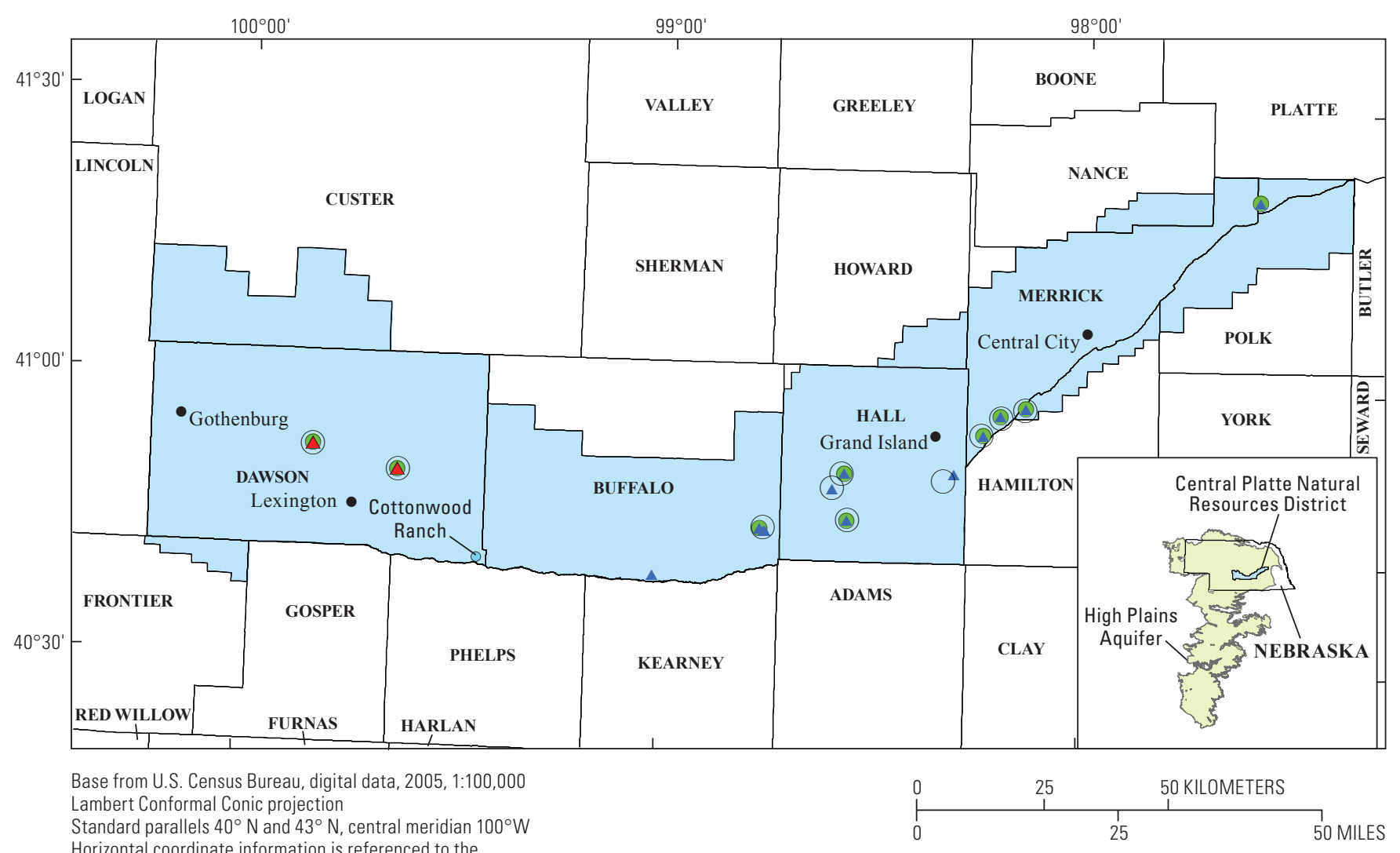
Horizontal coordinate information is referenced to the North American Datum of 1983 (NAD 83)

EXPLANATION

$\begin{array}{ll}\Delta & \text { Aquifer test and flowmeter site } \\ \Delta & \text { Previous aquifer test sites } \\ \bigcirc & \text { MRS sounding } \\ \bigcirc & \text { TDEM sounding }\end{array}$

Figure 1. Aquifer test locations and surface geophysical data-collection locations within the Central Platte Natural Resources District, Nebr.

Borehole logs typically are used in conjunction with regional bedrock topography, outcrop observations, and other ancillary information to build groundwater-flow models that best reflect understanding of the scale and geometry of the studied aquifer. Given the heterogeneity and size of certain aquifers, availability of reliable geologic data commonly is relatively sparse. Lack of reliable geologic data is a significant limitation to model results and is one of the common sources of model error (Konikow and Bredehoeft, 1992). The quantitative estimates and assignment of hydraulic properties for various hydrostratigraphic units used in COHYST groundwater-flow models were described by Cannia and others (2006). Quantitative estimates of hydraulic properties, such as hydraulic conductivity and specific yield, were assigned from lithologic descriptions of test holes (Johnson, 1967; Peckenpaugh and Dugan, 1983). Historically, the only means of obtaining additional detailed, quantitative information on an aquifer system has been through installation of observation wells and performance of aquifer tests. Drilling additional test holes, installing observation wells, and performing aquifer tests are all time-consuming and expensive. Given the heterogeneity and size of the aquifer systems simulated with the COHYST groundwater-flow models, an improved, more cost-effective approach was needed to provide quantitative estimates of aquifer properties. One approach was to combine nonintrusive surface geophysical methods with a strategic drilling program to provide greater aquifer coverage with fewer wells. Surface geophysical techniques have been used successfully to interpret elevations of changes in lithologic layers between test holes and to infer vertical and horizontal distributions of aquifer properties (Ball and others, 2006; Stanton and others, 2003). These data can be used to develop more accurate hydrogeologic inputs for groundwater-flow models, as well as to provide more detailed information on saturated thickness and aquifer storage for management plans.

Currently, a growing body of work suggests that the surface nuclear magnetic resonance (SNMR) technique can provide information about water content and hydraulic conductivity of the measured area, similar to that of an aquifer test (Legchenko and others, 2006; Plata and Rubio, 2008; Nielsen and others, 2011). Surface NMR soundings are nonintrusive and are collected in a matter of hours, making this technique time- and cost-effective in comparison to test-hole drilling, well installation, and aquifer testing. Previous work, 
completed as a pilot project using the SNMR technique at the Cottonwood Ranch site near Elm Creek and Lexington, Nebr. (fig. 1), showed promising results; lack of ground-truth data, such as aquifer tests, in the immediate study area, however, led to inability to assess the accuracy of the produced data sets. A novel surface nuclear magnetic-resonance modeling and inversion method has been developed that incorporates electrical conductivity and effects due to magnetic-field inhomogeneities (Irons and others, 2010).

To evaluate the utility of the SNMR technique in estimating aquifer properties, the U.S. Geological Survey (USGS), in cooperation with the CPNRD, compared SNMR soundings with data from four aquifer tests completed in Dawson County, Nebr., at two locations (sites 58A and 72A). In addition, comparisons were made with borehole electromagnetic (EM) flowmeter tests at sites 58A and 72A (Anderson and others, 2009). Electromagnetic flowmeters represent another cost-effective method to determine aquifer properties (Paillet, 2000), but flowmeter installations still require the drilling of a borehole. Comparisons of SNMR inversions in other parts of the CPNRD where aquifer tests were performed also have been completed.

\section{Acknowledgments}

This project would not have been possible if not for the help of many people. We would like to thank the following individuals for their help in data collection and processing: Chad Ailes, Alton Anderson, Benjamin Bloss, Tom Downey, Brian Imig, Jim Goeke, Elliot Grunewald, Jonah Sullivan, Andy Teeple, and Dave Walsh. There were many long days and nights involved in this project, and their hard work is greatly appreciated. Additionally, the following people provided invaluable intellectual input: Wade Kress, Katherine Dlubac, Jim Goeke, Elliot Grunewald, Kristina Keating, Rosemary Knight, Steve Peterson, and Dave Walsh. We would also like to thank Jeff Lucius, Andy Kass, and John Williams for assistance in preparing and reviewing this report.

We would like to thank the landowners who graciously allowed access to their property, including Calvin Stock and Steve Weides. Finally, this project would not have been possible without the financial support and cooperation with the Central Platte Natural Resources District and the Nebraska Environmental Trust.

\section{Purpose and Scope}

The purpose of this report is to compare collected SNMR data to the results from four aquifer tests completed in two locations in Dawson County, Nebr. Individual, traditional constant-discharge aquifer tests were performed in the Quaternary alluvial deposits (one at each site) and in the Tertiary Ogallala Group (one at each site). In addition to traditional aquifer tests, aquifer properties were quantified by borehole electromagnetic (EM) flowmeter data collected at each site.

\section{Study Area Description}

The Central Platte Natural Resources District (CPNRD) lies within the Great Plains Physical Province (Fenneman, 1946) and covers the Platte River valley and uplands to the north and south, from the western border of Dawson County to just upstream of the mouth of the Loup River near Columbus, Nebr. (fig. 1). The Platte River valley is the predominant landform in the CPNRD, where a major subdominant landform is the loess-covered uplands that flank the Platte River valley to the north and south. Those loess-covered uplands (herein referred to simply as uplands) also include dissected plains, sand hills, and bluffs.

Land use within the CPNRD is primarily agricultural. Of the 865,500 hectares that comprise the CPNRD, the land for agricultural crops and other uses is broken down to approximate percentages as follow: 38.4 for irrigated corn and soybeans; 41.1, rangeland or pasture; 9.2, dryland crops; 3.5, riparian woodlands; 3.0 , irrigated alfalfa; 2.3 , urban or developed; 1.6, open water and wetlands; and all other land uses constituting less than a percent (Center for Advanced Land Management Information Technologies, 2010). Center-pivot or gravity-irrigated corn and soybean production dominates all irrigation in the central Platte River valley. Surface-water irrigation also is prevalent but utilized primarily in the western part of the CPNRD. Surface-water canals include Cozad, Gothenburg, Dawson County, Kearney, Thirty-Mile, Orchard Alfalfa, and Elm Creek (Peterson, 2007). Precipitation is variable from east to west across the CPNRD with more arid conditions occurring to the west.

Precipitation averaged 55.7 centimeters per year $(\mathrm{cm} / \mathrm{yr})$ from 1895 to 2010 at Gothenburg, Nebr. (western Dawson County) and $65.3 \mathrm{~cm} / \mathrm{yr}$ from 1930 to 2009 near Central City, Nebr., in the eastern part of the CPNRD (National Oceanic and Atmospheric Administration, 2010). Approximately 65 percent of the precipitation is received from thunderstorms during the growing season from April through August. Low humidity, abundant sunshine, and persistent winds contribute to relatively high rates of evaporation (Gutentag and others, 1984).

The climate is characterized by cold winters and warm summers typical of continental mid-continent locations (Carney, 2008). Mean monthly temperatures ranged from $-3.7^{\circ} \mathrm{C}$ in January to $24.3^{\circ} \mathrm{C}$ in July at Gothenburg during the period of 1895 to 2010. Mean monthly temperatures (1930 to 2009) were similar in Central City, ranging from $-4.3{ }^{\circ} \mathrm{C}$ in January to $25.2{ }^{\circ} \mathrm{C}$ in July (National Oceanic and Atmospheric Administration, 2010).

\section{Hydrogeology}

Much of the CPNRD is lowland of the modern Platte River valley (Center for Advanced Land Management Information Technologies, 2010), and the entire CPNRD overlies the High Plains aquifer (Gutentag and others, 1984). Previous investigations have described the geology and occurrence of groundwater within the study area (Darton, 1898 and 
1905; Lugan and Wenzel, 1938; Waite, 1949; Peckenpaugh and Dugan, 1983). Condon (2005) described the geologic history of the area. Cannia and others (2006) created a hydrostratigraphic framework and characterized underlying aquifers of the CPNRD and surrounding areas. That hydrostratigraphic framework was used in recently published COHYST groundwater-flow models (Carney, 2008; Peterson, 2007) which include all or parts of the CPNRD.

The eastern border of the CPNRD roughly corresponds with the eastern edge of the High Plains aquifer system (fig. 1). The part of the High Plains aquifer that lies within the CPNRD consists of one or more hydrologically connected geologic units of late Tertiary or Quaternary age (Gutentag and others, 1984; Weeks and Gutentag, 1988). The base of the High Plains aquifer varies from Tertiary deposits in the west to Upper Cretaceous deposits in the east (Cannia and others, 2006). Table 1 summarizes in a generalized geologic section the principal geologic units of the High Plains aquifer in the CPNRD.

Hydrogeologic characteristics are variable between the lowlands and the uplands in the CPNRD. In the lowlands (the Platte River valley), Quaternary alluvial sand and gravel deposits form the primary aquifer in the CPNRD. In the upland areas, however, where Quaternary sand and gravel deposits are unsaturated, absent, or of only insufficient thickness, the Ogallala Group substitutes as the primary aquifer of the CPNRD. Within the respective primary aquifers, depth to groundwater in the CPNRD is variable, ranging from near land surface adjacent to the Platte River or other major tributaries, to more than $60 \mathrm{~m}$ below land surface in the

Table 1. Generalized geologic section of the principal geologic units of the High Plains aquifer in the Central Platte Natural Resources District, Nebr.

\begin{tabular}{|c|c|c|c|c|c|}
\hline Age & Series & \multicolumn{2}{|c|}{ Stratigraphy } & \begin{tabular}{|c|} 
Lithology \\
\end{tabular} & Hydrostratigraphy \\
\hline \multirow{3}{*}{ Quaternary } & \multirow{2}{*}{ 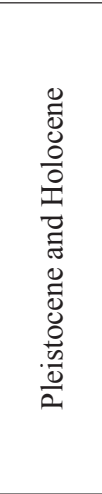 } & \multicolumn{2}{|c|}{ Valley-fill deposits } & $\begin{array}{l}\text { Stream-laid deposits of gravel, sand, silt, } \\
\text { and clay associated with the most recent } \\
\text { cycle of erosion and deposition along } \\
\text { present streams. Forms part of High Plains } \\
\text { aquifer where hydraulically connected to } \\
\text { underlying Quaternary and Tertiary deposits }\end{array}$ & \multirow{6}{*}{ High Plains aquifer } \\
\hline & & \multicolumn{2}{|c|}{ Eolian deposits } & $\begin{array}{l}\text { Dune sand: fine to medium sand with small } \\
\text { amount of clay, silt, and coarse sand formed } \\
\text { into hills and ridges by the wind. Forms part } \\
\text { of High Plains aquifer where saturated. } \\
\text { Loess deposits: silt with lesser amounts } \\
\text { of very fine sand and clay deposited as } \\
\text { windblown dust. }\end{array}$ & \\
\hline & 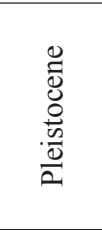 & \multicolumn{2}{|c|}{$\begin{array}{l}\text { Unconsolidated } \\
\text { alluvial deposits }\end{array}$} & $\begin{array}{l}\text { Stream-laid deposits of gravel, sand, silt, and } \\
\text { clay locally cemented by calcium carbon- } \\
\text { ate into caliche or mortar beds. Forms part } \\
\text { of the High Plains aquifer where hydrauli- } \\
\text { cally connected laterally or vertically to } \\
\text { Tertiary deposits. }\end{array}$ & \\
\hline \multirow{4}{*}{ Tertiary } & \multirow[t]{2}{*}{$\begin{array}{l}\stackrel{0}{0} \\
\stackrel{0}{0} \\
\stackrel{0}{\Xi}\end{array}$} & \multicolumn{2}{|c|}{ Ogallala Group } & $\begin{array}{l}\text { Poorly sorted clay, slit, sand and gravel } \\
\text { generally unconsolidated; forms caliche } \\
\text { layers or mortar beds when cemented } \\
\text { by calcium carbonate. Ogallala com- } \\
\text { prises large part of High Plains aquifer } \\
\text { where saturated. }\end{array}$ & \\
\hline & & \multicolumn{2}{|c|}{ Arikaree Group } & Fine-grained sandstone & \\
\hline & \multirow{2}{*}{ 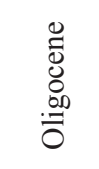 } & \multirow{2}{*}{ 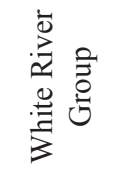 } & Upper & Siltstone and sandstone & \\
\hline & & & Lower & Siltstone and claystone & \multirow[b]{2}{*}{ Confining unit } \\
\hline Cretaceous & 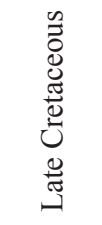 & \multicolumn{2}{|c|}{ Pierre Shale } & Shale & \\
\hline
\end{tabular}

Modified from Gutentag and others, 1984. 
uplands of Dawson County (University of Nebraska-Lincoln, Conservation and Survey Division, 1998). Recharge in the CPNRD primarily is from local precipitation but also can come from seepage from the Platte River and its tributaries, seepage from canals and laterals, and applied irrigation water (Waite, 1949). Steele (1994) described recharge from precipitation in various physiographic settings in the CPNRD. Precipitation falling in the Platte valley in Dawson County became recharge to the groundwater system within 6 hours, whereas precipitation that fell on terrace deposits west of Grand Island took approximately 11 days before reaching the water table.

\section{Description of Hydrostratigraphic Units}

Hydrostratigraphic units found within the CPNRD include the Upper Cretaceous units, the White River Group, Ogallala Group, and Quaternary alluvium, all components of the High Plains aquifer. Upper Cretaceous units and the Oligocene Brule Formation of the White River Group (referred to hereinafter as the Brule Formation) form the base of the High Plains aquifer in the CPNRD area (Cannia and others, 2006). In the eastern part of the CPNRD, the High Plains aquifer is underlain by relatively impermeable Cretaceous units that include the Pierre Shale and the Niobrara Formation (Peterson, 2007). The Brule Formation is relatively impermeable massive siltstone composed primarily of eolian silt but contains localized alluvial deposits (Cannia and others, 2006). The Brule Formation is considered the base of the aquifer beneath the CPNRD (Weeks and others, 1988; Peterson, 2007; Carney, 2008).

The Oligocene to Miocene Arikaree Group (herein referred to as the Arikaree) largely is limited to the western part of Nebraska (Swinehart and others, 1985). The Arikaree likely exists only locally in paleovalleys in the western part of the CPNRD. Thicknesses of the Arikaree probably are less than $30 \mathrm{~m}$. The Arikaree is a massive, very fine- to finegrained sandstone with localized beds of volcanic ash, silty sand, and sandy clay (Condra and Reed, 1943). The Arikaree is considered part of the High Plains aquifer system, however, the Arikaree does not yield large volumes of water to wells (Gutentag and others, 1984).

The Ogallala Group (herein referred to as the Ogallala) formed from a poorly sorted mixture of sand, silt, clay, and gravel (Condra and Reed, 1943). The Ogallala generally is unconsolidated or weakly consolidated but does contain layers of sandstone cemented by calcium carbonate. Within the CPNRD the Ogallala has not been subdivided into formations recognized in other areas because of the difficulty in correlating units in the subsurface. The Ogallala was deposited by aggrading streams that filled paleovalleys eroded into Cretaceous or pre-Ogallala Tertiary rocks (Swinehart and others, 1985). The base of the Ogallala is a complex surface formed from multiple episodes of erosion and deposition. The location of Ogallala paleovalleys in Nebraska has been proposed by previous researchers (Swinehart and others, 1985; Swinehart and Diffendal, 1989), but the paleovalleys may be only a fraction of the drainage systems that existed during the Miocene. Much of the deposition of the Ogallala was restricted in valleys along drainage systems originating from mountains in present-day Wyoming and Colorado (Swinehart and others, 1985). Deposition of the Ogallala may have occurred on broad, low-relief plains as well (Swinehart and Diffendal, 1989).

The Ogallala underlies the western part of the CPNRD and is the principal hydrogeologic unit in the High Plains aquifer system. In the CPNRD, the Ogallala is an important water source (Waite, 1949) and reaches a maximum thickness of more than $120 \mathrm{~m}$ in northwestern Dawson County (University of Nebraska-Lincoln, Conservation and Survey Division, 2010; Diffendal, 1991). Previous studies (Chen and others, 2005; U.S. Department of the Interior Bureau of Reclamation, 1993, unpub. written commun. to Central Platte Natural Resources District, Nebr., dated June 22, 1993, Aquifer test data-Prairie Bend unit [aquifer test], 28 p.) indicate hydraulic conductivity $(\mathrm{K})$ values for the Ogallala in the CPNRD generally are around $5.6 \times 10^{-7}$ to $5.9 \times 10^{-5} \mathrm{~m} / \mathrm{s}$. Throughout the CPNRD, the saturated thickness of the Ogallala varies locally but generally ranges from between 30 and $150 \mathrm{~m}$. As seen from aquifer tests from that Bureau of Reclamation communication and other studies (such as Chen and others, 2005), where overlying saturated Quaternary deposits exist, those sandy and gravelly units can be in hydraulic contact with the Ogallala. McGuire and Kilpatrick (1998), however, reported that the overlying Quaternary deposits are not in direct contact with the Ogallala. As a result, for the CPNRD, the Ogallala generally acts as a leaky confined aquifer; this varies locally, however, and trends towards less leaky to the east, as described in the paragraph below.

Quaternary deposits of clay, or silt and clay, directly overlie the Ogallala throughout the CPNRD. These clay, or silt and clay, deposits (herein referred to as clay) typically separate the Ogallala from overlying sand and gravel deposits (alluvium), especially in lowland areas. In the upland areas clay deposits also exist, but sand and gravel overlying the clay deposits and underlying eolian deposits are more localized. All told, the clay deposits typically act as a leaky confining unit to the Ogallala. This confining unit ranges in thickness from about $3 \mathrm{~m}$ in the west to more than $35 \mathrm{~m}$ in the eastern part of the CPNRD. In the western part of the CPNRD, clay deposits locally occur in hydraulic connection with the underlying Ogallala. In the eastern part of the CPNRD, where the clay deposits are thicker, the hydraulic connection between the Ogallala and the overlying alluvium is less tenable.

Alluvial deposits in the lowlands largely are sand and gravel units with interlayered silt and clay. Groundwater typically is found throughout these deposits at depths which vary from less than $1 \mathrm{~m}$ near the major rivers to more than $10 \mathrm{~m}$ near the margins of the Platte River valley. The upland deposits largely are loess, directly overlying localized alluvium or directly in contact with the Ogallala. Depths to groundwater in the upland areas varies from less than $10 \mathrm{~m}$ in isolated, small sand and gravel pockets to more than $50 \mathrm{~m}$. 
Where sufficient saturated deposits are present in the CPNRD, the Quaternary alluvial sand and gravel deposits (herein referred to as the alluvial deposits) form a primary aquifer largely because of their widespread distribution, shallow depth, and ability to yield sufficient groundwater supplies to high-capacity wells. The alluvial deposits are not confined to the Platte River valley. The historical Platte River (Pliocene and Pleistocene versions of the Platte River) deposited sand and gravel over much of south-central Nebraska (Condon, 2005). The thickness of the fluvial Pleistocene, Pliocene, and Holocene sediments ranges from less than $8 \mathrm{~m}$ in Dawson County to more than $68 \mathrm{~m}$ in the eastern part of the CPNRD (Condon, 2005). Those older fluvial deposits locally exist beneath some of the upland deposits but have not been extensively mapped. McGuire and Kilpatrick (1998) and Chen and others (2003) report hydraulic conductivity $(\mathrm{K})$ values for the alluvial aquifer of $1.1 \times 10^{-3}$ to $1.6 \times 10^{-3} \mathrm{~m} / \mathrm{s}$. The alluvial aquifer sustains yields to wells from about 3,000 to 5,700 liters/minute in the Platte River valley (Waite, 1949).

\section{Methods and Approach}

This section outlines the methods and approach used in this report. A thorough introduction to theory and the physical basis of the nuclear magnetic resonance method is given, as well as its application to groundwater investigations. Recent improvements in data inversion and a new inversion method account for dephasing of the free-induction decay (FID) signal. Transient electromagnetic (TEM) methods are introduced, along with their processing and inversion for electrical resisitivty models. The third part of the Methods and Approach section focuses on the design and analytical methods of the four aquifer tests that were completed within the CPNRD. Flow and fluid-property $\log$ data collection is described briefly and summarizes the datacollection procedures stated by Anderson and others (2009).

\section{Site Selection}

Site selection for location of the two aquifer tests followed a planned approach that included inventory of available hydrogeological data and additional data collection. Within Dawson County, over 100 potential sites (not shown on map) were identified that could fill important data gaps in the Platte River Cooperative Hydrology Study (COHYST) groundwater model. From that set of locations, 23 were selected based on physical characteristics such as access to the site, proximity of surface water, drainage, and a review of known hydrogeology. At the 23 selected sites, TEM soundings were collected to build the electrical stratigraphy at each location (Payne and Teeple, 2011). Eleven sites for surface nuclear magnetic resonance (SNMR) data collection were selected from the 23 TEM sites based on evaluation of aquifer characteristics, primarily aquifer thickness (fig. 1). A subset of three locations was selected by evaluation of the TEM and SNMR data for detailed test-hole drilling, logging, and borehole geophysical logs (Anderson and others, 2009). Finally, two sites were selected for aquifer tests within the alluvium and Ogallala formations respectively (fig. 1).

\section{Surface Nuclear Magnetic Resonance}

The SNMR method was proposed and demonstrated by Semenov (1987) and relies on the principle that an ensemble of hydrogen protons in liquid water forms a weak bulk magnetization expressed as $\mathbf{M}_{N}^{(0)}(\mathbf{r}, T)$ in the presence of the Earth's magnetic field $\mathbf{B}_{0}$, according to Curie's law (for example Abragam, 1961):

$$
\begin{aligned}
\mathbf{M}_{N}^{(\mathrm{O})}(\mathbf{r}, T) & =2 n_{\mathrm{H}_{2} \mathrm{O}} B_{0} \frac{\gamma_{\mathrm{H}}^{2} \hbar^{2}}{4 k_{B} T} f(\mathbf{r}) \hat{\mathbf{B}}_{0} \\
& =\chi_{N}(T) f(\mathbf{r}) \mathbf{B}_{0},
\end{aligned}
$$

where $2 n_{H_{2} 0}$ represents the bulk molecular number density of protons $\left(2 \times\right.$ number density of water molecules, $2 n_{\mathrm{H}_{2} 0}=$ $\left.3.33679 \times 10^{28}\left[\mathrm{~m}^{-3}\right]\right)$ in liquid water, $\gamma_{\mathrm{H}}$ is the gyromagnetic ratio of hydrogen and equals $0.2675\left[\mathrm{nT}^{-1} \mathrm{~s}^{-1}\right]$. The terms $k_{B}\left(=1.38066 \times 10^{-23}\left[\mathrm{~J} \cdot \mathrm{K}^{-1}\right]\right)$ and $\hbar\left(=1.05457 \times 10^{-34}[\mathrm{~J} \cdot \mathrm{s}]\right)$ are the Boltzman and scaled Plank constants, $\mathrm{J}$ is joules, and $T$ is the temperature in Kelvin $(\mathrm{K})$. Together these terms define $\chi_{N}$, the nuclear paramagnetic susceptibility. If the media is fully saturated, the term $f(\mathbf{r})$ is the fraction of water (porosity) in a unit volume. The shorthand $\mathbf{r}(=[x, y, z])$ denotes a point in three-space. The temperature dependence of the magnetization is relatively minor over the range of temperatures normally encountered in geophysical field work, and is dropped from the notation from this point forward.

\section{Nuclear Magnetic Resonance Dynamics}

$\mathbf{M}_{N}^{(0)}(\mathbf{r})$ is too small to be measured directly but may be observed by tipping it away from its equilibrium position with electromagnetic (EM) fields. Recall that the bulk magnetization is due to an ensemble of individual protons. Each of these protons may absorb photons in EM radiation, raising the energy state of the protons - which changes its alignment and energy state. Bloch (1946) found that for large sample numbers, the stochastic response of the ensemble of protons can be modeled using the following classical and phenomenological model:

$$
\begin{aligned}
\frac{\partial}{\partial t} \mathbf{M}_{N}(\mathbf{r}, t) & =\gamma_{\mathrm{H}}\left(\mathbf{M}_{N}(\mathbf{r}, t) \times\left[\mathbf{B}_{0}+\mathbf{B}_{T}(\mathbf{r}, t)\right]\right) \\
& -\frac{\mathbf{M}_{N}(\mathbf{r}, t) \cdot \hat{\mathbf{x}}}{T_{2}^{*}(\mathbf{r})} \hat{\mathbf{x}}-\frac{\mathbf{M}_{N}(\mathbf{r}, t) \cdot \hat{\mathbf{y}}}{T_{2}^{*}(\mathbf{r})} \hat{\mathbf{y}} \\
& -\frac{\left(\mathbf{M}_{N}(\mathbf{r}, t)-\mathbf{M}_{N}^{(0)}(\mathbf{r})\right) \cdot \hat{\mathbf{z}}}{T_{1}(\mathbf{r})} \hat{\mathbf{z}} .
\end{aligned}
$$


This differential equation is referred to as the Bloch equation and forms the framework for analysis in almost all applications of NMR. The unit vector $\hat{z}$ is aligned with $\mathbf{B}_{0}$, while $\hat{\mathbf{x}}$ and $\hat{\mathbf{y}}$ are perpendicular to the static field and are themselves orthogonal. It typically is useful to define $\hat{\mathbf{x}}$ and $\hat{\mathbf{y}}$ locally, at every point $\mathbf{r}$. The net effect is that the bulk magnetization vector is tipped out of its equilibrium state by a transmitted magnetic field $\mathbf{B}_{T}$, but the magnetization will continue to precess about the static field $\mathbf{B}_{0}$, recovering back towards its equilibrium state. It is possible to do this efficiently as $\mathbf{M}_{N}^{(0)}(\mathbf{r})$ not only aligns, but also precesses about $\hat{\mathbf{B}}_{0}$ at a specific frequency, in $\mathrm{Hz}$, as given by:

$$
v_{L}=\frac{\gamma_{\mathrm{H}} B_{0}}{2 \pi} .
$$

This is called the Larmor frequency (the angular Larmor frequency $\left.\omega_{L}=\gamma_{\mathrm{H}} B_{0}[\mathrm{rad} / \mathrm{sec}]\right)$. Due to this precession and the cross product in equation 2, it is only the perpendicular (with respect to $\hat{\mathbf{B}}_{0}$ ) portion of $\mathbf{B}_{T}$ that also rotates about $\mathbf{B}_{0}$ which can interact with the magnetization. In SNMR, a transmitted magnetic field $\left(\boldsymbol{B}_{T}\left(\mathbf{r}, \omega_{L}\right)\right)$ generated by an ungrounded wire loop carrying current oscillating at the Larmor frequency is used to tip the magnetization, and it becomes necessary to compute the portion of the transmitted field that co-rotates with the spins. It is convenient to calculate the field $\boldsymbol{B}_{T}\left(\mathbf{r}, \omega_{L}\right)$ that would be generated by a unit current in the loop, and then scale the solution by the amplitude of the AC current $\left(I_{T}^{0}\right)$. This calculation is a function of the electrical conductivity, magnetic permeability, and dielectric permittivity of the media (for example, Jackson, 1998). In the case of a layered earth, $\boldsymbol{B}_{T}(\mathbf{r}, \omega)$ may be computed quasi-analytically in the Hankel domain (Ward and Hohmann, 1987).

\section{Calculation of the Co-rotating Field}

In general it is not simply the projection of $\boldsymbol{B}_{T}\left(\mathbf{r}, \omega_{L}\right)$ onto the plane perpendicular to $\hat{\mathbf{B}}_{0}$ that co-rotates with the protons; only part of the field will be doing so. The electrical conductivity retards and distorts the transmitted magnetic field (Shushakov, 1996a). In this case the projected field $\left(\boldsymbol{B}_{T}^{\perp}\left(\mathbf{r}, \omega_{L}\right)\right)$ is an elliptically polarized complex field. As shown in figure 2 , this field may be decomposed into two circularly polarized real fields, one rotating clockwise $\left(\mathbf{B}_{T}^{+}\left(\mathbf{r}, I_{T}^{0}, t\right)\right)$, and the other anticlockwise $\left(\mathbf{B}_{T}^{-}\left(\mathbf{r}, I_{T}^{0}, t\right)\right)$ (Weichman and others, 2000; Valla and Legchenko, 2002; Hertrich and others, 2005). It is only the clockwise-rotating part of the field that co-rotates with the protons. This decomposition of $\boldsymbol{B}_{T}^{\perp}\left(\mathbf{r}, \omega_{L}\right)$ takes the form

$$
\begin{aligned}
\mathbf{B}_{T}^{ \pm}\left(\mathbf{r}, I_{T}^{0}, t\right) & =\frac{1}{2} I_{T}^{0}\left(\alpha_{T}(\mathbf{r}) \mp \beta_{T}(\mathbf{r})\right) \\
& \times\left(\cos \left[\omega_{L} t+\phi_{T}-\zeta_{T}(\mathbf{r})\right] \hat{\mathbf{b}}_{T}(\mathbf{r})\right. \\
& \left.\mp \sin \left[\omega_{L} t+\phi_{T}-\zeta_{T}(\mathbf{r})\right] \hat{\mathbf{B}}_{0} \times \hat{\mathbf{b}}_{T}(\mathbf{r})\right) .
\end{aligned}
$$

In equation $4, \phi_{T}$ is the phase of the transmitter current, and $\zeta_{T}(\mathbf{r})$ is the position-dependent phase delay due to the conductivity effects. The rest of the terms define the elliptic decomposition (Weichman and others, 2000):

$$
\begin{gathered}
\mathcal{B}_{T}^{\perp}\left(\mathbf{r}, \omega_{L}\right)=\mathcal{B}_{T}\left(\mathbf{r}, \omega_{L}\right)-\left(\mathcal{B}_{T}\left(\mathbf{r}, \omega_{L}\right) \cdot \hat{\mathbf{B}}_{0}\right) \hat{\mathbf{B}}_{0} \\
\alpha_{T}(\mathbf{r})=\frac{1}{\sqrt{2}} \sqrt{\left|\mathcal{B}_{T}^{\perp}\left(\mathbf{r}, \omega_{L}\right)\right|^{2}+\left|\left(\mathcal{B}_{T}^{\perp}\left(\mathbf{r}, \omega_{L}\right)\right)^{2}\right|} \\
\beta_{T}(\mathbf{r})=\operatorname{sgn}\left[j \hat{\mathbf{B}}_{0} \cdot \mathcal{B}_{T}^{\perp}\left(\mathbf{r}, \omega_{L}\right) \times \mathcal{B}_{T}^{\perp *}\left(\mathbf{r}, \omega_{L}\right)\right] \\
\frac{1}{\sqrt{2}} \sqrt{\left|\mathcal{B}_{T}^{\perp}\left(\mathbf{r}, \omega_{L}\right)\right|^{2}-\left|\left(\mathcal{B}_{T}^{\perp}\left(\mathbf{r}, \omega_{L}\right)\right)^{2}\right|} \\
e^{\left(j \zeta_{T}(\mathbf{r})\right)}=\sqrt{\frac{\left(\mathcal{B}_{T}^{\perp}\left(\mathbf{r}, \omega_{L}\right)\right)^{2}}{\left|\left(\mathcal{B}_{T}^{\perp}\right)^{2}\left(\mathbf{r}, \omega_{L}\right)\right|}} \\
\hat{\mathbf{b}}_{T}(\mathbf{r})=\frac{1}{\alpha_{T}(\mathbf{r})} \mathfrak{R}\left(e^{\left(-j \zeta_{T}(\mathbf{r})\right)} \mathcal{B}_{T}^{\perp}\left(\mathbf{r}, \omega_{L}\right)\right) .
\end{gathered}
$$

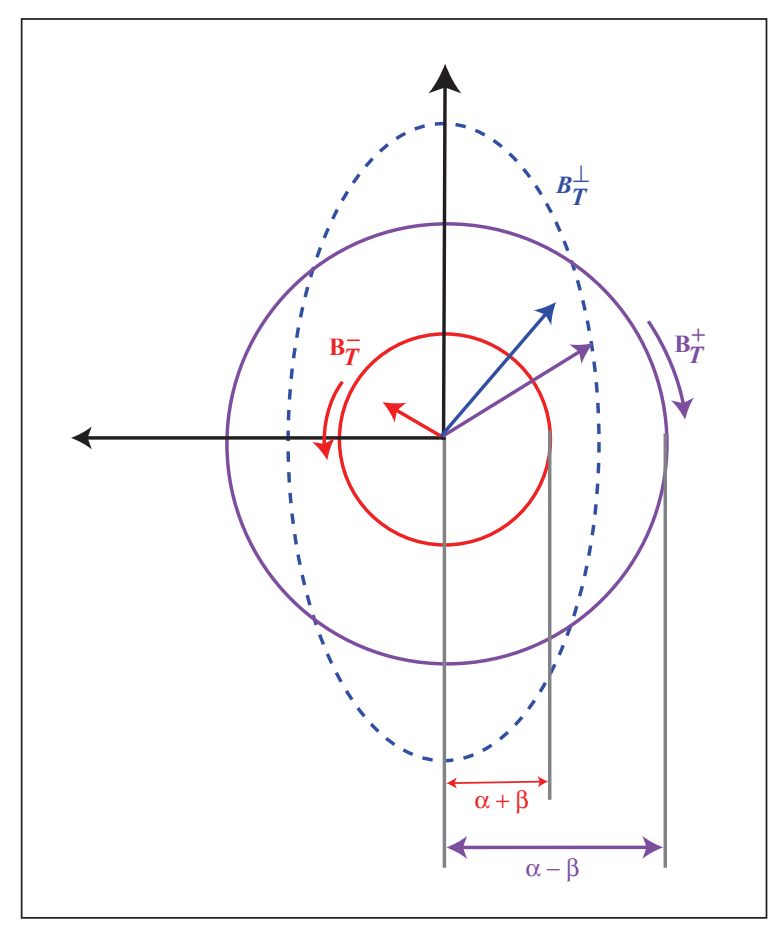

Figure 2. An elliptically-polarized time-varying complex magnetic field $\left(\boldsymbol{B}_{T}^{\perp}(\mathbf{r}, t)\right.$, located at some point $\mathbf{r}$ may be decomposed into two circularly polarized real components $\mathbf{B}_{T}^{+}(\mathbf{r}, t)$ and $\mathbf{B}_{T}^{-}(\mathbf{r}, t)$, rotating clockwise and anticlockwise, respectively. The sum of these components results in $\left(\boldsymbol{B}_{T}^{\perp}(\mathbf{r}, t)\right.$. The real scalars $\alpha$ and $\beta$ are used to define the circularly polarized components. 


\section{Tipping of the Bulk Magnetization Vector}

After calculating the co-rotating field, the Bloch equations may be solved to determine the behavior of the magnetization due to the tipping pulse. Following the notation of Weichman and others (2000), the tipping of $\mathbf{M}_{N}^{(0)}(\mathbf{r})$ by $\mathbf{B}_{T}^{+}\left(\mathbf{r}, I_{T}^{0}, t\right)$ can be written as

$$
\begin{aligned}
\mathbf{M}_{N}(\mathbf{r}, t) & =\mathbf{M}_{N}^{(0)}(\mathbf{r}) \cos \left[\theta_{T}\left(\mathbf{r}, I_{T}^{0}, t\right)\right] \\
& +\left[\mathbf{M}_{N}^{(0)}(\mathbf{r}) \times \hat{\mathbf{B}}_{T}^{+}(\mathbf{r}, t)\right] \sin \left[\theta_{T}\left(\mathbf{r}, I_{T}^{0}, t\right)\right] .
\end{aligned}
$$

The tip (or flip) angle $\theta_{T}\left(\mathbf{r}, I_{T}^{0}, t\right)$ is a function of the amplitude and duration of application of $\mathbf{B}_{T}^{+}\left(\mathbf{r}, I_{T}^{0}, t\right)$ and may be computed

$$
\theta_{T}\left(\mathbf{r}, I_{T}^{0}, t\right)=\gamma_{\mathrm{H}} \int_{0}^{t}\left|\mathbf{B}_{T}^{+}\left(\mathbf{r}, I_{T}^{0}, t^{\prime}\right)\right| d t^{\prime}
$$
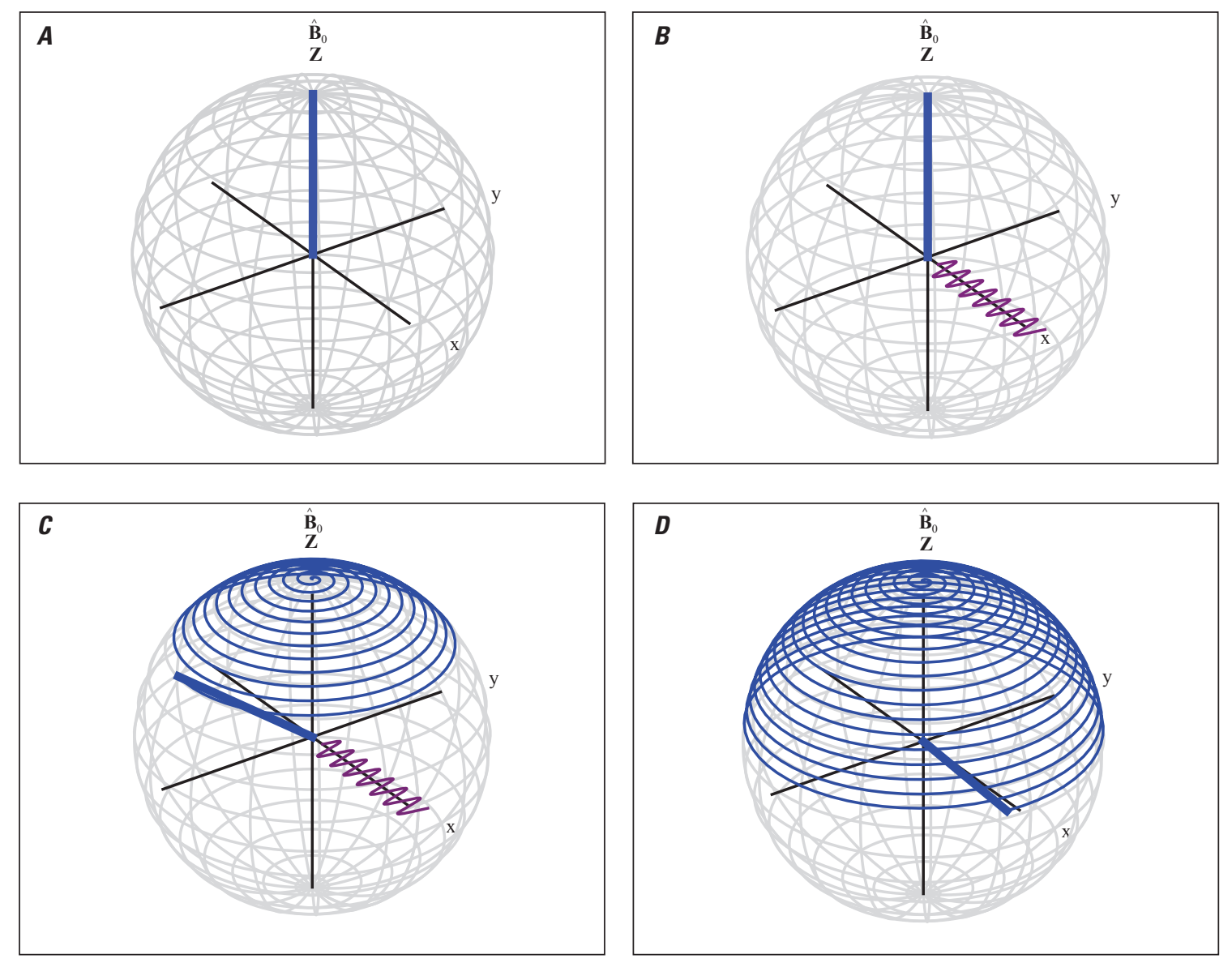

Figure 3. For a static magnetic field $\hat{\mathbf{B}}_{0}$ oriented along the $z$ axis, the bulk magnetization $\mathbf{M}_{N}^{(0)}$ (depicted as a solid blue line) will also be pointed in the $\hat{\mathbf{z}}$ direction as shown in $(A)$. Upon the application of a transverse magnetic field $\mathbf{B}_{T}^{+}$shown in purple in $(B), \mathbf{M}_{N}$ will be tipped out of its equilibrium point $(C)$. After the transmitter has turned off, $\mathbf{M}_{N}(\mathbf{r})$ continues to oscillate around $\hat{\mathbf{B}}_{0}(D)$ and will decay back towards its equilibrium point. The position of $\mathbf{M}_{N}(\mathbf{r})$ in $(D)$ represents a $2 / \pi$ tipping. These plots neglect relaxation during pulse effects. 
duration of the transmitter pulse $\tau_{p}$, the flip angle $\theta(\mathbf{r}, q)$ can be varied spatially, and different parts of the subsurface can be probed, as shown in figure 4 . In general, larger currents and longer pulse moments investigate deeper parts of the subsurface.

\section{NMR Relaxation and Recovery}

After tipping, $\mathbf{M}_{N}(\mathbf{r}, t)$ continues to oscillate about $\mathbf{B}_{0}$, but decays back towards its equilibrium point $\mathbf{M}_{N}^{(0)}(\mathbf{r})$, so that $\mathbf{M}_{N}(\mathbf{r}, \infty) \rightarrow \mathbf{M}_{N}^{(0)}(\mathbf{r})$. There are two mechanisms for this decay: loss of coherence among spins, and changes in the net quantum-energy state of the magnetization. The spin lattice, or $T_{1}(\mathbf{r})$, relaxation describes recovery of $\mathbf{M}_{N}(\mathbf{r}, t)$ on the axis parallel to $\hat{\mathbf{B}}_{0}$. This recovery is the result of excited protons returning to a non-excited state and describes the return of the bulk magnetization towards the Boltzmann distribution described in equation 1 (Zimmerman and others, 2000, chap. 2).

Conversely, $T_{2}^{*}(\mathbf{r})$ describes decay on the plane perpendicular to the static field. This decay is due to the loss of phase coherence between the spins and is commonly called spinspin relaxation. No change in the energy level of the protons is necessary for this to occur. The mechanisms for this decay are molecular interactions and inhomogeneity in the static magnetic field.

These decay processes are illustrated in figure 5 . It is important to note that the magnitude of $\mathbf{M}_{N}(\mathbf{r}, t)$ is not necessarily constant, and under any circumstance encountered in Earth's field, NMR $T_{2}{ }^{*} \leq T_{1}$, resulting in full decay in the transverse plane before the longitudinal signal has fully recovered

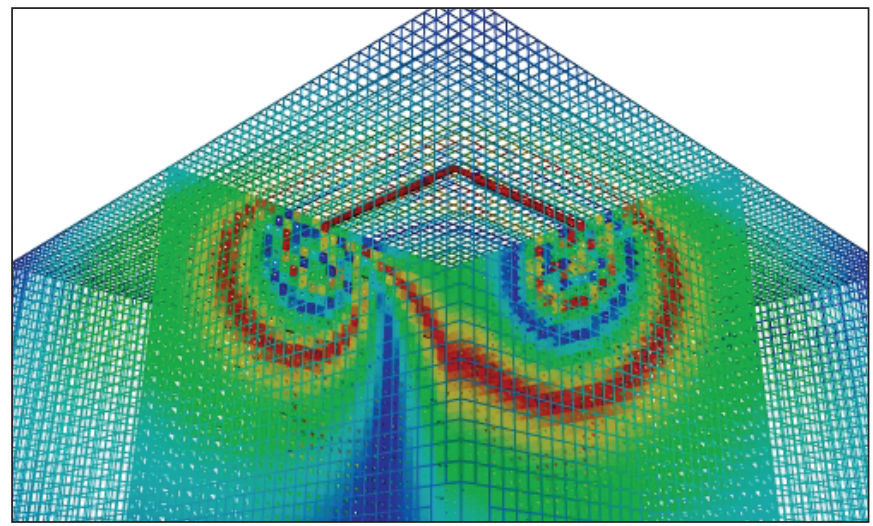

Figure 4. A plot of the tipping angle $\theta_{T}(\mathbf{r}, q)$ in a homogeneous saturated water model, for a single pulse moment. Red represents $\pi / 2$ tipping angle regions, which contribute the most signal. Blue areas have 0 degrees tipping angle, and these areas contribute no signal. Within the context of the complicated geometry, as the transmitter current is increased, deeper parts of the subsurface can be investigated.

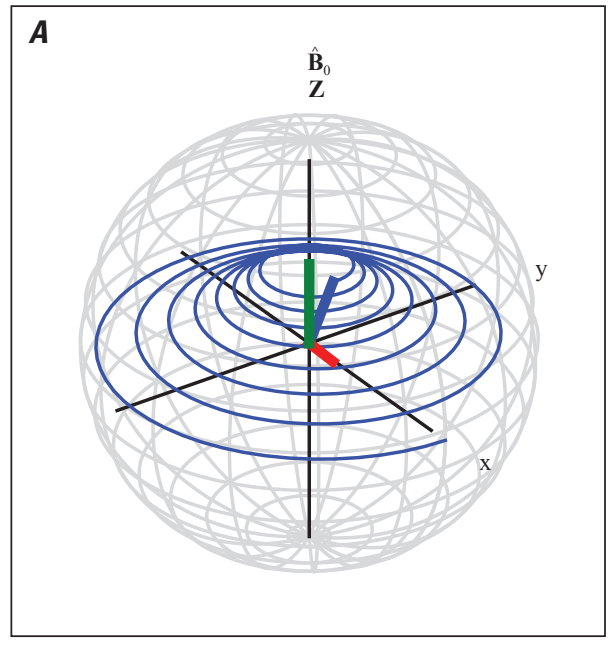

$\boldsymbol{B}$

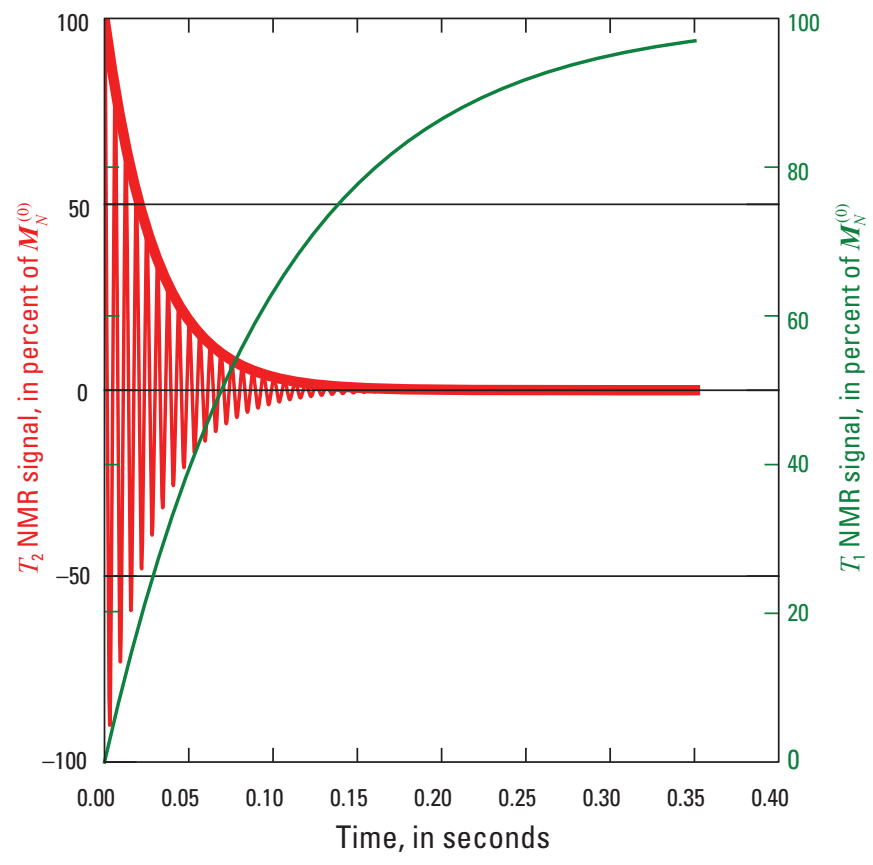

Figure 5. After being tipped, the magnetization $\mathbf{M}_{N}(\mathbf{r}, t)$ (depicted as a solid blue line) continues to precess around $\hat{\mathbf{B}}_{0}$ but recovers towards its equilibrium location $\mathbf{M}_{N}^{(0)}(\mathbf{r})$. This process is shown in $(A)$. The decay in the transverse $(x, y)$ plane is defined by the $T_{2}^{*}(\mathbf{r})$ decay constant and is shown in red. Recovery in the longitudinal $(\hat{\mathbf{z}})$ direction is defined by the $T_{1}(\mathbf{r})$ parameter and is shown in green. In $(B)$, a simulated nuclear magnetic resonance (NMR) signal is shown. The $T_{1}$ and $T_{2}^{*}$ data are shown and plotted as a relative percentage of $\mathbf{M}_{N}^{(0)}$. The $T_{2}^{*}$ data oscillate at the Larmor frequency and decay according to $T_{2}^{*}$ (envelope shown in bold), whereas $T_{1}$ smoothly recovers towards unity. Practically speaking, it is not possible to observe $T_{1}$ directly, as the rate of signal change is too slow to induce measurable voltage. 
(Levitt, 2001, § 11.9.2). This behavior is encapsulated in the Bloch equation; again following the notation of Weichman and others (2000), the NMR equation of motion may be written as

$$
\begin{aligned}
\mathbf{M}_{N}(\mathbf{r}, t) & =\mathbf{M}_{N}^{(0)}(\mathbf{r})\left\{1-e^{-\left(t-\tau_{l}\right) / T_{1}(\mathbf{r})}\right. \\
& \left.+e^{-\left(t-\tau_{l}\right) / T_{1}(\mathbf{r})} \cos \left[\theta_{T}(\mathbf{r}, q)\right]\right\} \\
& +e^{-\left(t-\tau_{t}\right) / T_{2}^{*}(\mathbf{r})}\left[\mathbf{M}_{N}^{(0)}(\mathbf{r})\right. \\
& \left.\times \hat{\mathbf{B}}_{T}^{+}(\mathbf{r}, t)\right] \sin \left[\theta_{T}(\mathbf{r}, q)\right]
\end{aligned}
$$

$\mathbf{B}_{T}^{+}\left(\mathbf{r}, I_{T}^{0}, t\right)$ continues to be defined even after the transmitter pulse has terminated. The first term in equation 12 describes the $T_{1}(\mathbf{r})$ recovery while the second term gives the $T_{2}^{*}(\mathbf{r})$ portion of the motion of $\mathbf{M}_{N}(\mathbf{r}, t)$. The parameters $\tau_{l}$ and $\tau_{t}$ are the lengths of the longitudinal and transverse pulses, which are generally the same in SNMR surveys and correspond to the duration of the pulse $\tau_{p}$.

\section{Relaxation during the Tipping Pulse}

In equation 12 and in figure 3 , decay processes are assumed to start at the culmination of the tipping pulse. In other words, it is assumed that no decay occurs during the tipping pulse. The SNMR pulses commonly are long enough that this assumption is violated, and significant relaxation during the pulse (RDP) does occur. While accounting completely for this effect is complicated, there is a simple approximation that is quite effective. Letting $\tau_{l, t} \equiv \tau_{l, t} \approx \tau_{p} / 2$ in equation 12 accounts for RDP to a high order (Weichman and others, 2000; Walbrecker and others, 2009).

\section{Surface Nuclear Magnetic Resonance Voltage Response}

The progression of $\mathbf{M}_{N}(\mathbf{r}, t)$ in equation 12 may be observed inductively using closed loop(s) of wire. The same loop of wire used for the transmitter is often employed as a receiver. In general terms, the induced voltage in a receiver loop may be described using an adjoint formulation (Weichman and others, 2000):

$$
V_{R}^{N}(q, t)=-\int_{V} \int_{0}^{\infty} \mathcal{B}_{R}\left(\mathbf{r}, t^{\prime}\right) \cdot \partial_{t} \mathbf{M}_{N}\left(\mathbf{r}, t-t^{\prime}\right) d t^{\prime d^{3}} r .
$$

The complex magnetic field $\boldsymbol{B}_{R}(\mathbf{r}, t)$ describes the hypothetical "receiver field" that would be emitted from a unit current in the receiver. The measured voltage $\left(V_{R}^{N}\right)$ is proportional to the rate of change of the flux through the receiver loop. From equation 12 , only the $T_{2}^{*}$ component of $\mathbf{M}_{N}(\mathbf{r}, t)$ is oscillating at the Larmor frequency; for this reason, it is the only directly measurable quantity. The time scale for $T_{1}(\mathbf{r})$ is on the scale of tens of ms to several seconds, meaning that $\partial_{t} \mathbf{M}_{N}(\mathbf{r}, t) \cdot \hat{\mathbf{B}}_{0}$ will be very small. Weichman and others (2000) found that the $T_{1}$ portion of the transient signal is immeasurably small, typically on the order of a $\mathrm{nV}$ or two. It is also an essentially DC signal (slow power-law recovery) that will be removed in the processing and filtering of the SNMR data. This allows the $\mathbf{M}_{N}(\mathbf{r}, t)$ term in equation 12 to be truncated to:

$$
\mathbf{M}_{N}^{\perp}(\mathbf{r}, t)=e^{-\left(t-\tau_{p} / 2\right) / T_{2}^{*}(\mathbf{r})}\left[\mathbf{M}_{N}^{(0)}(\mathbf{r}) \times \hat{\mathbf{B}}_{T}^{+}(\mathbf{r}, t) \sin \left[\theta_{T}(\mathbf{r}, q)\right]\right.
$$

Equation 13 typically is reformulated in terms of $\mathbf{B}_{T}^{+}\left(\mathbf{r}, I_{T}^{0}, t\right)$, by substituting in equation 14 . Only the perpendicular part of the adjoint field $\left(\boldsymbol{B}_{R}^{\perp}(\mathbf{r}, t)\right)$ contributes to the voltage response, due to the dot product $\boldsymbol{B}_{R} \cdot \partial_{t} \mathbf{M}_{N}^{\perp}$. The receiver field can be decomposed into circular components in the same manner as the transmitter field using equation 4 and the same decomposition found in equations 5-9, substituting $R$ for $T$, and setting $I_{R}^{0} \equiv 1$. It is only the counter-rotating portion of $\left(\boldsymbol{B}_{R}^{\perp}\right)$ that enters the Bloch equation, because the adjoint receiver field plays backwards from the earth to the receiver loop but is computed playing from the receiver loop into the earth (Weichman and others, 2000; Valla and Legchenko, 2002; Hertrich and others, 2005). Computing $\boldsymbol{B}_{T}^{+}$ in the $\mathbf{M}_{N}$ term can easily be done as only the Larmor frequency is required. However, $\boldsymbol{B}_{R}(\mathbf{r}, t)$ is needed for all times, and the complete dynamics of this field are complicated. One common approach is to model only early times, which allows the $T_{2}^{*}(\mathbf{r})$ terms to be neglected in equation 13 , and $\boldsymbol{B}_{R}(\mathbf{r}, t) \rightarrow \boldsymbol{B}_{R}\left(\mathbf{r}, \omega_{L}\right)$. The approach is effective for modeling the voltage and phase of the NMR response near the pulse shut-off for initial amplitude calculations and takes the form (Weichman and others, 2000):

$$
\begin{aligned}
\bar{V}_{R}^{N}(q, t \approx 0)= & -\omega_{L} \int\left|\mathbf{M}_{N}^{(0)}\right| \sin \left[\theta_{T}(\mathbf{r})\right] \\
\times & e^{j \zeta_{T}(\mathbf{r})} \mathcal{B}_{R}^{\perp}\left(\mathbf{r}, \omega_{L}\right) \\
& \cdot\left[\hat{\mathbf{b}}_{T}\left(\mathbf{r}, \omega_{L}\right)-j \hat{\mathbf{B}}_{0} \times \hat{\mathbf{b}}_{T}\left(\mathbf{r}, \omega_{L}\right)\right] d^{3} r \\
= & -\omega_{L} \chi_{N}(T) B_{0} \int f(\mathbf{r}) \sin \left[\theta_{T}(\mathbf{r})\right] \\
& e^{j\left[\zeta_{T}(\mathbf{r})+\zeta_{R}(\mathbf{r})\right]}\left[\alpha_{R}(\mathbf{r})+\beta_{R}(\mathbf{r})\right] \\
\times & {\left[\hat{\mathbf{b}}_{R}\left(\mathbf{r}, \omega_{L}\right) \cdot \hat{\mathbf{b}}_{T}\left(\mathbf{r}, \omega_{L}\right)\right.} \\
+ & \left.j \hat{\mathbf{B}}_{0} \cdot \hat{\mathbf{b}}_{R}\left(\mathbf{r}, \omega_{L}\right) \times \hat{\mathbf{b}}_{T}\left(\mathbf{r}, \omega_{L}\right)\right] d^{3} r \\
= & \int \mathcal{K}(\mathbf{r}, q) f(\mathbf{r}) d^{3} r .
\end{aligned}
$$

The bar over $\bar{V}_{R}^{N}$ denotes that these equations model the complex envelope representation of the SNMR signal, which is obtained via a quadrature detection scheme. This historically has been the most common representation of SNMR field data, although a new generation of instruments instead report a real oscillating time series (Dlugosch and others, 2011). In equation $16, \mathcal{K}$ represents the initial amplitude kernel and $f(\mathbf{r})$ is again the free-water model. If modeling the NMR response of entire time series is needed, equation 15 may be updated by (Weichman and others, 2000):

$$
\mathcal{B}_{R}\left(\mathbf{r}, \omega_{L}\right) \rightarrow e^{-\left(t-\tau_{p}\right) / T_{2}^{*}(\mathbf{r})} \mathcal{B}_{R}\left(\mathbf{r}, \pm \omega_{L}-j / T_{2}^{*}(\mathbf{r})\right) .
$$

Use of this substitution, as opposed to honoring equation 12 fully, neglects small-order electromagnetic memory effects in the signal but has been used extensively in the literature (Legchenko and Valla, 2002; Valla and Legchenko, 2002; Mohnke and Yaramanci, 2005; Braun and others, 2005; Müeller-Petke and Yaramanci, 2010). 
Surface NMR tipping pulses typically are in the range $10-40 \mathrm{~ms}$, and except in a few notable exceptions it is usually desirable for $\tau_{p}<<T_{2}^{*}$. There exists some additional dead time $\tau_{d}$ between the end of the transmitter pulse and the collection of data to allow for instrumentation switching. The NMR time series described by equation 15 , with the substitution of equation 17, is called the free-induction decay (FID), the most basic SNMR measurement. Other multiple-pulse experiments are possible and are briefly discussed below. Figure 6 illustrates an idealized FID SNMR dataset.

\section{Effects of Inhomogeneities in the Static Magnetic Field}

As stated before, $T_{2}^{*}$ decay is due to both molecular interactions and inhomogeneities in $\mathbf{B}_{0}$. Gradients in the static magnetic field, at any scale over which $\theta_{T}(\mathbf{r}, q)$ is non-zero, cause spins to precess at slightly different Larmor frequencies, causing them lose coherence with time (called de-phasing). This has significant implications when interpreting SNMR data, as the impact on the data can be quite significant, and rarely are these field variations well-characterized or understood. It also is only those molecular interactions affecting $T_{2}^{*}$ that can be related to hydrologic parameters, and generally speaking, the effect due to magnetic field inhomogeneities only serves to obfuscate the relationship.

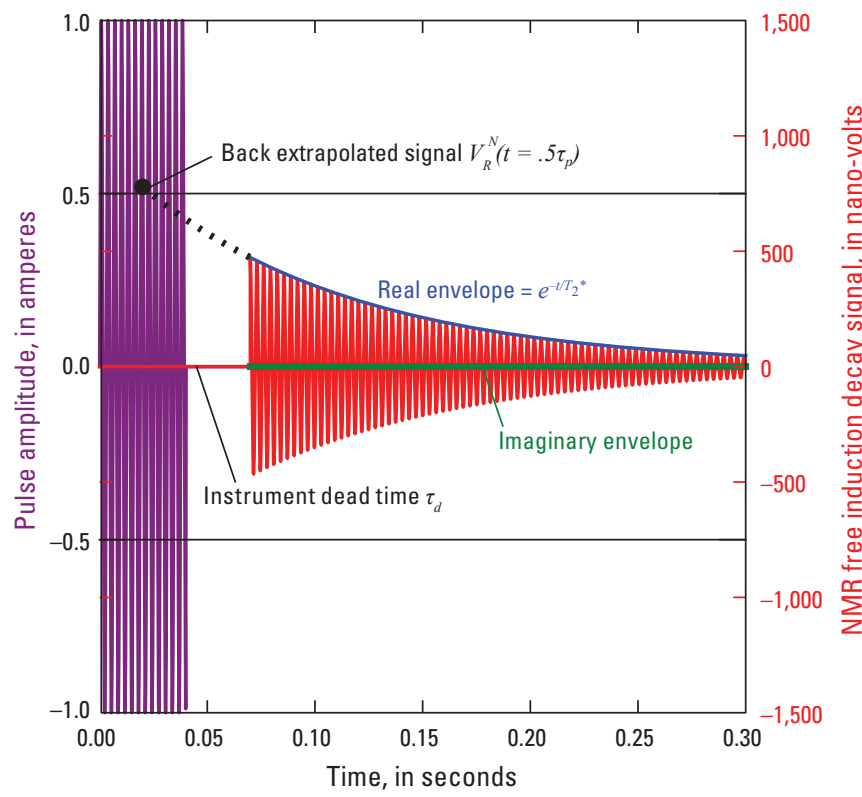

Figure 6. The progression of an idealized surface nuclear magnetic resonance (SNMR) time series for a single pulse moment. The transmitter pulses for $\tau_{p}$ seconds, shown in purple. After a brief dead time, $\tau_{d}$, the free-induction decay (FID) signal is recorded (shown in red), which decays exponentially to zero. The blue and green lines represent the complex envelope representation of the data. The black dotted line represents the backwards extrapolation of the recorded data $V_{R}^{N}$ to "zero" time, to correct for relaxation during $\tau_{p}$ and $\tau_{d}$.
Although equations 12 and 14 suggest that the transverse decay can be well-described by a single exponential value, variability in the precession frequency causes both faster than expected decay, as well as non-exponential decay. These effects can introduce significant error into analysis of the data. Two main mechanisms impact the decay process: dephasing of spins due to static fields, and diffusion of spins across changing magnetic field conditions. A third decay parameter, called $T_{2}(\mathbf{r})$, is introduced, which is less affected by static dephasing effects.

\section{Spin-echo Pulses}

Each spin in a media will precess according to equation 3 , so that if variability is present in $\mathbf{B}_{0}$, the spins will assume a distribution of Larmor frequencies. If the variation in $\mathbf{B}_{0}$ is relatively small, this distribution will be compact around a central frequency. Under most circumstances this is the case. As the frequencies are all close, immediately after the tipping pulse, the spins will be nearly in-phase with each other, and the net sum of the spins will result in a measurable signal. As time progresses, the spins will get increasingly out of phase with each other, and the coherence of the signal will be lost.

Hahn (1950) found that this coherence could be re-established by applying a second $180^{\circ}$ pulse at an offset time $\tau_{s}$. This pulse flips the spins, reversing the direction of precession. This means that spins that were ahead and precessing faster than others will be behind, but still precessing faster. The opposite is true for the "slow" spins; they will be ahead of the faster spins after the 180-degree pulse. The dynamics that caused the spins to dephase are then played in reverse, and a Hahn echo observed at a time $2 \times \tau_{s}$. Under ideal circumstances, a series of these measurements at different $\tau_{s}$ offsets can be used to measure the $T_{2}$ decay parameter. How successful this type of experiment is at removing magnetic effects depends on whether the dephasing gradients are time-varying or static. The spins that make up the NMR signal are in constant motion, so that even if $\mathbf{B}_{0}$ does not change temporally, the magnetic field observed by a moving spin can vary.

\section{Static Dephasing Processes}

If $\mathbf{B}_{0}$ is constant relative to a single (moving) spin, then the Hahn echo pulses will recover all of the signal lost due to magnetic field inhomogeneities. If the spins were stationary in space, did not interact, and $\mathbf{B}_{0}$ was held perfectly constant, then the Hahn refocusing pulses would be able to remove perfectly all of the effect in the NMR signal due to gradients in $\mathbf{B}_{0}$. These assumptions go into the fast-diffusion approximation (Brownstein and Tarr, 1979), which is often assumed in the analysis of NMR data in geological settings.

Under this assumption, the relationship between the two decay terms $T_{2}(\mathbf{r}, t)$ and $T_{2}^{*}(\mathbf{r})$ is often modeled as (for example, Farrar and Becker, 1971):

$$
\frac{1}{T_{2}^{*}}=\frac{1}{\tilde{T}_{2}}+\frac{1}{T_{I H}} \approx \frac{1}{\tilde{T}_{2}}+\frac{\gamma_{\mathrm{H}}}{2 \pi} \nabla \mathbf{B} .
$$


The tilde over $T_{2}$ denotes that this parameter is idealized, and only molecular interactions are assumed to be contributing to the decay, and $T_{I H}$ encapsulates all of the inhomogeneity effects. One obvious shortcoming of this approach is that simply inserting the result of equation 18 into either equations 14 or 15 will produce strictly exponential decay, but in practice, dephasing effects introduce non-exponential decay, even under the fast-diffusion approximation (Grunewald and Knight, 2011).

\section{Diffusion}

It is important to note that the fast-diffusion approximation is never entirely justified. The spins are in rapid motion and are interacting weakly. As spins move across gradients in $\mathbf{B}_{0}$, their instantaneous phase will be affected by the local field through which the spins move. This changing phase due to the Brownian motion of the protons reduces the effectiveness of the refocusing pulses and is called diffusion. Torrey (1956) modified the Bloch equations to include this phenomenon, but incorporating such effects is more complicated and involves $\nabla \mathbf{B}_{0}$ in nonlinear fashion. Carr and Purcell (1954) found that a succession of tightly spaced echo pulses (a Carr-PurcellMeiboom-Gill—or, CPMG_-pulse) can minimize diffusion effects and recover $T_{2}$ robustly in many circumstances.

Grunewald and Knight (2011) use a random walk algorithm to model NMR dynamics in a single pore containing a magnetic field gradient. A similar approach is taken in figure 7, which illustrates FID decay and Hahn echoes in the presence of a simple gradient in $\mathbf{B}_{0}$. However, as this approach is stochastic, it would be very expensive to apply to an entire SNMR inversion. We discuss a different approach in the next section, which still reproduces the dynamics of static dephasing processes, made practicable by an alternative modeling scheme to equation 13.

\section{Implications of Magnetic Field Inhomogeneities for Surface Nuclear Magnetic Resonance}

On one hand, the SNMR community has known about the impact of magnetic field gradients since the method's inception. On the other hand, the issue has been widely neglected. Originally, only the initial amplitude of the signal (equation 15) was analyzed. In theory, the initial amplitude of the signal is not affected by any decay process, so such effects were neglected. In practice, however, instrument dead time and relaxation during pulse (RDP) effects preclude the true measurement of $V_{R}^{N}(q, 0)$, and decay processes impact the early signal (Walbrecker and others, 2009).

As the decay process began to be incorporated into analysis and inversion, it was initially assumed that the Earth's magnetic field was completely uniform over the survey area, and no dephasing effects were present. Older instruments had fairly long dead times $(\approx 40 \mathrm{~ms})$, which meant that SNMR could only detect relatively slowly decaying signals, with long decay times. In addition, with long instrument dead times, measurements were limited to locations with relatively low subsurface magnetic susceptibility where dephasing effects were minimized, making more appropriate the uniform magnetic field assumption. Under such an assumption, $T_{2}^{*}$ is a reasonable proxy for $T_{2}$ and $T_{1}$.

Shushakov (1996b) studied SNMR measurements over a frozen lake and sediments to evaluate $T_{1}, T_{2}$, and $T_{2}^{*}$ SNMR measurements; he found that the assumption that $T_{2}^{*} \approx T_{2} \approx T_{1}$ was not valid, even with older equipment. Newer-generation instruments have much shorter dead times, allowing SNMR to be used in increasingly challenging locations. Both MüellerPetke and others (2011) and Knight and others (2012) compared SNMR data with borehole NMR data and found that the assumption that $T_{2}^{*} \approx T_{2}$ was violated at both locations, and that $T_{2}^{*}$ was in general not a good proxy for $T_{2}$. However, both studies confirmed that the SNMR data were correlated with changes in aquifer characteristics and to changes in borehole $T_{2}$ data, just not in a way that supports direct linear mapping between the two. To some extent this complicates interpretation of SNMR data, discussed in the next subsection.

To date, only purely exponential (or multi-exponential) decay has been used to fit the FID data. From Grunewald and Knight (2011) and figure 7B, it is clear that dephasing effects can introduce nonexponential decay. The measured SNMR response typically is low-amplitude and noise-limited. This makes using the entire time series to estimate parameters a more reliable approach than simply taking a value at, for example, the earliest time. The backwards extrapolation of a nonexponential signal under the assumption also introduces significant error. Although the tipping process is nonlinear, the FID response represents the impulse response of the magnetization after tipping (Ernst and others, 1990). This makes invaluable a thorough understanding and ability to model accurately the FID response when using the entire dataset to estimate parameters. Inversions can be successful only if they are able to reproduce data accurately in a way that is consistent with the physics of the experiment.

Substantial attention has been paid to making measurements of $T_{1}$ and $T_{2}$ using SNMR. The challenge lies in the fact that $\theta_{T}(\mathbf{r}, q)$ is distributed spatially nonuniformly, and significant signal comes from $\theta_{T}(\mathbf{r}, q)<\pi / 2$ (Mohnke and Yaramanci, 2005). This makes it difficult to apply pulses of specific tipping angles necessary for such measurements. Progress towards successful measurements is discussed below.

\section{Surface Nuclear Magnetic Resonance $T_{2}$ Measurements}

Hahn echoes can be observed using SNMR equipment (Legchenko and others, 2002; Shushakov and Fomeko, 2004). Observations typically have involved using two pulses of roughly equal amperage, but with the second pulse twice as long as the first and with a $\pi / 2$ phase offset between the two. This approach limits the length of the first pulse and, therefore, detectability of rapidly decaying $T_{2}$ measurements, as well as the depth of investigation. Phase cycling is relied on to cancel the unwanted FID response (Levitt, 2001) from locations where $\theta_{T}(\mathbf{r}, q) \neq \pi / 2$ for the first pulse. This also reduces the total signal amplitude, resulting in such measurements having 

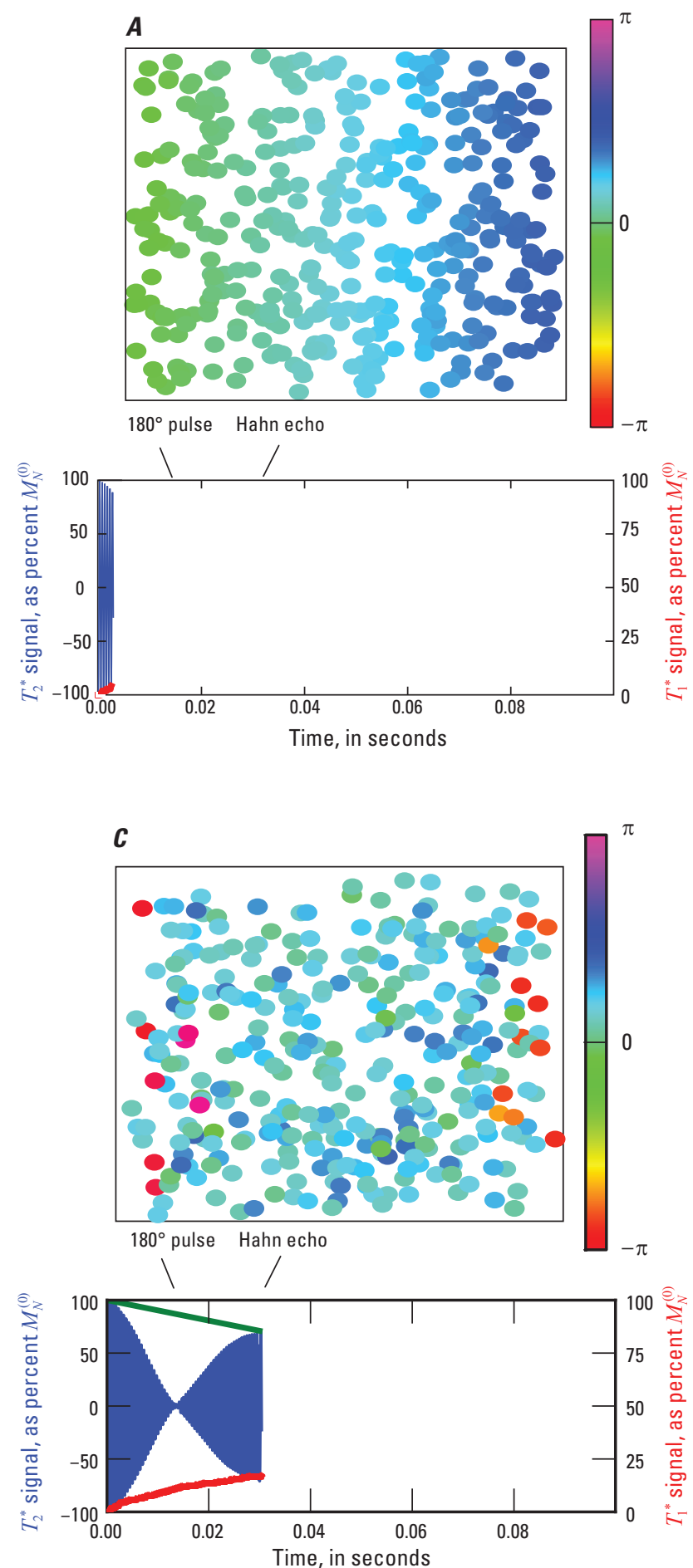
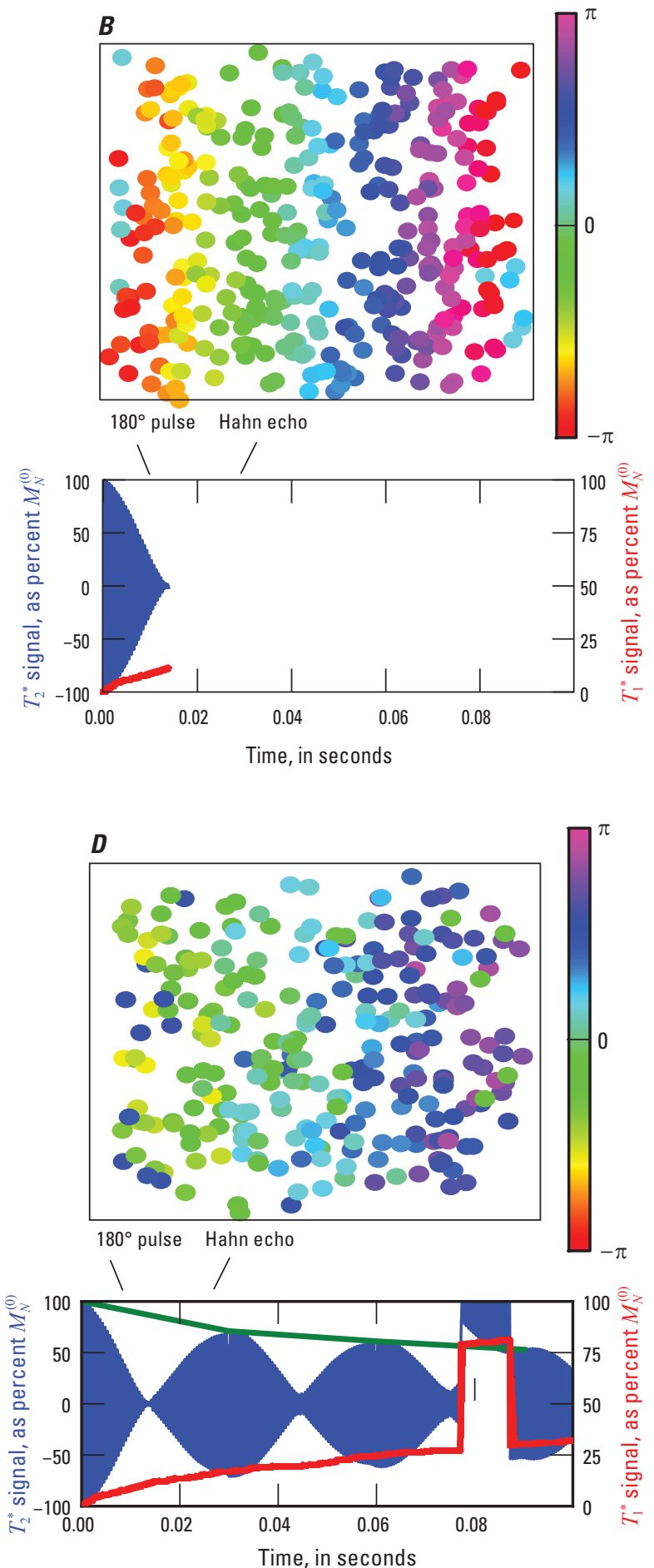

Figure 7. Plots illustrate the discrepancy between $T_{1}, T_{2}$, and $T_{2}^{*}$. The colored circles represent independent spins moving in a pore, in which magnetic field gradient is present. The gradient causes spins on the righthand side to precess at a faster rate than on the left side. The color of the circles represents their instantaneous phase. Over time the spins diphase. As the spins randomly move around, if they encounter a pore wall, there is a probability they will lose their excitation state. It is only these thermal reactions which contribute to the $T_{1}$ recovery, plotted in red. The discrepancy between $T_{1}$ and $T_{2}$ can be explained to high order using only the concepts of diffusion and dephasing. Right after initial tipping pulse $(A)$, all of the spins are in phase with each other. These spins quickly dephase and move randomly around the pore; the observed decay is the FID, or $T_{2}^{*}$ data, as shown in $(B)$. A 180-degree pulse can then be applied, which reverses the direction of motion and causes a refocusing Hahn echo to be observed (C). Complete coherency is not present in $(C)$ due to the random motion of the spins. Not all the signal can be recovered through refocusing pulses; this effect is called diffusion. A series of these refocusing echoes defines the $T_{2}$ parameter $(D)$, plotted in green. 
a shallower depth of investigation than single-pulse SNMR experiments (Legchenko and others, 2010). Comprehensive inversions of spin-echo data have not been developed yet, and analysis of those datasets generally is more limited than other pulse sequences. Currently, SNMR instruments do not support multiple-echo pulse experiments such as Carr-PurcellMeiboom-Gill spin-echo pulses. Since diffusion increases with echo time in a single-echo Hahn pulse, this could complicate analysis in some locations.

\section{Surface Nuclear Magnetic Resonance $T_{1}$ Measurements}

Two of the more common approaches to measuring $T_{1}$ in laboratory or imaging settings, inversion recovery and pulsing of the $\mathbf{B}_{0}$ field, are not currently possible using SNMR apparatus under field conditions. Instead, "pseudosaturation" recovery pulses are employed, which typically involve two separate pulses of equal moment, separated by some repetition-time delay. Such pulses have been deployed with relatively good success in the past (Legchenko and others, 2004; Mohnke and Yaramanci, 2005) but the long survey-acquisition time generally has kept these datasets to two sets of pulses, which is generally insufficient to fit $T_{1}$ well. Additionally, off-resonance transmitter pulses have a particularly complicated effect on the quadrature detection dataset (Walbrecker and others, 2011a). More-sophisticated phase cycling can remove much of this unwanted effect (Walbrecker and others, 2011b). The use of finite-length pulses again limits the ability to detect quickly decaying $T_{1}$ signal in quickly decaying media; even two pulses stacked back-to-back typically will result in some signal due to relaxation effects during the pulses. Similar to the spinecho pulse case, inversion of these data lags behind FID pulse sequences. Furthermore, field instruments commonly lack the flexibility to collect $T_{1}$ data with desired delays or phasecycling. These sophisticated $T_{1}$ pulse sequences were not available at the time of data collection in this study.

\section{Processing of Surface Nuclear Magnetic Resonance Field Data}

In the Earth's magnetic field, the measurable NMR response is small, and the method suffers from low signal-tonoise ratio to the point that the method's potential commonly has been hampered seriously. Often several strategies must be employed to acquire usable data, and in some situations, useful data collection still will not be possible. Legchenko and Valla (2003) discussed filtering common powerline harmonic noise, but often there are additional noise sources as well. Numerous advances in noise mitigation have improved the reliability and quality of the experiments. These improved techniques include analog noise-cancelling loops (Trushkin and others, 1994; Legchenko and others, 2011), software-based noise cancelling built on remote reference loops (Radić, 2005; Walsh, 2008), as well as advanced digital processing and filtering (Strehl, 2006). Legchenko and Valla (1998) discussed processing the complex-valued, quadrature-detected time series. Those filtering steps all can impact the NMR signal as well. It therefore is important to incorporate any filtering done to the field data into inversion schemes.

\section{Inversion of Surface Nuclear Magnetic Resonance Data}

The goal of inversion is to map geophysical data to the earth model that, together with the instrument, produced it. In the case of SNMR, the decaying time series are inverted for $f(\mathbf{r})$ and decay parameters, such as $T_{2}^{*}$ (and/or $\left.T_{1}, T_{2}\right)$. Onedimensional inversions are the most common and mature type of SNMR inversion and are applicable to many hydrogeologic settings. Inversions fall into three main categories: initial amplitude, time slice, and comprehensive.

Initial amplitude inversions seek to solve equation 16 for $f(\mathbf{r})$. This is useful for determining the total water content (porosity, in saturated media) in the subsurface but cannot deliver any additional hydrologic parameters. The relationship between the initial amplitude of the SNMR data and $f(\mathbf{r})$ is straightforward and physically based. Practical schemes for inverting the initial amplitude SNMR signal for 1-D detectable free water content have been presented numerous times in the literature (Legchenko and Shushakov, 1998; Weichman and others, 2002; Guillen and Legchenko, 2002; Mohnke and Yaramanci, 2002). While the weak signal of SNMR surveys can make these inversions challenging, the relationship between free water and the initial-amplitude SNMR signal is direct and well-established. However, several assumptions required by these inversion strategies are not always realistic (for example, mono-exponential decay and/or no relaxation during pulse or instrument dead time).

Time-slice inversions fit decay parameters to the SNMR dataset in addition to solving for $f(\mathbf{r})$. Legchenko and Valla (2002) and Mohnke and Yaramanci (2005) outlined 1-D examples. Individual time gates in the SNMR record can be inverted simultaneously or sequentially for the apparent $f(\mathbf{r})$ model at that instant. Such models can then be fit with decay parameters in a post-inversion step. This approach is susceptible to noise as each time gate is considered separately. Additionally, constraining the water model across time gates becomes necessary and adds further complexity to the inversion.

Comprehensive inversion schemes instead process the entire SNMR dataset in one step. This is advantageous, as the inversion can deal more robustly with higher noise levels given the larger dataset. Comprehensive inversion takes advantage of the correlated nature of the data across time gates to deliver a solution that is consistent with the dataset as a whole. The problem of constraining the water model across time gates is also dealt with implicitly. Müeller-Petke and Yaramanci (2010) outlined the only published example of this type of approach. These inversions, however, incur a high cost in terms of problem size. The SNMR datasets in the time domain are large, and simultaneously inverting all of the data can be memory-intensive and slow. 


\section{Estimation of Hydraulic Properties using Surface Nuclear Magnetic Resonance}

As stated earlier, the initial amplitude of the SNMR signal is directly proportional to the porosity of the subsurface (in the saturated case) and is a directly invertible parameter. For this reason, SNMR has established itself as a powerful tool for groundwater detection (Gev and others, 1996; Yaramanci and others, 1999; Legchenko and Valla, 2002).

The task of using NMR to characterize aquifer properties such as hydraulic conductivity $(\mathrm{K})$ and transmissivity $(\mathrm{T})$, as well as differentiating between bound and free water, is more tenuous. The decay parameters $T_{1}$ and $T_{2}$ have been related to pore size and interconnectivity but are also affected by rock properties (Kleinberg and others, 1994; Kenyon, 1997):

$$
T_{1,2}(\mathbf{r}) \propto \frac{V_{p}(\mathbf{r})}{\rho_{1,2}(\mathbf{r}) S_{p}(\mathbf{r})} .
$$

In this equation, $V_{P}$ is the pore volume, $S_{P}$ is the surface area of the pores, and $\rho_{1,2}$ is the surface relaxivity affecting the $T_{1,2}$ decay process. It is clear that in earth materials, pores are not uniform, and $T_{1,2}$ will take a distribution of values in accordance with variability of pore sizes (Mohnke and Yaramanci, 2008).

If $T_{2}^{*}$ is to be used, the effects of magnetic inhomogeneities must be considered:

$$
T_{2}^{*-1}(\mathbf{r})=T_{2 B}^{-1}+T_{2 I H}^{-1}(\mathbf{r})+\rho_{2} S_{p}(\mathbf{r}) / V_{p}(\mathbf{r}) .
$$

The bulk fluid relaxation $T_{2 B}$ is the decay that would be observed for a uniform bulk of fluid and is typically much longer than the other two terms. The decay therefore is dominated by the last two terms. The presence of the $T_{2 I H}$ term complicates the relation shown in equation 19. A frequently used approach to handling this is to use locally derived calibration factors, such that $T_{2} \approx c_{p} T_{2}^{*}$; this allows established models relating $T_{2}$ to hydraulic parameters to be used. The most commonly used model for SNMR takes the general form (Legchenko and others, 2004) as follows:

$$
K_{S N M R}=c_{p} T_{1,2,2 *}^{\alpha} \theta_{S N M R}^{\beta} .
$$

This model differs from borehole NMR models in the literature in that the NMR data are being related to hydraulic conductivity $K$, rather than hydraulic permeability $(\kappa)$. The reason for this deviation is that SNMR data are commonly compared with and calibrated against aquifer tests, which measure hydraulic conductivity. The borehole equations take the same form but substitute $K$ for $\kappa$; since this is an empirical relationship, it is acceptable that the dimensionality of the two sides of equation 19 are not equivalent. Different values for $c_{p}, \alpha$, and $\beta$ have been proposed in the borehole-NMR literature. Seevers (1966) advocated setting $c_{p}=1, \alpha=2$, and $\beta=1$. In dual-porosity sandstones, Kenyon and others (1988) found instead using $c_{p}=1$, that $\alpha=2$, and $\beta=4$ yielded better estimates of permeability. It is also common for the $T$ used in equation 20 to be the logarithmic mean of the estimated distribution of the parameter.

It commonly is the case that the SNMR data are compared with aquifer-test-derived hydraulic transmissivities instead of hydraulic conductivities. The SNMR transmissivity of a layer (Legchenko and others, 2004) is given by:

$$
T_{S N M R}=\int_{\triangle Z} K_{S N M R}(z) d z
$$

SNMR data have been compared with aquifer tests numerous times in the literature (Legchenko and others, 2002, 2004, 2006; Plata and Rubio, 2008). Whether $T_{2}^{*}$ or $T_{1}$ data are used, the most common approach is to calibrate the SNMR data locally using aquifer tests, to determine appropriate values for $c_{p}, \alpha$, and $\beta$. Typically only the $c_{p}$ parameter is calibrated, and the others are held fixed. Nielsen and others (2011) performed calibration of $c_{p}$ on a formation-by-formation basis over a large study in Denmark. Ideally, a single calibration factor could be used, as it is not always easily distinguishable from geophysical data at what depth formation boundaries occur. The high cost of aquifer tests also limits the number of calibration sites. The question of verification also is difficult as aquifer tests are complicated and have their own uncertainties, which are commonly difficult to quantify. In most cases, SNMR data have been able to provide insight into the hydrogeologic framework of an area at minimum cost.

\section{Frequency Domain Formulation}

The SNMR forward modeling and inverse problems traditionally have been approached in the time domain (Legchenko and Valla, 2002). Weichman and others (2000) proposed, but did not investigate, considering instead the problem in the Fourier domain:

$$
\mathcal{V}_{R}^{N}(\omega)=\mathrm{j} \omega \int \mathcal{B}_{\mathrm{R}}(\mathbf{r}, \omega) \cdot \mathcal{M}_{\mathrm{N}}(\mathbf{r}, \omega) \mathrm{d}^{3} \mathrm{r} .
$$

At the date of their paper, the only commercially available system delivered complex-valued demodulated timedomain data, which makes this approach cumbersome. With a real-valued time series, however, demodulating in the frequency domain is attractive, and the advantage of this approach over the time-domain formulation is severalfold. First, the SNMR signal is bandlimited, and only a narrow band of frequencies needs to be considered, resulting in significant compression. Second, most SNMR processing flows incorporate Fourier filtering. It is easy to add those effects into the frequency-domain formulation. Also, in the presence of noise, fitting the real-time envelope can introduce a bias. Offfrequency effects due to transmitting slightly away from the Larmor frequency additionally have a complicated impact on the demodulated time-domain data (Walbrecker and others, 2011a). The same level of downsampling is not possible in the time domain. Furthermore, the decimation does not remove any signal, since the frequency content around the bandlimited 
signal is completely retained. In other words, the decimation is completely in the null space of the modeling kernel function $\mathcal{K}(\mathbf{r}, q)$. Time-domain decimation indiscriminately removes both signal and noise. It is also much easier to incorporate dephasing effects in the frequency-domain.

\section{Equation of Motion}

The equation of motion for the protons on the transverse plane may be described as follows:

$$
\begin{aligned}
\mathbf{M}_{\mathrm{N}}^{\perp}(\mathbf{r}, \mathrm{t}) & =\mathrm{e}^{-\left(\mathrm{t}-\tau_{\mathrm{p}}\right) / \mathrm{T}_{2}^{*}(\mathbf{r})} \sin \left[\theta_{\mathrm{T}}\left(\mathbf{r}, \tau_{\mathrm{T}}\right)\right] \\
& \times\left[\mathbf{M}_{\mathrm{N}}^{(0)}(\mathbf{r}) \times \hat{\mathbf{B}}_{\mathrm{T}}^{+}(\mathbf{r}, t)\right] .
\end{aligned}
$$

The reason that only the motion on the perpendicular $\left(T_{2}^{*}\right.$ effect) plane is considered is that this is the only part directly observable in the SNMR data record. We begin by examining the cross product:

$$
\begin{aligned}
\mathbf{M}_{\mathrm{N}}^{(0)}(\mathbf{r}) \times \hat{\mathbf{B}}_{\mathrm{T}}^{+}(\mathbf{r}, t) & =\mathbf{M}_{\mathrm{N}}^{(0)}(\mathbf{r}) \\
& \times\left[\cos \left[\omega_{\mathrm{L}} \mathrm{t}+\phi_{\mathrm{T}}-\zeta_{\mathrm{T}}(\mathbf{r})\right] \hat{\mathbf{b}}_{\mathrm{T}}(\mathbf{r})\right. \\
& \left.-\sin \left[\omega_{\mathrm{L}} \mathrm{t}+\phi_{\mathrm{T}}-\zeta_{\mathrm{T}}(\mathbf{r})\right] \hat{\mathbf{B}}_{0} \times \hat{\mathbf{b}}_{\mathrm{T}}(r)\right] \\
& =\cos \left[\omega_{\mathrm{L}} \mathrm{t}+\phi_{\mathrm{T}}-\zeta_{\mathrm{T}}(\mathbf{r})\right] \mathbf{M}_{\mathrm{N}}^{(0)}(\mathbf{r}) \times \hat{\mathbf{b}}_{\mathrm{T}} \\
& -\sin \left[\omega_{\mathrm{L}} \mathrm{t}+\phi_{\mathrm{T}}-\zeta_{\mathrm{T}}(\mathbf{r})\right] \mathbf{M}_{\mathrm{N}}^{(0)}(\mathbf{r}) \times\left(\hat{\mathbf{B}}_{0} \times \hat{\mathbf{b}}_{\mathrm{T}}(\mathbf{r})\right) .
\end{aligned}
$$

The vector triple product can be simplified:

$$
\begin{aligned}
\mathbf{M}_{\mathrm{N}}^{(0)}(\mathbf{r}) & \times\left(\hat{\mathbf{B}}_{0} \times \hat{\mathbf{b}}_{\mathrm{T}}(\mathbf{r})\right) \\
& =\mathbf{B}_{0}\left(\mathbf{M}_{\mathrm{N}}^{(0)} \cdot \hat{\mathbf{b}}_{\mathrm{T}}(\mathbf{r})\right) \\
& -\hat{\mathbf{b}}_{\mathrm{T}}(\mathbf{r})\left(\mathbf{M}_{\mathrm{N}}^{(0)}(\mathbf{r}) \cdot \hat{\mathbf{B}}_{0}\right) .
\end{aligned}
$$

$\mathbf{M}_{\mathrm{N}}^{(0)}$ and $\hat{\mathbf{b}}_{\mathrm{T}}$ are perpendicular vectors ( $\hat{\mathbf{b}}_{\mathrm{T}}$ lies on the perpendicular plane of $\mathbf{M}_{\mathrm{N}}^{(0)}$ ), and the inner product vanishes. $\hat{\mathbf{B}}_{0}$ is a unit vector pointing in the direction of $\mathbf{M}_{\mathrm{N}}^{(0)}$. The inner product of a vector with its own unit vector is simply its magnitude, which allows for the simplification:

$$
\begin{aligned}
\mathbf{M}_{\mathrm{N}}^{(0)}(\mathbf{r}) & \times\left(\hat{\mathbf{B}}_{0} \times \hat{\mathbf{b}}_{\mathrm{T}}(\mathbf{r})\right)=\mathbf{B}_{0}\left(\mathbf{M}_{\mathrm{N}}^{(0)} \cdot \hat{\mathbf{b}}_{\mathrm{T}}(\mathbf{r})\right) \\
& -\hat{\mathbf{b}}_{\mathrm{T}}(\mathbf{r})\left(\mathbf{M}_{\mathrm{N}}^{(0)} \cdot \hat{\mathbf{B}}_{0}\right)=-\hat{\mathbf{b}}_{\mathrm{T}}\left|\mathbf{M}_{\mathrm{N}}^{(0)}\right| .
\end{aligned}
$$

The rewritten expression is:

$$
\begin{aligned}
\mathbf{M}_{\mathrm{N}}^{(0)} & \times \hat{\mathbf{B}}_{\mathrm{T}}^{+}(\mathbf{r}, \mathrm{t})=\cos \left[\omega_{\mathrm{L}} \mathrm{t}+\phi_{\mathrm{T}}-\zeta_{\mathrm{T}}(\mathbf{r})\right] \mathbf{M}_{\mathrm{N}}^{(0)}(\mathbf{r}) \\
& \times \hat{\mathbf{b}}_{\mathrm{T}}(\mathbf{r})+\sin \left[\omega_{\mathrm{L}} \mathrm{t}+\phi_{\mathrm{T}}-\zeta_{\mathrm{T}}(\mathbf{r})\right] \hat{\mathbf{b}}_{\mathrm{T}}(\mathbf{r})\left|\mathbf{M}_{\mathrm{N}}^{(0)}(\mathbf{r})\right| \\
& =\left|\mathbf{M}_{\mathrm{N}}^{(0)}\right|\left[\cos \left[\omega_{\mathrm{L}} \mathrm{t}+\phi_{\mathrm{T}}-\zeta_{\mathrm{T}}(\mathbf{r})\right] \hat{\mathbf{M}}_{\mathrm{N}}^{(0)}(\mathbf{r})\right. \\
& \left.\times \hat{\mathbf{b}}_{\mathrm{T}}+\sin \left[\omega_{\mathrm{L}} \mathrm{t}+\phi_{\mathrm{T}}-\zeta_{\mathrm{T}}(\mathbf{r})\right] \hat{\mathbf{b}}_{\mathrm{T}}(\mathbf{r})\right] .
\end{aligned}
$$

This equation simply describes the circular motion of the magnetization vector on the perpendicular plane. To ease notation, we introduce the second vector lying on the perpendicular plane:

$$
\hat{\mathbf{b}}_{\mathrm{T}}^{\perp}(\mathbf{r})=\hat{\mathbf{M}}_{\mathrm{N}}^{(0)}(\mathbf{r}) \times \hat{\mathbf{b}}_{\mathrm{T}}(\mathbf{r})
$$

Now $\mathbf{b}_{\mathrm{T}}$ and $\mathbf{b}_{\mathrm{T}}^{\perp}$ are two unit vectors lying on the perpendicular plane of $\mathbf{M}_{\mathrm{N}}^{0}$, that are themselves orthogonal. Together, they form a basis on the perpendicular plane. Equation 23 can now be written as:

$$
\begin{aligned}
\mathbf{M}_{\mathrm{N}}^{(0)}(\mathbf{r}) & \times \hat{\mathbf{B}}_{\mathrm{T}}^{+}(\mathbf{r}, \mathrm{t})=\left|\mathbf{M}_{\mathrm{N}}^{(0)}(\mathbf{r})\right|\left(\cos \left[\omega_{\mathrm{L}} \mathrm{t}+\phi_{\mathrm{T}}-\zeta_{\mathrm{T}}(\mathbf{r})\right] \hat{\mathbf{b}}_{\mathrm{T}}^{\perp}(\mathbf{r})\right. \\
& \left.+\sin \left[\omega_{\mathrm{L}} \mathrm{t}+\phi_{\mathrm{T}}-\zeta_{\mathrm{T}}(\mathbf{r})\right] \hat{\mathbf{b}}_{\mathrm{T}}(\mathbf{r})\right) .
\end{aligned}
$$

The equation of motion (equation 22) then takes the form:

$$
\begin{aligned}
\mathbf{M}_{\mathrm{N}}^{\perp}(\mathbf{r}, \mathrm{t}) & =\left|\mathbf{M}_{\mathrm{N}}^{0}(\mathbf{r})\right| \sin \left[\theta_{\mathrm{T}}\left(\mathrm{r}, \tau_{\mathrm{p}}\right)\right]\left\{\mathrm{e}^{-\left(\mathrm{t}-\tau_{\mathrm{p}}\right) / \mathrm{T}_{2}^{*}(\mathbf{r})}\right. \\
& \times\left[\cos \left[\omega_{\mathrm{L}} \mathrm{t}+\phi_{\mathrm{T}}-\zeta_{\mathrm{T}}(\mathbf{r})\right] \mathbf{b}_{\mathrm{T}}^{\perp}(\mathbf{r})\right. \\
& \left.\left.+\sin \left[\omega_{\mathrm{L}} \mathrm{t}+\phi_{\mathrm{T}}-\zeta_{\mathrm{T}}(\mathbf{r})\right] \mathbf{b}_{\mathrm{T}}(\mathbf{r})\right]\right\}
\end{aligned}
$$

Only the sine, cosine, and exponential terms contain any time dependence. Taking the Fourier transform of $\mathbf{M}_{\mathrm{N}}^{\perp}(\mathbf{r}, \mathbf{t})$ :

$$
\begin{aligned}
\mathcal{F}\left\{\mathbf{M}_{\mathrm{N}}^{\perp}(\mathbf{r}, \mathrm{t})\right\} & =\mathcal{F}\left\{\mathrm{e}^{-\left(\mathrm{t}-\tau_{\mathrm{p}}\right) / \mathrm{T}_{2}^{*}(\mathbf{r})}\left[\mathbf{M}_{\mathrm{N}}^{(0)}(\mathbf{r}) \times \hat{\mathbf{B}}_{\mathrm{T}}^{+}(\mathbf{r}, \mathrm{t})\right] \sin \left[\theta_{\mathrm{T}}\left(\mathbf{r}, \tau_{\mathrm{p}}\right)\right]\right\} \\
& =\left|\mathbf{M}_{\mathrm{N}}^{0}(\mathbf{r})\right| \sin \left[\theta_{\mathrm{T}}\left(\mathbf{r}, \tau_{\mathrm{p}}\right)\right] \mathcal{F}\left\{\mathrm{e}^{-\left(\mathrm{t}-\tau_{\mathrm{p}}\right) / \mathrm{T}_{2}^{*}(\mathrm{r})}\right. \\
& \times\left[\operatorname { c o s } \left[\omega_{\mathrm{L}} \mathrm{t}+\phi-\zeta_{\mathrm{T}}(\mathbf{r}) \mathbf{b}_{\mathrm{T}}^{\perp}(\mathbf{r})\right.\right. \\
& \left.\left.+\sin \left[\omega_{\mathrm{L}} \mathrm{t}+\phi-\zeta_{\mathrm{T}}(\mathbf{r})\right] \hat{\mathbf{b}}_{\mathrm{T}}(\mathbf{r})\right]\right\}
\end{aligned}
$$

Only data after the pulse and related dead time $\left(\tau_{\mathrm{p}}+\tau_{\mathrm{d}}\right)$ are recorded, by letting the term $\mathrm{e}^{-\left(t \tau_{\mathrm{p}}\right) / T_{2}^{*}} \rightarrow \mathrm{e}^{-t T_{2}^{*}} \mathrm{e}^{\left(-\left(\tau_{\mathrm{p}} / 2+\tau_{\mathrm{d}}\right) T_{2}^{*}\right)}$. Incorporating the phase effect due to the pulse and dead time offset into $\theta_{\mathrm{T}}$ allows data to be modelled which mimics the recorded data. That is, for our modeled data, $\mathrm{t}=0$ corresponds to $\mathrm{t}=\tau_{\mathrm{p}}+\tau_{\mathrm{p}}$ in the actual experiment. We use the term $\tau_{\text {offset }}$, to denote this delay. The use of $\tau_{\mathrm{p}} / 2$ accounts for some of the decay during the transmitted pulse (Weichman and others, 2000; Walbrecker and others, 2009). The Fourier transform may be written:

$$
\begin{aligned}
\mathcal{M}_{\mathrm{N}}(\mathbf{r}, \omega) & =\left|\mathbf{M}_{\mathrm{N}}^{(0)}(\mathbf{r})\right| \mathrm{e}^{-\frac{\tau_{\mathrm{d}}+\frac{\tau_{\mathrm{P}}}{2}}{2}(\mathrm{r})} \sin \left[\theta_{\mathrm{T}}(\mathbf{r})\right] \\
& \times\left[\frac{\left[\cos \left[\phi-\zeta_{\mathrm{T}}(\mathbf{r})\right]\left(\frac{1}{\mathrm{~T}_{2}^{*}(\mathbf{r})}+j \omega\right)-\omega_{\mathrm{L}} \sin \left[\phi-\zeta_{\mathrm{T}}(\mathbf{r})\right]\right.}{\omega_{\mathrm{L}}^{2}+\left(\frac{1}{\mathrm{~T}_{2}^{*}(\mathbf{r})}+j \omega\right)^{2}}\right] \hat{\mathbf{b}}_{\mathrm{T}}(\mathbf{r}) \\
& +\left[\frac{\sin \left[\phi-\zeta_{\mathrm{T}}(\mathbf{r})\right]\left(\frac{1}{\mathrm{~T}_{2}^{*}(\mathbf{r})}+j \omega\right)+\omega_{\mathrm{L}} \cos \left[\phi-\zeta_{\mathrm{T}}(\mathbf{r})\right]}{\omega_{\mathrm{L}}^{2}+\left(\frac{1}{\mathrm{~T}_{2}^{*}(\mathbf{r})}+j \omega\right)^{2}}\right] \hat{\mathbf{b}}_{\mathrm{T}}(\mathbf{r}) \\
& =\left[\mathbf{M}_{\mathrm{N}}^{(0)}(\mathbf{r}) \mid \mathrm{e}^{-\left(\tau_{\mathrm{d}}+\tau_{\mathrm{p}} / 2\right) / \mathrm{T}_{2}^{*}(\mathbf{r})} \sin \left[\theta_{\mathrm{T}}(\mathbf{r})\right]\left[\mathcal{M}_{\mathrm{N} 1}(\mathbf{r}) \hat{\mathbf{b}}_{\mathrm{T}}^{\perp}(\mathbf{r})\right.\right. \\
& \left.+\mathcal{M}_{\mathrm{N} 2}(\mathbf{r}) \hat{\mathbf{b}}_{\mathrm{T}}(\mathbf{r})\right] .
\end{aligned}
$$


The inner product of the adjoint receiver field with equation 24 enters the voltage response (equation 21). The adjoint field is defined by a unit current in the receiver loop. Only the perpendicular portion (due to the dot product) enters the voltage-response equation. The field from that current can be decomposed in the same manner as the transmitter field, and in fact, it is $\mathbf{B}_{\mathrm{R}}^{-}$that enters the voltage response (Weichman and others, 2002; Legchenko and Valla, 2002). This is evident either from the fact that in equation 13 the receiver field plays backwards, as the signal is not coming from the loop and propagating into the subsurface, but rather the opposite. Alternatively, in equation 21, the Hermitian form of the complex inner product reverses the direction of the receiver field. The final frequency domain modeling equation therefore is:

$$
\begin{aligned}
\mathcal{V}_{R}^{N}(\omega)= & j \omega \int \mathbf{B}_{\mathrm{R}}^{\perp}(\mathbf{r}, \omega) \cdot \mathcal{M}_{\mathrm{N}}(\mathbf{r}, \omega) d^{3} r \\
= & j \omega \int \mathbf{B}_{\mathrm{R}}^{-}(\mathbf{r}, \omega) \cdot \mathcal{M}_{\mathrm{N}}(\mathbf{r}, \omega) d^{3} r \\
= & j \omega \int\left|\mathbf{M}_{\mathrm{N}}^{(0)}(r)\right|\left[\alpha_{R}(\mathbf{r}, \omega)+\beta_{R}(\mathbf{r}, \omega)\right] e^{-\left(\tau_{d}+\tau_{p} / 2\right) / T_{2}^{*}(\mathbf{r})} \\
& \sin \left[\theta_{T}(\mathbf{r})\right] e^{j\left[\zeta_{R}(\mathbf{r}, \omega) \tau_{\sigma f f s e t}\right]} \\
& \times\left\{\mathcal{M}_{\mathrm{N} 1}(\mathbf{r}, \omega) \hat{\mathbf{b}}_{\mathrm{R}}(\mathbf{r}, \omega) \cdot \hat{\mathbf{b}}_{\mathrm{T}}\left(\mathbf{r}, \omega_{L}\right)\right. \\
& \left.+\mathcal{M}_{\mathrm{N} 2}(\mathbf{r}, \omega) \hat{\mathbf{B}}_{0} \cdot\left(\hat{\mathbf{b}}_{\mathrm{R}}(\mathbf{r}, \omega) \times \hat{\mathbf{b}}_{\mathrm{T}}\left(\mathbf{r}, \omega_{L}\right)\right)\right\} d^{3} r \\
= & j \omega \int \mathcal{K}\left(q, r, f(\mathbf{r}), T_{2}^{*}(\mathbf{r}), \omega\right) d^{3} r .
\end{aligned}
$$

In the case where the transmitter and receiver are coincident, the cross product $\left(\hat{\mathbf{b}}_{R} \times \hat{\mathbf{b}}_{T}\right)$ vanishes, and all the signal comes from $\mathcal{M}_{N 1}$.

\section{Incorporating Dephasing Effects}

Dephasing is the process in which coherence in the magnetization of the molecules, after being tipped, decays over time. The typical approach to handling the dephasing in the SNMR FID data incorporates scaling $T_{2}{ }^{*}$ using equation 18. The shortcoming with this approach is that it cannot

Figure 8. $\quad \mathrm{A} T_{2}^{*}$-millisecond exponential decay, shown in green, is dephased under the static, non-interacting spin assumption. The dephased signal, shown in blue, is the result of summing Larmor frequencies over a $20-\mathrm{Hz}$ window defined by a normalized Gaussian probability density function (pdf). The simulated data are in good agreement with random-walk simulations shown in figure 7(B) and Grunewald and Knight (2011). The red line is an exponential fit to the dephased data, assuming $20 \mathrm{~ms}$ of instrument dead time. The dashed red line is the backwards extrapolation into the dead time to arrive at the initial amplitude. The dephasing causes significant error in this extrapolation. The cyan line represents the commonly held model of magnetic field inhomogeneity on the NMR signal, $T_{2 I H}=\Delta \mathbf{B}_{0} \gamma_{H} /(2 \pi)$, which fails to reproduce the nonexponential decay and is a poor approximation of the dephased signal. $\mathbf{B}_{0}$ is the static magnetic field, $\gamma_{H}$ is the gyromagnetic ratio of hydrogen, $T_{2}^{*}$ describes the envelope of the free-induction decay signal, and $T_{2 I H}$ is the envelope of decay due to static-field inhomogeneity. $\mathbf{M}_{\mathrm{N}}^{(0)}$ is the initial paramagnetic nuclear magnetization. produce nonexponential decay and, therefore, does not model the dynamics of dephasing. As a result, we instead adopt a hybrid approach which assumes a large ensemble of stationary, non-interacting spins, oscillating at slightly different Larmor frequencies. The distribution of the spins is assumed to be known. The effects of this dephasing model are demonstrated in figure 8 , where a $150-\mathrm{ms} T_{2}{ }^{*}$ signal is dephased by a $\gamma \Delta \mathbf{B}_{0}=20 \mathrm{~Hz}$ local field inhomogeneity. In this simulation, the probablity density function (pdf) of the spins assumed a Gaussian distribution. The interesting part of this plot is the nonexponential nature of the recorded signal. Substantial error is introduced in fitting dephased data to a single exponential, especially in extrapolating to the initial amplitude. The model used to produce this graph is simple - define a normalized pdf $<\omega_{L}, \phi>$ and computed scaled $\mathcal{M}$ terms for each Larmor frequency in the modeling kernel. We then carried out an integration over the $\phi$ term within equation 25 .

$$
\begin{aligned}
\mathcal{V}_{N}(\omega) & \left.=j \omega \iint \phi\left(\omega_{L}^{\prime}\right) \mathcal{K}\left(q, \mathbf{r}, T_{2}^{*}(\mathbf{r}), \omega, \omega_{L}^{\prime}\right)\right) d \omega_{L}^{\prime} f(\mathbf{r}) d^{3} r \\
& =j \omega \int \mathcal{K}_{D P}\left(q, \mathbf{r}, T_{2}^{*}(\mathbf{r}), \omega\right) f(\mathbf{r}) d^{3} r
\end{aligned}
$$

where the $D P$ subscript on $\mathcal{K}$ represents the fact that a dephasing term has been added. Equations 25 and 26 take the same general form, and the same solution schemes may be used to solve either system. We show in the next section that this dephased model (with $\phi$ defined over a Gaussian distribution) is able to reproduce field data taken in Nebraska to a greater level than is possible with the strictly exponential model in equation 25 .

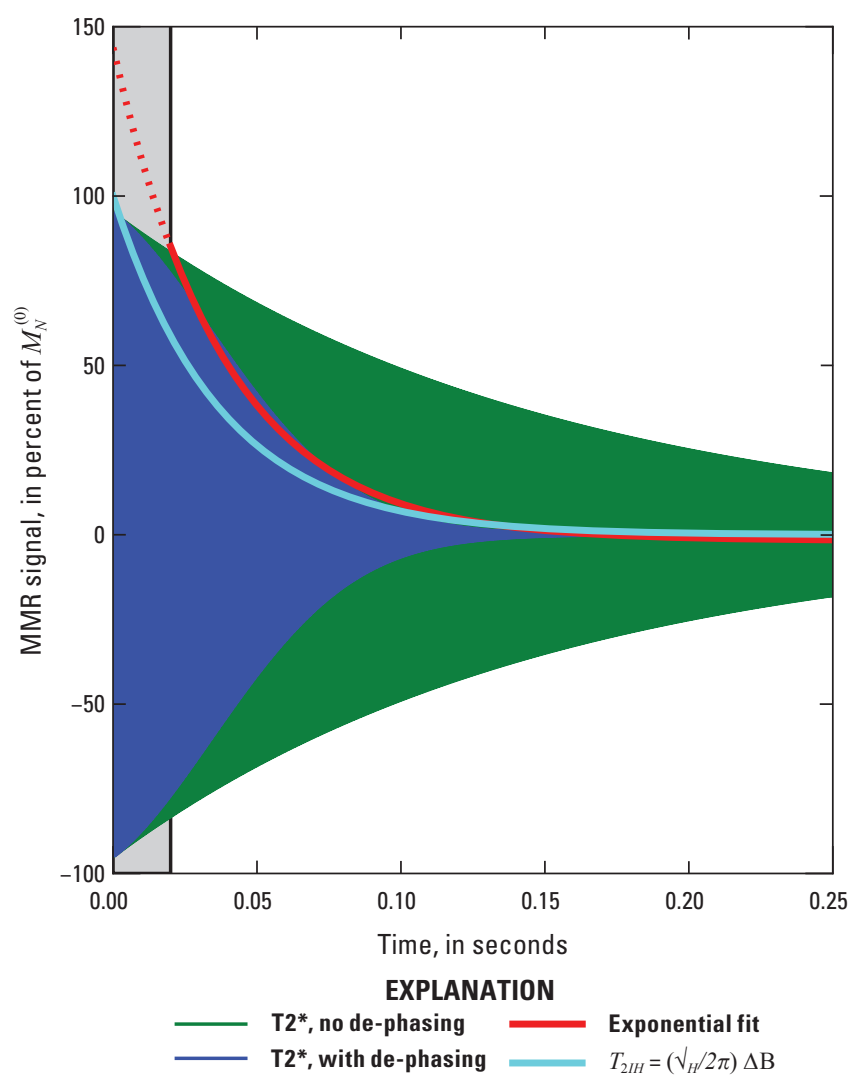




\section{Linear 1-D Inversion Formulation}

Inverting equations 25 or 26 directly for $f(\mathbf{r})$ and $T_{2}{ }^{*}(\mathbf{r})$ is a nonlinear problem for several reasons. First, the forwardmapping operator is a function of both electrical conductivity $(\sigma(\mathbf{r}))$ and water content, which makes it necessary to have an electrical conductivity model for a linear inversion. Second, since the modeling kernel is a coupled function of both $T_{2}^{*}(\mathbf{r})$ and $f(\mathbf{r})$, a further linearization step is needed.

\section{Linearization of the Problem}

We begin by discussing a general inversion scheme that is developed into a 1-D inversion that can be applied to FID and pseudosaturation recovery $\left(T_{l}\right)$ datasets. If $\sigma$ is known, the problem may be formulated as a linear system. We used TEM inversions to estimate electrical conductivity models, which were then used as in inputs into the inversion algorithm. Although equations 24 and 25 are general, commonly it is useful to consider only the 1-D problem. In fact for single-loop datasets, it is necessary, as no lateral information is available. This simplifies the integral in this equation, simply over the $z$ dimension:

$$
\begin{aligned}
\mathcal{V}_{R}^{N}(\omega) & =j \omega \int \mathcal{K}\left(q, \mathbf{r}, T_{2}^{*}, \omega\right) f(\mathbf{r}) d^{3} r \\
& \rightarrow j \omega \int \mathcal{K}\left(q, z, T_{2}^{*}, \omega\right) f(z) d z .
\end{aligned}
$$

The notation $T_{2}^{*}(\mathbf{r})$ is a little misleading. The NMR response generally is not characterized by a single decay parameter, but in fact is a linear combination of decaying spins, a fact observed across scales. Multi-exponential fits are necessary to fit most SNMR data (Mohnke and Yaramanci, 2005), which, applied to our formulation, yields:

$$
\mathcal{V}_{R}^{N}(\omega)=j \omega \iint \mathcal{K}\left(q, z, T_{2}^{*}, \omega\right) f\left(z, T_{2}^{*}\right) d T_{2}^{*} d z .
$$

The free-water model $f$ can now be interpreted as the fractionated water model over the range of possible $T_{2}^{*}$ exponential values. The need for a multi-exponential fit is due to changing pore characteristics across the survey area; in other words, not every spin will decay at the same rate in any porous media, as local porosity and pore shapes are never completely uniform. Solving specifically for a distribution is a nonlinear problem, but it is possible instead to formulate the inversion as a series of $T_{2}^{*}$ bins which cover the range of the expected distribution:

$$
\mathcal{V}_{R}^{N}[q, \omega]=j \omega \sum_{i z=0}^{n z} \sum_{i T_{2}=0}^{n T_{2}} \mathcal{K}\left[q, i z, i T_{2}^{*}, \omega\right] f\left[i z, i T_{2}^{*}\right] .
$$

In equation $29, \mathcal{K}$ is a rank-4 tensor; while $\mathcal{V}_{R}^{N}$ and $f$ are rank 2 . The discretization step from equation 27 to equation 28 requires converting the depth integrals to discrete intervals. This may be accomplished using a finite-difference style of mesh where each layer interval incorporates the volume of that respective layer. As $f$ and $\mathcal{V}$ do not share free variables, equation 29 is a linear system. Unwinding the matrices $f$ and $\mathcal{V}$ into 1-D vectors, and correspondingly, $\mathcal{K}$ into a 2-D matrix, allows the system to be written in the form $\mathcal{V}=\mathcal{K} \mathbf{f}$.

\section{Modulus Solution}

While in theory the inversion will benefit from taking into account both the amplitude and phase information from the data (Braun and others, 2005; Weichman and others, 2000), in practice this is often not possible because it typically is difficult to model accurately the phase of the data. This especially is true when the entire dataset is inverted, as opposed to inversion of only the initial amplitude. Some postulated reasons for this include (1) off-resonance transmitter effects, (2) unreliable phase information in low signal-tonoise conditions, (3) nonexact input conductivity models, or (4) imperfectly reported transmitter-current phases from the instrument. The true causes for this difficulty remain an open field of study. It would be desirable to include the entire dataset in the inversion. Because of these uncertainties, however, only the modulus of the spectrum was inverted, rather than both the real and imaginary parts of the complex kernel, making $\mathcal{K}$ and $\mathcal{V}$ real. This process results in the real linear system:

$$
\mathbf{v}=\mathbf{K f}
$$

\section{Model and Data Space}

The inversion solves for the model vector $\mathbf{f}$, which is the partial water concentration defined at each depth layer and $T_{2}{ }^{*}$ bin. The dimensionality of $\mathbf{f}$ is therefore $n T_{2}{ }^{*} \times$ nlay $=M$ where $n T_{2}{ }^{*}$ is the number of $T_{2}{ }^{*}$ bins and nlay is the number of depth layers.

A typical free-induction decay (FID) SNMR dataset contains $n p$ pulse moments, generally between 20 and 60 . For each pulse moment, a time series is recorded. Depending on the instrumentation, this time series is either (1) realvalued and sampled sufficiently as to not alias at the Larmor frequency, or (2) complex-valued, delivering the quadrature detection-scheme-derived complex-valued amplitude envelope and instantaneous phase. In this paper, data from the Vista Clara, Inc. GMR instrument are considered, which provides a real dataset, sampled at $1 \times 10^{4}$ samples per second, corresponding to a Nyquist frequency of $5 \mathrm{kHz}$. Typical time series range from $100 \mathrm{~ms}$ to $1 \mathrm{~s}$, depending on the decay of the signal. In Nebraska, most datasets were about $300 \mathrm{~ms}$ in length. A typical SNMR dataset therefore will then have something on the order of $3,000 \times n p$ real data points. In the case of 50 pulse moments, this translates into 150,000 data to be inverted. It is for this reason that time-domain whole-dataset inversions are slow and extremely memory-intensive.

In order to make the solution solvable, it becomes necessary to downsample (or subsample) the dataset. For real data sampled at $1 \times 10^{4}$ samples per second, the Nyquist frequency is $5,000 \mathrm{~Hz}$. Larmor frequencies typically are above $2 \mathrm{kHz}$, so downsampling by a factor of about two is approximately the limit of decimation. If the data are fit to a complex-valued envelope, additional downsampling may be applied. Instantaneous phase values are not that stable, however, so downsampling the 
envelope in a meaningful way can be difficult. In addition, this operation also makes an assumption on the rate of phase and amplitude change that is not necessarily grounded. The other problem with downsampling in time is that it indiscriminately removes both significant data and noise.

Alternatively, in the frequency domain, only frequencies around the Larmor frequency need to be considered. Compression levels greater than 25 were easily achievable, and no NMR signal was lost, as the downsampling is entirely in the nullspace of $\mathcal{K}$. This reduction of the nullspace improves the numerical properties of the system to be inverted. It is also typically the case as well that a Fourier-domain window filter has been applied to the data; it makes no sense to invert data outside such a filter.

\section{Tikhonov 1-D Inverse Problem Solution}

We take an optimization approach to solving the discretized linear problem (Parker, 1977). We seek to minimize an objective function $\Phi=\Phi_{d}+\lambda \Phi_{m}$ subject to $0 \leq \theta_{S N M R} \leq 1$. Where $\Phi_{d}$ is the data-misfit function, and $\Phi_{m}$ is the model objective function, defined by the following:

$$
\begin{gathered}
\Phi_{d}=\mathbf{W}_{d}\left\|\left(\mathbf{K f}-\mathbf{v}^{o b s}\right)\right\|^{2} \\
\Phi_{m}=\alpha_{s} \int v^{2} d z d T_{2}^{*}+\alpha_{T_{2}^{*}}\left\{\left\{\frac{\partial f}{\partial T_{2}^{*}}\right\}^{2} d z d T_{2}^{*}\right. \\
+\alpha_{z} \int\left\{\frac{\partial f}{\partial z}\right\}^{2} d z d T_{2}^{*}=\left\|\mathbf{W}_{m} \mathbf{f}\right\|^{2} .
\end{gathered}
$$

$\mathbf{K}$ is a matrix formed from the linearization of the forward imaging kernel function, $\mathbf{f}$ is the model of partial water content at each depth and $T_{2}^{*}$ bin, and $\mathbf{v}^{\text {obs }}$ is the observed data. $\mathbf{W}_{d}$ is a data-weighting matrix related to the noise statistics; I may be used when the noise is not well characterized. Additionally, if the noise is not well understood, it is unclear how much regularization should be applied so that the optimal solution $\mathbf{m}$ : $\phi_{d}^{*}$, contains no noise artifacts but has the greatest amount of structure available in the data.

To determine the optimal value of the trade-off parameter $\lambda$, an $L$-curve criterion was used (Hansen, 1992). The premise behind the L-curve is initially to allow $\lambda$ to take a very large initial value. Output from that inversion will then be made to satisfy solely the model objective function. If there is a smallest model term $\alpha_{s}$, then the reconstructed model at high $\lambda$ will be the null solution. Many more inversions are then performed, while monotonically decreasing $\lambda$. Each new inversion will add model structure, as the data objective function carries more weight in the total objective function. Generally speaking, the data misfit initially will be reduced substantially during this process, with modest changes in the reconstructed model. At some point, however, it requires significantly more complex models to explain the data. The result is an "L-shaped" curve when plotting $\Phi_{d}$ on the ordinate and $\Phi_{m}$ on the abscissa in log space. There generally is an inflection point that can be interpreted as $\Phi_{d}^{*}$, the optimal solution. While not as mathematically rigorous as some other methods such as cross validation, in practice the L-curve criterion performs well in the presence of correlated and non-Gaussian noise, assumptions which often are incorporated in other approaches. We will show that SNMR noise typically is non-Gaussian.

\section{Non-negativity Constraint}

As stated before, a constraint on the feasible solutions limiting solutions to physically possible models is necessary. Formally this constraint takes the form $0 \leq \theta_{S N M R} \leq u$, where $u$ is the upper bound on porosity. The absolute maximum value $u$ can take is 1 , but smaller values may be taken as a priori information. The SNMR porosity for the depth layer $i z$ can be computed as follows:

$$
\theta_{S N M R}[i z]=\sum_{i T_{2}^{*}}^{n T_{2}^{*}} f\left[i z, i T_{2}^{*}\right] \leq u .
$$

Within this sum, however, an individual $T_{2}^{*}$ bin cannot be negative, so it is necessary to constrain $f\left[i z, i T_{2}^{*}\right] \geq 0$. Calvetti and others (2004) and Li and Oldenburg (2000) outline interiorpoint, log-barrier Tikhonov inversion schemes, a hybrid of which was followed for solving the constrained linear problem. The technique requires modifying the objective function to take the following form:

$$
\begin{aligned}
B\left(f, \mu_{x}, \mu_{y}\right) & =\phi-\mu_{x} \sum_{j=1}^{n z \times n T_{2}^{*}} \ln (f[j]) \\
& -\mu_{y} \sum_{i z=1}^{n z} \ln \left(1-\frac{\sum_{i T_{2}^{*}=1}^{n T_{2}^{*}} f\left[i z, i T_{2}^{*}\right]}{u}\right) .
\end{aligned}
$$

Minimizing $B$ is no longer a linear problem. We apply an interior-point method to minimize the function. To arrive at a solution given $\lambda, \mu_{x}, \mu_{y}$ solve the linear system:

$$
\begin{aligned}
& \left(\mathbf{K}^{T} \mathbf{K}+\mu_{x} \mathbf{X}^{-2}+\mu_{y} \mathbf{Y}^{-2}+\lambda \mathbf{W}_{m}^{T} \mathbf{W}_{m}\right) \mathbf{f} \\
& \quad=\mathbf{K}^{T} \mathbf{W}_{d}^{T} \mathbf{W}_{d} \mathbf{v}^{\text {obs }}+2 \mu_{x} \mathbf{X}^{-1} \mathbf{c}+2 \mu_{y} \mathbf{Y}^{-1} \mathbf{c}
\end{aligned}
$$

for $\mathbf{f}$, where $\mathbf{c}=[1, \ldots, 1]^{T}$ and $\mathbf{X}=\operatorname{diag}\left\{f_{1}, \ldots, f_{M}\right\}$. The matrix $\mathbf{Y}$ is given by the following:

$$
\mathbf{Y}\left[i z \times n T_{2}^{*}+i T_{2}^{*}, i z \times n T_{2}^{*}+i T_{2}^{*}\right]=1-\frac{\sum_{i T_{2}^{*}=1}^{n n *^{*}} f\left[i z, i T_{2}^{*}\right]}{u} .
$$

The tradeoff parameter $\lambda$ ensures that the matrix on the left-hand side is positive semidefinite, and Krylov subspace iterative solvers may be used to solve the system; we adapted a conjugate gradient solver from Barrett and others (1994).

The log-barrier terms prevent the solution from approaching the bounds of the feasible set. However, $\mathbf{f}$, should be allowed to approach the limits of the constraint. To allow for 
this, the barrier multipliers $\mu_{x}$ and $\mu_{y}$ are relaxed as a solution is sought to equation 34 . for a given $\lambda$ so that $B \rightarrow \phi$. This interior point-search algorithm proceeds as follows:

1. Set initial values of $\lambda, \mu_{x}, \mu_{y}$, and an initial guess for $\mathbf{f}^{(0)}$ that satisfies the constraints;

2. Solve for a particular $\lambda$ :

a. Solve equation 34. for $\tilde{\mathbf{f}}^{(j)}$, and $\mathbf{h}^{(j)}=\tilde{\mathbf{f}}^{(j)}-\mathbf{f}^{(j)}$,

b. Determine the step length $d$ :

$$
d=\min \left\{1,0.9995 \min _{1 \leq k \leq M} \frac{\mathbf{e}_{k}^{T} \mathbf{f}^{(j)}}{\left|\mathbf{e}_{k}^{T} \mathbf{h}^{(j)}\right|}\right\},
$$

where $\boldsymbol{e}_{k}$ is the Kronecker delta, at $k$.

c. Determine $\mathbf{f}^{(j+1)}=\mathbf{f}^{(j)}+d \mathbf{h}$,

d. Determine $\mu_{x}$ and $\mu_{y}$ according to the following:

$$
\begin{aligned}
& \mathbf{s}_{x}=\mu_{x}\left(\mathbf{X}^{-2} \tilde{\mathbf{f}}-2 \mathbf{X}^{-1} \mathbf{c}\right) \\
& \mathbf{s}_{y}=\mu_{y}\left(\mathbf{Y}^{-2} \tilde{\mathbf{f}}-2 \mathbf{Y}^{-1} \mathbf{c}\right)
\end{aligned}
$$

and update,

$$
\begin{aligned}
& \mu_{x}=\frac{\rho}{M}\left|\mathbf{s}_{\mathbf{x}}{ }^{T} \mathbf{f}^{(j+1)}\right| \\
& \mu_{y}=\frac{\rho}{M}\left|\mathbf{s}_{y}{ }^{T} \mathbf{f}^{(j+1)}\right|,
\end{aligned}
$$

where $\rho$ is a user-defined constant that controls the rate of convergence towards the boundary.

e. Return to (a) until $B-\Phi \approx 0$.

3. Relax the trade-off parameter $\lambda$, and return to 2 , until $L$-curve inflection point is observed.

\section{Discussion of Inversion Performance}

The algorithm above produces models at various $\lambda$ parameters. For data taken in central Nebraska we observed better results with the dephased kernel than with the purely exponential kernel. We used a 7-Hz Gaussian dephasing window. The justification for that level of dephasing was based on a borehole magnetometer survey (E. Grunewald, [then at Stanford University] now Vista Clara Inc., Mukilteo, Wash., 2009, personal commun.) as well as on inversion results (fig. 9). Consistently, lower data misfits at a higher model complexity were achieved using the dephased kernel. The dephased kernel also was consistently able to reproduce the field data better than the exponential kernel.

\section{Transient Electromagnetic Data Collection and Processing}

Transient electromagnetic (TEM) data were collected between April 2007 and April 2009 at 23 sites in 14 locations in the CPNRD (fig. 1). The TEM data were collected to enhance understanding of underlying hydrostratigraphic units, and the resulting information was used as a screening tool in determination of the location of aquifer test sites 58 and 72 . All collected data are provided in Payne and Teeple (2011) and include detailed description of all data-collection procedures. For this report, all TEM data were reprocessed using the SiTEM/Semdi inversion code (Auken and Nebel, 2001) and used as input for the inversion of the SNMR data. Data processing and inversion procedures are described in further detail in Abraham and others (2011a), Abraham and others (2011b), and Hobza and others (2011).

\section{Aquifer Tests}

Aquifer tests were used to determine four primary aquifer characteristics: $\mathrm{K}, \mathrm{T}$, specific yield $\left(\mathrm{S}_{\mathrm{y}}\right)$, and storativity (S). Hydraulic conductivity, with dimensions of length per unit time $(\mathrm{L} / \mathrm{t})$, is a measure of the capacity of an aquifer (or porous medium) to transmit water per unit time (note that for this study, emphasis was placed on horizontal or radial hydraulic conductivity $\left(\mathrm{K}_{\mathrm{r}}\right)$ ). Transmissivity, with dimensions of length squared per unit time $\left(\mathrm{L}^{2} / \mathrm{t}\right)$, is the product of $\mathrm{K}_{\mathrm{r}}$ and the thickness (b) of the aquifer. Specific yield is a dimensionless measurement of the volume of water that would drain under gravity alone per unit volume of aquifer. Specific yield is limited to unconfined (water-table) aquifers because unlike confined aquifers, unconfined aquifers are dewatered during the aquifer test. Storativity is a dimensionless measurement of the volume of water that can be released from or absorbed into an aquifer per unit surface area of the aquifer per unit change in hydraulic head (Lohman, 1972). Storativity typically is smaller in confined systems (generally $10^{-4}$ to $10^{-5}$ ) than in unconfined systems. Values of S in unconfined systems generally are about equal to $S_{y}$.

\section{Design of the Aquifer Tests and Methods of Analysis}

Four aquifer tests, two tests at each of two separate sites near Lexington, Dawson County, Nebr. (fig. 1), were conducted to determine hydraulic characteristics of aquifers in the alluvial and Ogallala deposits (alluvial and Ogallala aquifers, respectively). Both test sites (site 58A and site 72A) were adjacent to or at locations where geophysical properties of the deposits were measured using SNMR. Site 58A was located about $8.0 \mathrm{~km}$ west and $9.7 \mathrm{~km}$ north of Lexington (figs. 1 and 10). Two aquifer tests were conducted at site 58A during February-March 2010. Depth to groundwater at that site was about $4.6 \mathrm{~m}$. Site $72 \mathrm{~A}$ was located about $8.0 \mathrm{~km}$ east and $6.2 \mathrm{~km}$ north of Lexington (figs. 1 and 10). Two aquifer tests were conducted at site 72A during February-March 2008. Depth to groundwater at site $72 \mathrm{~A}$ was about $12.8 \mathrm{~m}$.

New wells were installed for aquifer testing. Sites 58A and $72 \mathrm{~A}$ each contained two production wells, one open only to the alluvial deposits and the other open only to the Ogallala deposits. Two production wells and 12 observation wells (11 

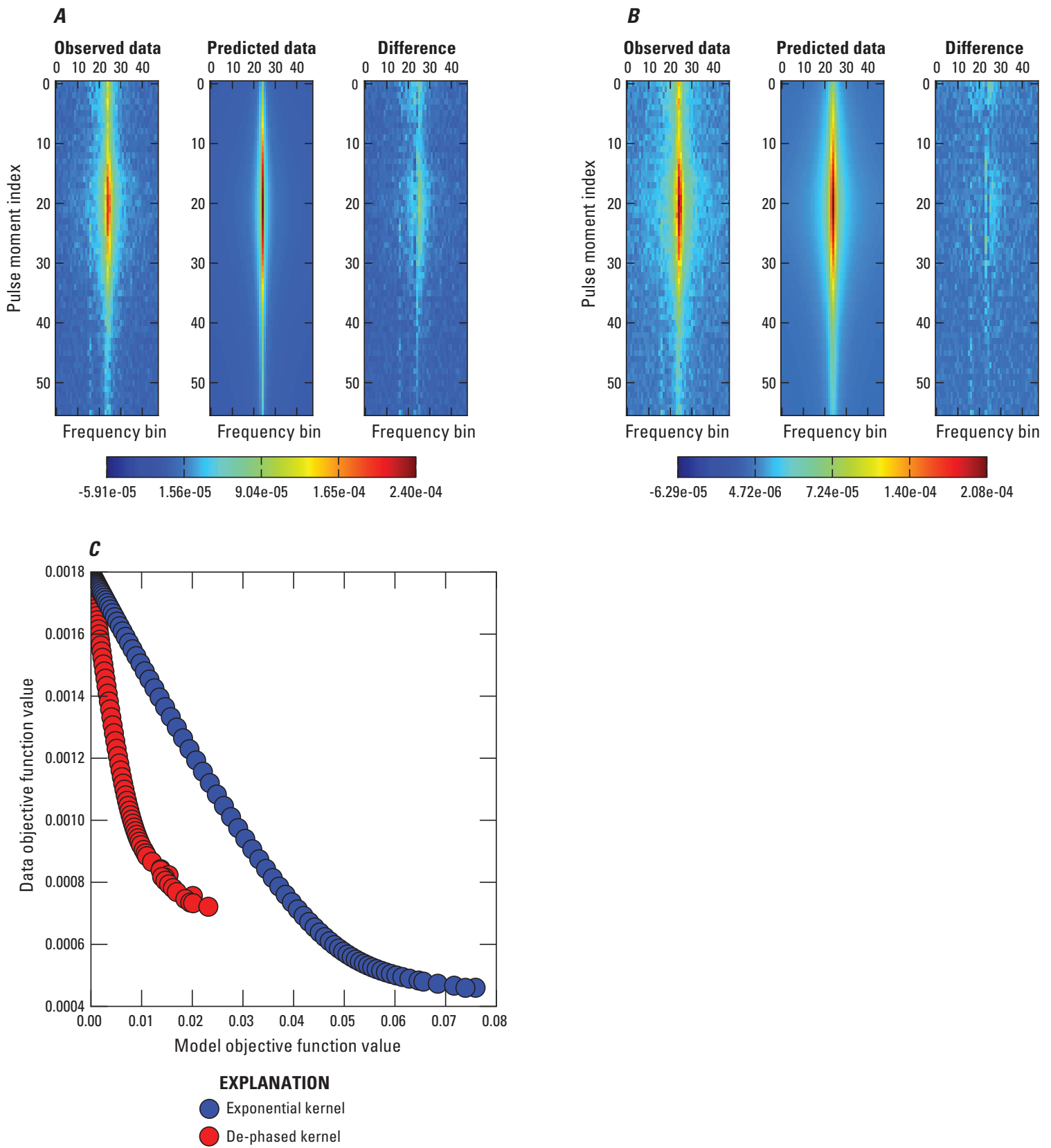

Figure 9. Comparison of the frequency-domain inversion using both strictly exponential $(A)$ and dephased $(B)$ kernels. For each inversion, the observed, predicted, and data misfit are plotted at the optimal trade-off level from the $L$-curve $(C)$. It can be seen that the dephased model was able to drive substantially lower data misfit.

wells used for the aquifer test analysis; table 4, Appendix) were installed at site 58A. Depth of the observation wells open to the alluvial deposits at site 58A ranged from about 18.3 to $24.4 \mathrm{~m}$, whereas the depth of observation wells open to the Ogallala deposits ranged from 33.5 to $131 \mathrm{~m}$ (tables 4 and 5; Appendix). Two production wells and 10 observation wells ( 9 wells used for the aquifer test analysis; table 4, Appendix) were installed at site 72A. Depth of all observation wells open to the alluvial deposits at site 72A was $22.9 \mathrm{~m}$. Depth of observation wells open to the Ogallala deposits at site $72 \mathrm{~A}$ ranged from 30.5 to $131 \mathrm{~m}$ (tables 4 and 5, Appendix).
The three shallowest observation wells per site all were open only to the alluvial deposits. The three observation wells at site $72 \mathrm{~A}$ were fully screened in the saturated sand and gravel deposits of the alluvial aquifer. Two of the three observation wells at site 58A were screened (at $24.4 \mathrm{~m}$ ) near the bottom of the saturated sand and gravel deposits of the alluvial aquifer, whereas the third well was screened (at $18.3 \mathrm{~m}$ ) near the top of the saturated sand and gravel deposits.

Sixteen observation wells, nine at site 58A and seven at site $72 \mathrm{~A}$, were open to the Ogallala. Fourteen of these 16 observation wells were open only to the Ogallala and were 

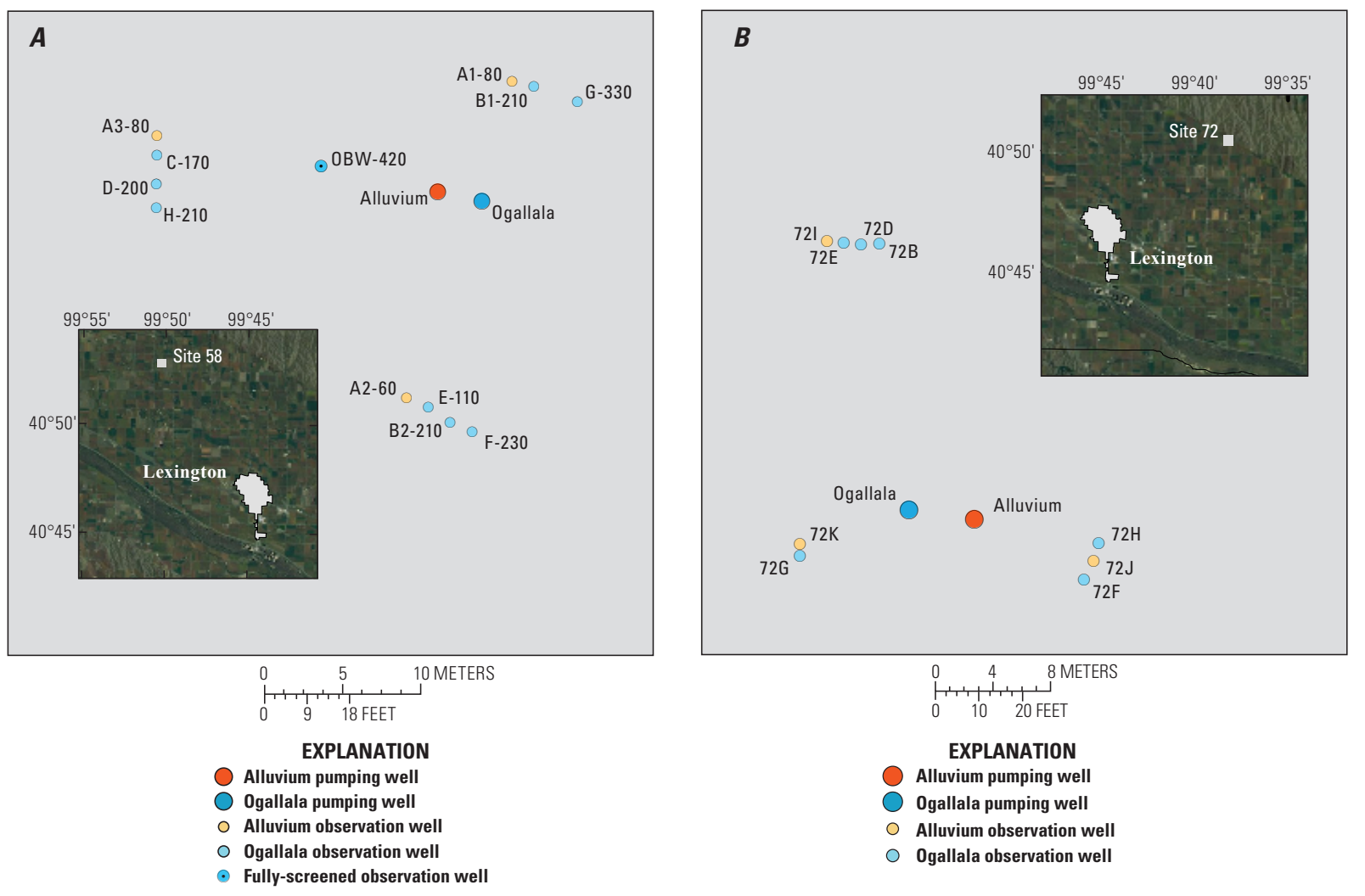

Figure 10. Maps showing locations of aquifer tests at $(A)$ site 58A and $(B)$ site 72A, Dawson County, Nebr.

used for aquifer-test data collection to characterize the hydraulic properties of the Ogallala. Ogallala observation wells were, for the most part, either open to different zones of the Ogallala (separate intervals and depths) or fully screened throughout the Ogallala (some observation wells were screened in the same interval but at a different radial distance from the pumping well) (table 4, Appendix). In addition, each site contained a single observation well open to both the alluvial and Ogallala aquifers (wells OW58A-430 and OW72A-430, respectively) (table 5, Appendix). Those two observation wells were used only for flowmeter tests and not for analysis of the aquifer tests.

Observation wells open to two aquifers during an aquifer test (such as OW58A-430 and OW72A-420) can allow water from one aquifer to flow through the observation well to the underlying or overlying aquifer. To prevent water from flowing from the producing aquifer to the non-producing aquifer, such as the lower (Ogallala) aquifer to the upper aquifer (alluvial deposits) during the alluvial aquifer test or from the upper aquifer to the lower aquifer during the Ogallala aquifer test, the two fully-screened observation wells were plugged at a point separating the screen open to the alluvial deposits and the screen(s) open to the Ogallala.

All four aquifer tests were $192 \mathrm{hr}$ in duration; $96 \mathrm{hr}$ of pumping was followed immediately by $96 \mathrm{hr}$ of water-level recovery. Regardless of test site or the aquifer tested, each of the four aquifer tests followed the same general procedure, and each test was conducted in a similar manner. The general procedure was to measure concurrently, at specified time intervals, water levels in each observation well using calibrated electric tapes, while dedicated submersible data loggers electronically logged changes in water levels. Hand measurements were collected on a time interval of $0.1 \mathrm{~min}$ to $1 \mathrm{hr}$, and data loggers were set to record at logarithmic intervals from less than $1 \mathrm{sec}$ to $1 \mathrm{hr}$. In addition, yield (discharge) from the production well generally was recorded at the same interval as the hand measurements (discharge generally was not measured at the same interval at the start of each test). Following cessation of the 96-hr pumping, the hand and electronic measurement processes were repeated for another $96 \mathrm{hr}$. The major difference was that a recovery curve was characterized during the recovery period, as opposed to a drawdown curve which was characterized during the pumping period. During and following each aquifer test, all data were downloaded from each data logger, then input into analytical software for analysis - all aquifer tests were analyzed using AQTESOLV Pro, version 4.5, software (HydroSOLVE, Inc., 2011). AQTESOLV software allowed selection and analysis of the data using many aquifer-test solutions in addition to partially penetrating wells. Use of partially penetrating wells was a primary modification from the main list of aquifer-test assumptions (table 2). 
An additional aquifer test was completed at site 58A in an observation well OW-430, which screened the entire thickness of the Ogallala. The purpose of that test was to determine if the completion of a single-well aquifer test used in conjunction with flow- and fluid-property logs would preclude the need for multiwell aquifer tests for comparisons to SNMR soundings. The well was pumped at a rate of $83 \mathrm{~L} / \mathrm{min}$ for 3 hours and $25 \mathrm{~min}$ utes, resulting in a quasi-steady-state drawdown of $1.05 \mathrm{~m}$. Recovery data were measured with submersible data loggers and verified with hand measurements. As with the other tests, results were analyzed using AQTESOLV Pro software, version 4.5 (HydroSOLVE, Inc., 2011).

\section{Analysis of Aquifer Tests in the Alluvial Deposits}

Aquifer-test data collected from wells open to the alluvial deposits (an unconfined aquifer) at sites 58A and 72A were analyzed using the Moench (1997) type-curve method for analysis of unconfined aquifers. Moench (1997) presented the Laplace transformation solution as a function for flow to a partially penetrating well of finite diameter in a water-table aquifer that is slightly compressible. The Moench (1997) solution allows for evaluation of the pumped well with partially penetrating observation wells. Furthermore, this solution accounts for effects of well-bore storage and skin effects and allows for the noninstantaneous release of water from the unsaturated zone. The noninstantaneous release of water from the unsaturated zone was the primary reason for selection of the Moench (1997) model. Primary assumptions used for the analysis of aquifer tests are listed in table 2.

Additional information on aquifer-test analysis or groundwater movement can be found in texts such as Kruseman and de Ridder (1990), Schwartz and Zhang (2003), and Todd and Mays (2005).

\section{Analysis of Aquifer Tests in the Ogallala Deposits}

Aquifer-test data collected from wells open to the Ogallala deposits (a confined aquifer) at sites 58A and 72A were analyzed using the Moench (1985) type-curve method for analysis of leaky aquifers. Data were corrected automatically for partially penetrating wells during analysis. Moench (1985) presented the Laplace transformation solution as a function for flow to a partially penetrating well of finite diameter in a water-table aquifer that is slightly compressible. The Moench (1985) solution allows for the evaluation of the pumped well and partially penetrating observation wells while accounting for well-bore storage and skin effects. This solution also allows for the noninstantaneous release of water from the unsaturated zone (unconfined system overlying the primary pumped aquifer). That latter part of the model solution was the primary reason for the selection of this particular model.

Aquifer-test analyses of the Ogallala data at site 58A indicate similar results, such as T values of about $3.5 \times 10^{-3} \mathrm{~m}^{2} / \mathrm{s}$ using the Moench (1985) solution and about $3.7 \times 10^{-3} \mathrm{~m}^{2} / \mathrm{s}$ using the Hantush (1960) solution. When comparisons of

Table 2. Primary assumptions used for analysis of aquifer tests, Dawson County, central Nebraska, 2008 and 2010.

\begin{tabular}{|c|c|}
\hline $\begin{array}{c}\text { Unconfined aquifer test in alluvial deposits } \\
\text { (modified from Moench, 1997) }\end{array}$ & $\begin{array}{l}\text { Confined aquifer test in Ogallala deposits } \\
\text { (modified from Moench, 1985) }\end{array}$ \\
\hline 1. Aquifer is seemingly infinite in areal extent; & 1. Aquifer is seemingly infinite in areal extent; \\
\hline $\begin{array}{l}\text { 2. Aquifer is homogeneous, anisotropic, and uniform in thickness } \\
\text { over the area influenced by the pumping test; }\end{array}$ & $\begin{array}{l}\text { 2. Aquifer is homogeneous, anisotropic, and uniform in thickness } \\
\text { over the area influenced by the pumping test; }\end{array}$ \\
\hline $\begin{array}{l}\text { 3. Aquifer is pumped at a continuous, constant discharge from a } \\
\text { specified zone beneath an initially horizontal water table; }\end{array}$ & 3. Aquifer is leaky confined; \\
\hline 5. Vertical flow across the base of the aquifer is negligible; & $\begin{array}{l}\text { 5. Pumping wells are fully penetrating (modified from fully } \\
\text { penetrating observation wells); }\end{array}$ \\
\hline 6. Groundwater density and viscosity are constant; & $\begin{array}{l}\text { 6. Water is released instantaneously from storage with decline } \\
\text { of hydraulic head; }\end{array}$ \\
\hline 7. Head within the well does not vary spatially; & 7. Vertical flow to the pumping well is negligible; \\
\hline $\begin{array}{l}\text { 10. At the interface of the well screen and the aquifer, a thin skin of } \\
\text { low-permeability material having no significant storage capacity } \\
\text { may be present; and }\end{array}$ & $\begin{array}{l}\text { 10. Confining bed(s) is(are) overlain or underlain by an infinite } \\
\text { constant-head plane source (case 1) or no-flow boundary } \\
\text { (case 2); and }\end{array}$ \\
\hline 11. Groundwater flow can be described by Darcy’s Law. & $\begin{array}{l}\text { 11. Groundwater flow can be described by Darcy's Law, and flow } \\
\text { is unsteady }\end{array}$ \\
\hline
\end{tabular}


residual versus simulated curves were compared against one another, however, the Moench (1985) solution had the better fit. In addition, the Hantush (1960) solution had (1) fewer parameters to constrain the solution, and (2) no effect from adjusting the ratio $\left(\mathrm{K}_{\mathrm{z}} / \mathrm{K}_{\mathrm{r}}\right)$, vertical $\mathrm{K}\left(\mathrm{K}_{\mathrm{z}}\right)$ to $\mathrm{K}_{\mathrm{r}}$. The only parameters that constrained the system in the Hantush (1960) solution were $T, S, K_{z} / K_{r}$, and the leakage parameter $(\beta)$. Excluding $\mathrm{K}_{\mathrm{z}} / \mathrm{K}_{\mathrm{r}}$, the other three parameters also were estimated in the Moench (1985) solution. Assumptions used for analysis of the aquifer test are presented in table 2 .

\section{Borehole Geophysical Data Collection}

Flow, or fluid-property, logs measure the vertical direction and rate of flow in a borehole or observation well. Flow logs typically are collected under ambient or pumping conditions. Flow occurs in a borehole when it penetrates multiple zones having different hydraulic heads. An electromagnetic flowmeter (Molz and Young, 1993) was used in this study. The operation of the electromagnetic flowmeter is based upon Faraday's Law, which states that the flow of an electrically conductive fluid through an induced magnetic field generates a voltage gradient that is proportional to its velocity. The calibrated measurement range of the electromagnetic flowmeter used in this effort, when equipped with a fully fitted diverter, is 0.19 to $56.8 \mathrm{~L} / \mathrm{min}$. A flexible rubber diverter focuses the borehole flow through the instrument's sensor. For this study, a diverter was chosen based on the nominal inside diameter of the screened observation-well casing.

The fluid-conductivity log measures the electrical conductivity of the borehole fluid which is related to the concentration of dissolved solids. Changes in the slope of the fluid-conductivity profile may indicate zones of fluid exchange between the well and the surrounding formation. In this study, fluid-conductivity logs were used to evaluate water quality and delineate possible flow patterns in wells. The fluid-conductivity logs were calculated from the measured fluid resistivity.

The temperature log records the temperature of air and water in the borehole. Fluid-temperature gradients that are variable with respect to depth may indicate the presence of vertical flow within the borehole. Temperature logs were used to identify possible flow zones.

Since Anderson and others (2009) described log analysis of selected test holes and wells in the High Plains aquifer, additional flow and fluid logs were collected in the fully screened observation well OW58A-430 (fig. 19; table 5). Observation well OW58A-430 was screened from 11.6 to $23.8 \mathrm{~m}$ and from 27.4 to $131 \mathrm{~m}$, across the entire thickness of the High Plains aquifer. A shallower 12.7-cm-diameter screen was open to the alluvial deposits and a lower 10.2-cmdiameter screen was open to the Ogallala. The step-down plumbing design allowed packing off of individual intervals. The two screens were connected by a reducing coupler and a short piece of blank casing surrounded by a bentonite seal. The depth of the blank casing was at the same interval as the semi-confining silt layer.
Flow and fluid-property logs were collected twice, once March 13, 2010, and again on May 21, 2010. Flow and fluidproperty logs were collected under ambient conditions; pumping used a rate of $18.2 \mathrm{~L} / \mathrm{min}$. After an initial examination of the collected flow and fluid-property logs, it was thought that the low pumping rate was insufficient to stress the lower portions of the aquifer given the strong downward regional gradient. Much of the ambient downward flow was from the overlying alluvium. Consequently, flow and fluid-property logs were recollected after packing off the upper screen with a $10.2-\mathrm{cm}$ PVC casing, with flow and fluid-property logs then recollected using a higher pumping rate of $22.3 \mathrm{~L} / \mathrm{min}$. Results from the second set of flow and fluid-property logs are presented below and discussed in the flowmeter-test section of this report.

\section{Analysis from Sites 58A and 72A}

As stated before, models such as equation 20, which relate nuclear magnetic resonance properties to hydrologic properties, are empirical and require calculation of regional calibration coefficients. Consequently, a regional study such as the current effort faces the complicated situation of simultaneously trying to calibrate the SNMR data while trying to validate and assess robustness of the results. Nielsen and others (2011) took an all-at-once approach and concurrently calculated calibration factors and assessed results at a large number of sites in Denmark. Their study benefited from the relatively compact size of their study area, as well as from the large number of similarly constructed aquifer tests. The situation in central Nebraska was not so conducive to that Danish approach, due to the much larger study area. Additionally, although numerous aquifer tests have been performed in the Platte River valley over the last few decades, those tests typically have been constructed for specific purposes and rarely have been comprehensive in nature-attempting, that is, to characterize the entire aquifer. For these reasons we have taken the different approach of performing two new aquifer tests that were designed to characterize hydraulic properties as completely as possible. Sites $58 \mathrm{~A}$ and $72 \mathrm{~A}$ are shown in figure 10; flowmeter data also were collected at the same locations. We then used the two sites as calibration sites for determining calibration factors for the SNMR inversions. After calculating those parameters, the calibrations were applied blindly to five additional previously performed aquifer tests in the area. We assessed the agreement between the SNMR-derived hydraulic conductivities and those provided by the aquifer tests. This section discusses the aquifer tests and the flowmeter data taken at calibration sites. Discussion of the SNMR data and inversion results at these two sites follows. Finally, we discuss determination of the calibration factor that was used at sites 58A and 72A. As a test of the broader regional validity of the calibration, it then was applied blindly to other historical aquifer test sites. 


\section{Aquifer Tests}

As mentioned in the Methods section, each aquifer was pumped for 96 hours followed by a 96-hr recovery period. Mean discharge for each test ranged from the higher production at site $58 \mathrm{~A}$ to the lower production of site $72 \mathrm{~A}$. Mean discharge from the alluvial production wells was about $5,700 \mathrm{~L} / \mathrm{min}$ at site $58 \mathrm{~A}$ and about $800 \mathrm{~L} / \mathrm{min}$ at site $72 \mathrm{~A}$. Mean discharge from the Ogallala production wells was about 5,200 L/min at site 58A and about 2,800 L/min at site 72A. Mean discharge for the alluvial aquifer test at site $72 \mathrm{~A}$ was substantially smaller than that at site $58 \mathrm{~A}(5,700 \mathrm{~L} / \mathrm{min}$ compared to $800 \mathrm{~L} / \mathrm{min})$ largely because of the difference in aquifer thickness. The alluvial aquifer thickness at site 58A was about $22 \mathrm{~m}$, whereas the alluvial aquifer thickness at site $72 \mathrm{~A}$ was much less, about $4.5 \mathrm{~m}$.

Results of the aquifer tests indicate that with respect to aquifer type (alluvial or Ogallala), $\mathrm{K}_{\mathrm{r}}$ at sites $58 \mathrm{~A}$ and $72 \mathrm{~A}$ were similar. Values of $\mathrm{K}_{\mathrm{r}}$ in the alluvial aquifers at both sites were at least an order of magnitude larger than values of $\mathrm{K}_{\mathrm{r}}$ in the Ogallala aquifers (table 6, Appendix). Composite analysis, looking at the aquifer as a whole, of the alluvial aquifer indicates $\mathrm{K}_{\mathrm{r}}$ values of $8.5 \times 10^{-4} \mathrm{~m} / \mathrm{s}$ at site $58 \mathrm{~A}$ and $1.0 \times 10^{-3} \mathrm{~m} / \mathrm{s}$ at site 72A. Composite analysis of the Ogallala aquifers at each site shows $\mathrm{K}_{\mathrm{r}}$ values ranging from $3.5 \times 10^{-5}$ to $3.9 \times 10^{-5} \mathrm{~m} / \mathrm{s}$ at sites $58 \mathrm{~A}$ and $72 \mathrm{~A}$, respectively (table 6 , Appendix).

As mentioned above in the Methods section, analysis of the unconfined aquifers (alluvial deposits) was completed using the Moench (1985) solution. Results of the aquifer-test analyses of data collected in the three observation wells open to the alluvium at site 58A show this aquifer is homogeneous with respect to radial distance. This is shown through examination of the similarity in shape and proximity of the response curves (fig. 11). Drawdowns from all three wells were within about $0.75 \mathrm{~m}$ during the test with the maximum drawdown of about $4 \mathrm{~m}$ occurring in the closed-hole observation well OW58A-A1-80 (fig. 11A). Maximum drawdown
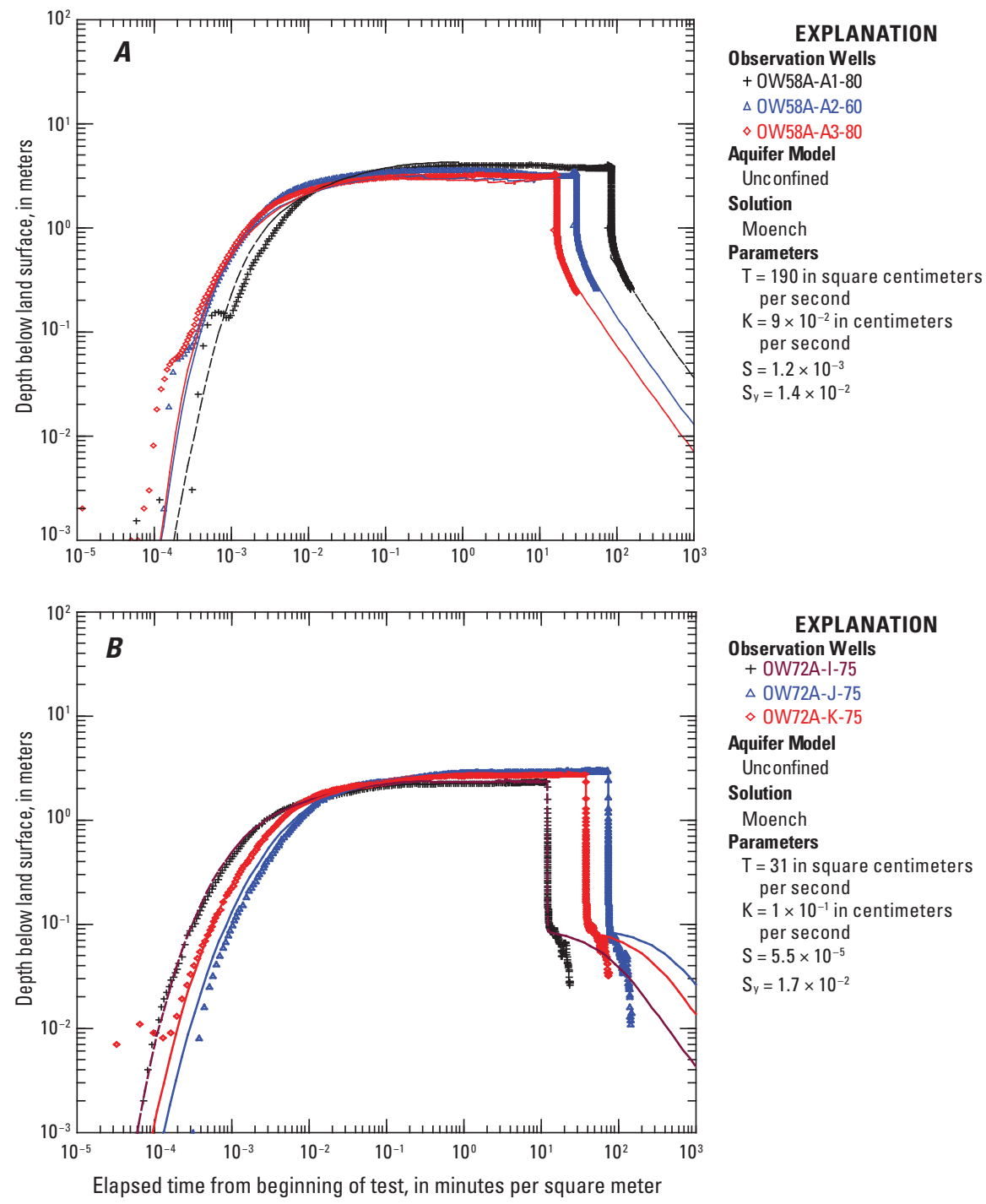

EXPLANATION

Observation Wells

$+0 \mathrm{~W} 72 \mathrm{~A}-\mathrm{I}-75$

$\triangle 0$ W $72 A-J-75$

$\diamond$ OW72A-K-75

Aquifer Model

Unconfined

Solution

Moench

Parameters

$\mathrm{T}=31$ in square centimeters

per second

$\mathrm{K}=1 \times 10^{-1}$ in centimeters

per second

$S=5.5 \times 10^{-5}$

$S_{y}=1.7 \times 10^{-2}$

Figure 11. Composite analysis of results for aquifer tests in alluvial deposits for $(A)$ site $58 \mathrm{~A}$, and $(B)$ site 72A. [Solid lines indicate type curve of aquifer test; T, transmissivity; K, hydraulic conductivity; S, Storativity; Sy, Specific yield] 
measured in the most distant observation well (OW58A-A3-80) was about $3.3 \mathrm{~m}$. Overall $\mathrm{T}, \mathrm{K}_{\mathrm{r}}$, and $\mathrm{S}_{\mathrm{y}}$ values for the alluvial aquifer (by composite analysis) at site $58 \mathrm{~A}$ were computed as $1.8 \times 10^{-2} \mathrm{~m}^{2} / \mathrm{s}, 8.5 \times 10^{-4} \mathrm{~m} / \mathrm{s}$, and $1.4 \times 10^{-1}$, respectively.

Results of aquifer-test analyses on data collected from observation wells open to the alluvial deposits at site $72 \mathrm{~A}$ show the alluvial aquifer at that location also is homogeneous. Like the alluvial observation wells at site 58A, drawdowns from all three wells were similar in shape and magnitude at site $72 \mathrm{~A}$ with the difference being about $0.5 \mathrm{~m}$. Values of $\mathrm{K}_{\mathrm{r}}$ for the alluvial aquifer at site $58 \mathrm{~A}$ were very similar to site $72 \mathrm{~A}$ at $1 \times 10^{-3} \mathrm{~m} / \mathrm{s}$. The other two aquifer properties varied somewhat; T was calculated as $3.1 \times 10^{-3} \mathrm{~m}^{2} / \mathrm{s}$ (smaller due to smaller aquifer thickness), and $\mathrm{S}_{\mathrm{y}}$ was $1.7 \times 10^{-2}$.

Water levels from observation wells open to the Ogallala declined somewhat during each alluvial aquifer test. These declines were not used for aquifer-test analysis, rather they were used to note that the thin confining layer between the alluvial and Ogallala acts as a leaky confining layer. Likewise, during each Ogallala aquifer test, drawdowns were observed and measured in all observation wells open to the alluvial aquifer.

Regarding the Ogallala aquifer, results of both Ogallala aquifer tests indicate the Ogallala in this general area of Dawson County is overlain by a leaky confined system. Similar to the alluvial systems described in paragraphs above, laterally the Ogallala acts as a fairly homogeneous deposit as evidenced from the composite graphs (fig. 12). Maximum drawdowns ranged from about 7.7 to $12.4 \mathrm{~m}$ at site $58 \mathrm{~A}$ and from about 5.4 to $7.6 \mathrm{~m}$ at site $72 \mathrm{~A}$.

Results of analysis of aquifer-test data indicate the values of $\mathrm{K}_{\mathrm{r}}$ in the Ogallala are about an order of magnitude less than $\mathrm{K}_{\mathrm{r}}$ values in the alluvial aquifer. Values of $\mathrm{K}_{\mathrm{r}}$ for the Ogallala were similar at both observation sites. As computed from the composite analysis they were $3.5 \times 10^{-5}$ and $3.9 \times 10^{-5} \mathrm{~m} / \mathrm{s}$,
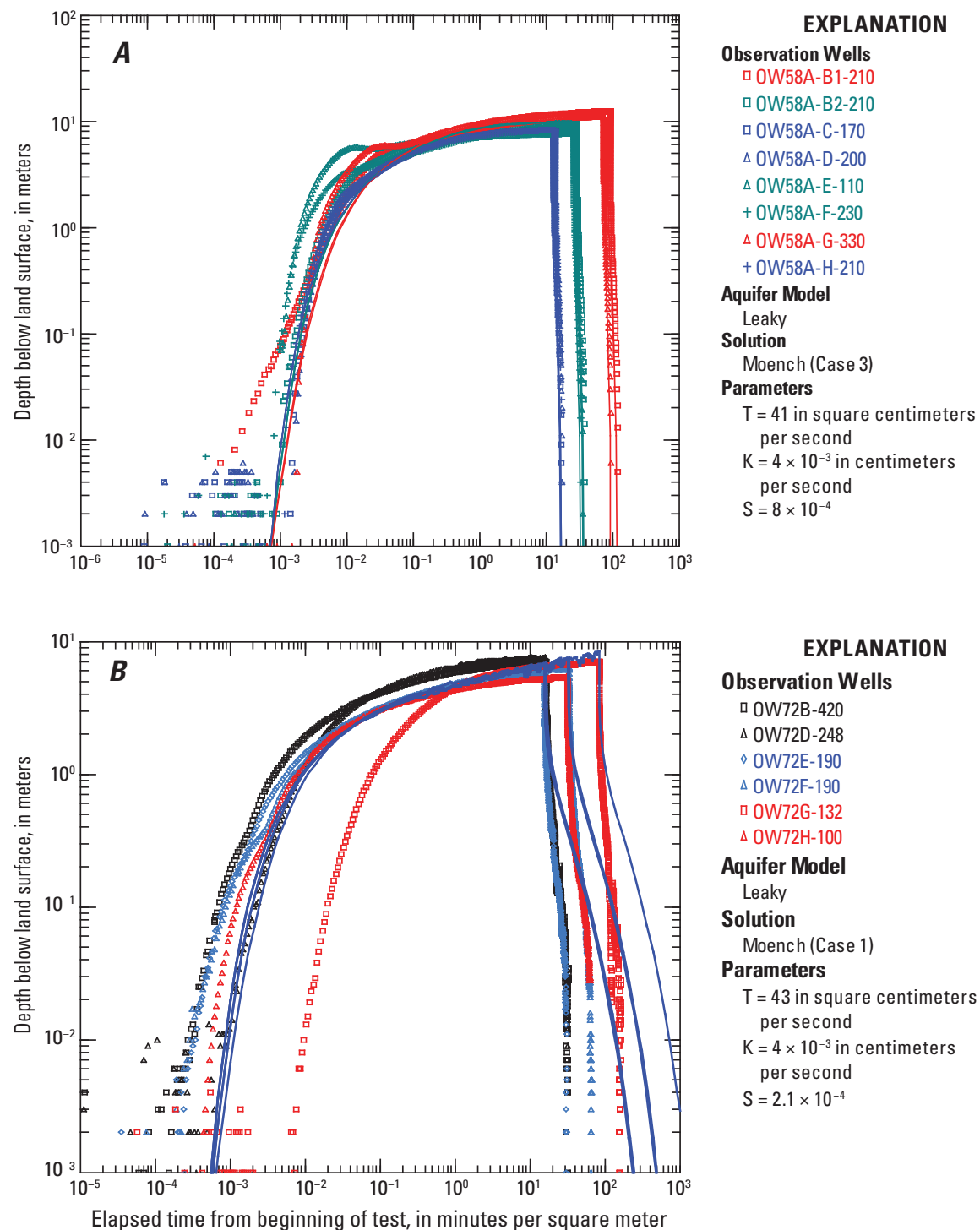

EXPLANATION

Aquifer Model Leaky

Solution

Moench (Case 1)

Parameters

$T=43$ in square centimeters per second

$\mathrm{K}=4 \times 10^{-3}$ in centimeters per second

$S=2.1 \times 10^{-4}$

Figure 12. Composite analysis of results for aquifer test in the Ogallala Group for $(A)$ site $58 \mathrm{~A}$, and $(B)$ site $72 \mathrm{~A}$. [T, transmissivity; K, hydraulic conductivity; S, Storativity] 
for sites OW58A and OW72A, respectively. Transmissivity properties for the Ogallala varied slightly, and $\mathrm{T}$ was calculated as $3.5 \times 10^{-3} \mathrm{~m}^{2} / \mathrm{s}$ at site OW58A and $4.1 \times 10^{-3} \mathrm{~m}^{2} / \mathrm{s}$ at site OW72A. Values of S were $8 \times 10^{-4}$ and $2.1 \times 10^{-3}$ for Sites OW58A and OW72A, respectively. The single well (OBW-430) test (in 2011) at site OW58A yielded nearly the same result as the Ogallala composite test with a transmissivity value of $3.7 \times 10^{-3} \mathrm{~m}^{2} / \mathrm{s}$ using the Moench (1985) solution.

Thickness of the alluvial aquifer at site 58A (about $22 \mathrm{~m}$ ) is much greater (by almost a factor of 5) than the thickness of the alluvial aquifer at site 72A (about $4.5 \mathrm{~m}$ ). Consequently, results of $K_{r}$ and $T$ were weighted by aquifer thickness. A weighted mean $\mathrm{K}_{\mathrm{r}}$ per aquifer as calculated from the aquifertest results shows a mean $\mathrm{K}_{\mathrm{r}}$ for the alluvium was $8.7 \times 10^{-4}$ $\mathrm{m} / \mathrm{s}$, whereas the weighted mean $\mathrm{K}_{\mathrm{r}}$ for the Ogallala was $3.5 \times 10^{-5} \mathrm{~m} / \mathrm{s}$. Likewise, weighted mean $\mathrm{T}$ per aquifer was $1.5 \times 10^{-2}$ and $3.5 \times 10^{-3} \mathrm{~m}^{2} / \mathrm{s}$ for the alluvial and Ogallala aquifers, respectively. The weighted mean $\mathrm{K}_{\mathrm{r}}$ results show the alluvial aquifer is about two orders of magnitude more transmissive than the Ogallala aquifer.

In conclusion, the four aquifer tests conducted in Dawson County in alluvial and Ogallala deposits were successful. These tests indicate that the alluvial aquifer in that part of the CPNRD is homogenous with respect to radial direction. Values of $\mathrm{K}_{\mathrm{r}}$ at both sites were comparable, the aquifer properties do not change substantially from site to site, and the primary constraint on the aquifers was their thickness. Tests in the Ogallala deposits indicate that the Ogallala in that part of the CPNRD is overlain by a leaky confined unit that is hydraulically connected to the overlying alluvium. At both locations the aquifer exhibited about the same (100-m) thickness.

\section{Uncertainty Analysis of SNMR Data Collection and Inversion Results}

Numerous sources of uncertainty exist in the SNMR results. There are two main sources of errors found in the data, including (1) those due to system internals and electronics, and (2) those due to environmental noise. The inversion is affected by error in the data, as well as by the inherent limitations in spatial resolution. Finally, the relationship linking $\theta_{S N M R}$ and $T_{2}^{*}$ to $K$ is empirical and is affected by a large number of factors. For such reasons it is difficult to determine absolute error bars on the estimates of $K$ and $\theta_{S N M R}$, and discussion must instead involve resolution and variability within the framework of inversion.

\section{Sources of Error in the Data}

System error is especially difficult to quantify, as manufacturers generally do not provide estimates of those errors. An incomplete list of potential sources of system error in SNMR includes timing errors, system gain bias, and reported pulsemoment inaccuracies. Small timing errors, such as the sampling interval being slightly different than reported, would manifest as a source of unexpected phase response and a shift in the apparent measured Larmor frequency. The use of the modulus of the data minimizes such timing errors, as the phase is not considered. Unaccounted-for system gain would bias the data. One way to assess that bias would be to collect system-calibration data over a frozen lake in the winter, with the same instrument as was used in field data collection (Shushakov, 1996b). For this study, we did not have access to that type of calibration data and cannot comment on the amount of error present due to system gain. The reported pulse moment also could be inaccurate, due either to a consistent error in reporting or to variability in pulse moment across stacks. It is, again, not possible to comment on the reported system measurement of a single pulse moment, but we were able to look into variability of the reported pulse moments across stacks. In figure 13, a sounding curve is plotted from data collected at site 58A and shown with one-standarddeviation error bars. It can be seen that at low pulse moments, the variability in reported values of $q$ is as large as the spacing. The amplitude variation is influenced both by variability in $q$, as well as in noise levels.

Environmental noise can be a significant limitation of SNMR. In figure 14, field data from site 58A are shown. In figure $14 A$ a single FID stack is shown, as well as a monoexponential fit of the envelope to the model $V(t)=B+V_{0} e^{-t} / T_{2}^{*}$. The offset $B$ provides an estimate of the bias of the regression envelope, due to the noise. In figure $14 B$, the last $10 \mathrm{~ms}$ of the record are shown for the entire dataset. It can be seen that the

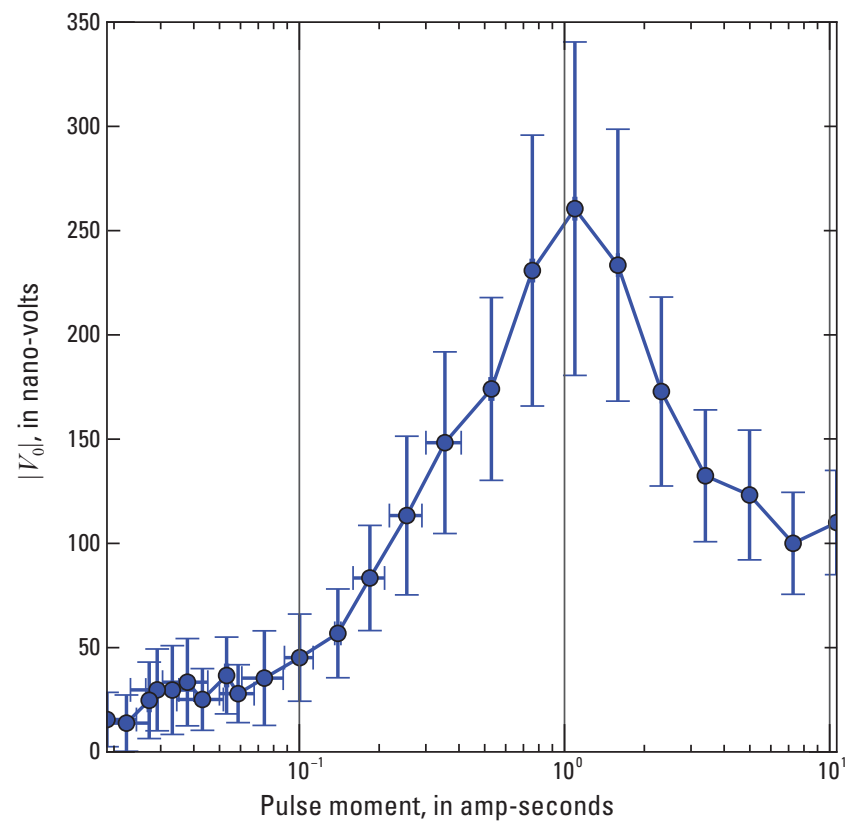

Figure 13. One-standard-deviation error bars of the surface nuclear magnetic resonance initial amplitude $\left|V_{0}\right|$ as a function of pulse moment across a single SNMR experiment comprised of 16 stacks. It can be seen that for small pulses, the variance in the pulse moment is on the order of the pulse-moment spacing. The variance in the signal amplitude is influenced by the variability of the pulse moments, as well as by environmental noise. 

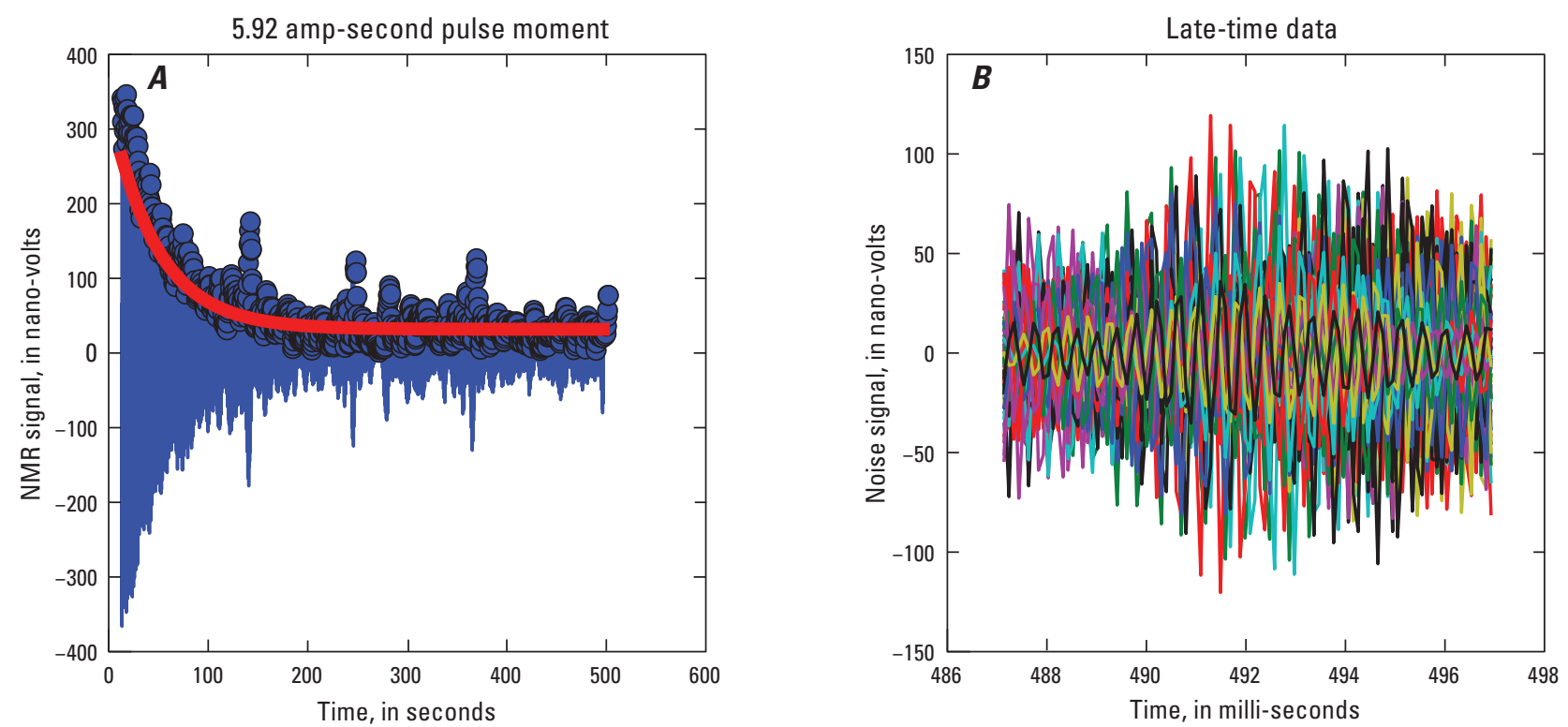

Figure 14. A typical surface NMR field record taken for a single pulse moment at site 58A, using a 100-m-square loop, is shown in $(A)$. The red line in $(A)$ is the result of a nonlinear least-squares regression result for a mono-exponential decay time constant for this record, $V(t)=B+V_{0} e^{-t / T_{2}^{*}}$, solving for the bias, $B$, the initial amplitude $V_{0}$, and the decay constant $T_{2}^{*}$. In $(B)$ the last $10 \mathrm{~ms}$ of data are shown; it is assumed that the entire NMR signal has decayed by that time, and $(B)$ shows a recording only of the noise.

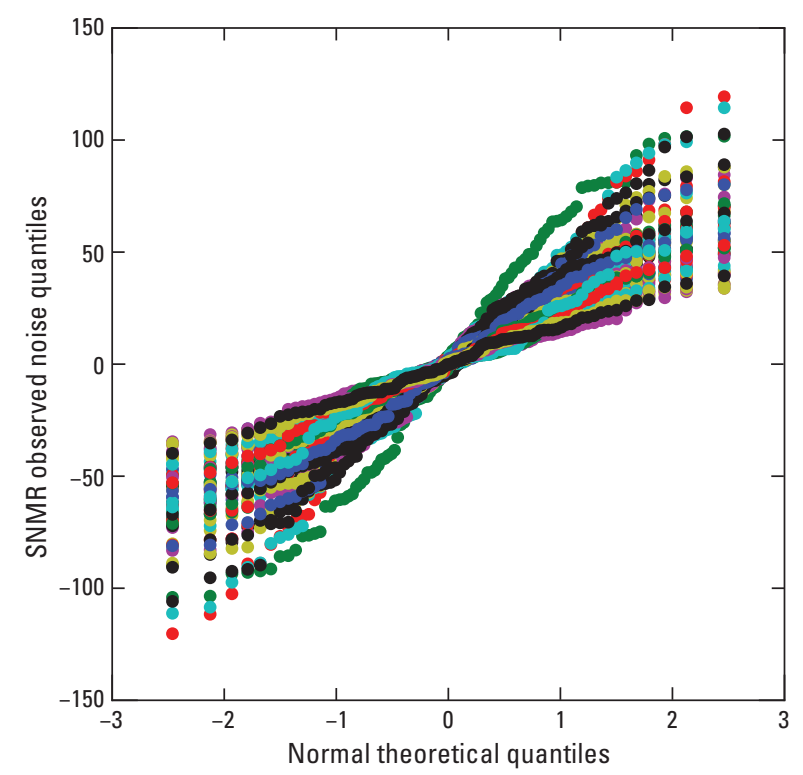

Figure 15. Surface nuclear magnetic resonance noise is non-Gaussian; a quantile-quantile plot of the late-time data from figure $14(B)$ is shown. If the noise were normal, the theoretical and observed quantiles would plot linearly.

noise level is relatively constant across the pulse moments; the noise, however, is clearly non-Gaussian. In figure 15, a quantilequantile plot illustrates deviation of the noise from normality. In the case of Gaussian signal, a quantile-quantile plot will show a straight line. The late-time noise (fig. 14B) provides a second means of estimating noise effects. The standard deviation $(\sigma)$ should be equal to $B$ from the regression if the noise levels are constant in time. Since it was based on fewer data points, however, this could be a slightly less robust estimate, assuming the envelope can be fit well with a single exponential. The mean $(\mu)$ of the late-time noise indicates whether there is some steady offset in the instrument signal. That mean is expected to be very near zero. In figure 16, a summary of the noise analysis is shown for this dataset from site $58 \mathrm{~A}$. In that plot, it can be seen that $\sigma$ and $B$ are in good agreement $(B=28.8 \mathrm{nV}$, and $\sigma=27.8 \mathrm{nV}$ ), and that the mean level of the noise is indeed nearly zero. A simple estimate of the signal-to-noise ratio (SNR) is determined by dividing the initial measured voltage by the bias estimate $B$. As the NMR signal decays with time, the SNR will decay as well. A similar noise summary plot is shown for site $72 \mathrm{~A}$ in figure 17 , where $B=11.4 \mathrm{nV}$, and $\sigma=\mathrm{nV}$.

\section{Inversion and Analysis Uncertainty and Error}

Assessing the error in a deterministic geophysical inversion such as ours is nontrivial. The most common approaches are based on calculating model-resolution and model-covariance matrices which provide information about the resolving power of the underlying physical experiment. A similar approach is to calculate the point-spread function of the inverted linear system. This is done by re-inverting compact models of unit amplitude, that is, models that are zero-valued, except for at one unitary $T_{2}{ }^{*}$ and depth bin. The result of the inversion then describes how sharply a model parameter can be recovered. This has been done in figure 18, where it can be seen that resolution decreases with depth. 


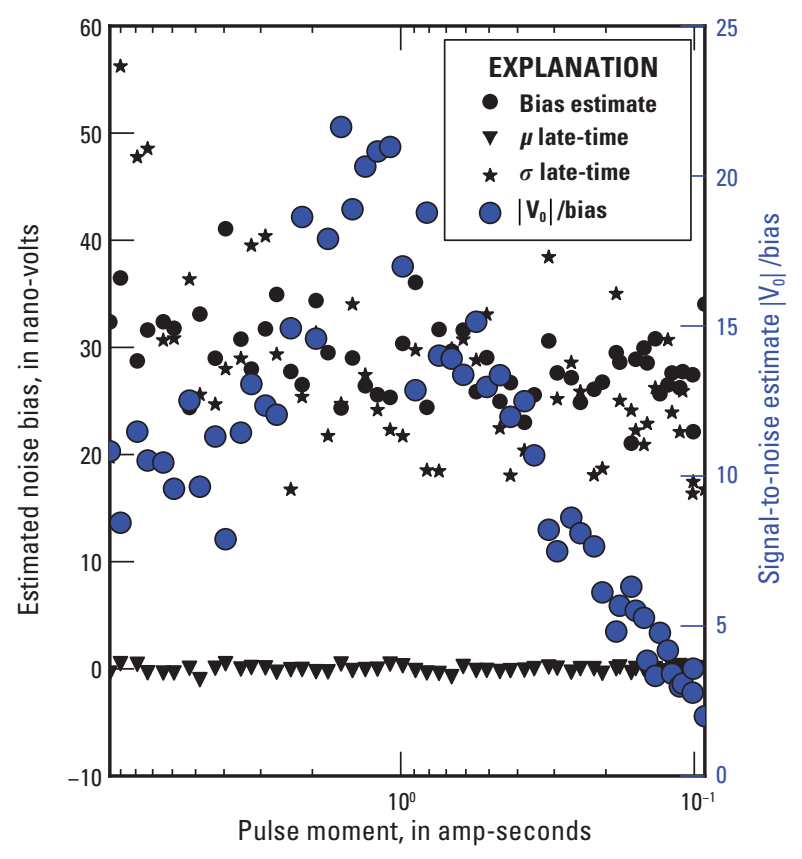

Figure 16. A summary of the estimated noise levels for the surface nuclear magnetic resonance data taken at site $58 \mathrm{~A}$. The bias estimate from the regression shown in figure $14 \mathrm{~A}$ is compared with the mean $(\mu)$ and standard deviation $(\sigma)$ from the late-time data shown in figure $14 \mathrm{~B}$. Parameter $V_{0}$ is the initial amplitude of the data.

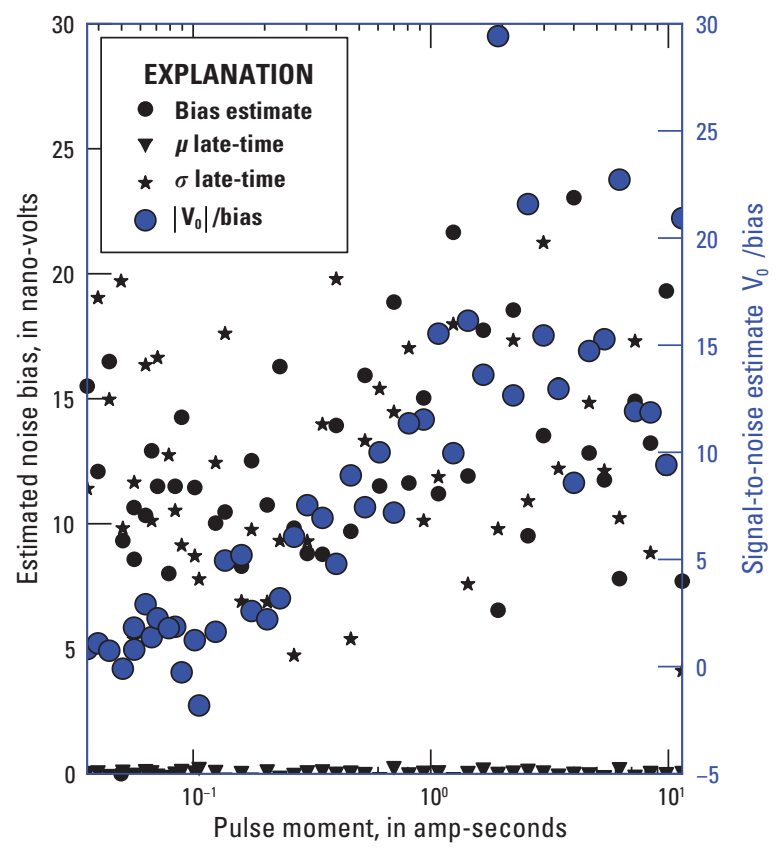

Figure 17. A summary of estimated noise levels from data taken at site $72 A$. The bias term $(B)$ comes from a regression of the field data fitting the model $V(t)=B+$ $V_{0} e^{-t / T_{2}^{*}}$. The mean $(\mu)$ and standard deviation $(\sigma)$ come from the last 10 milliseconds of data. Parameter $V_{0}$ is the initial amplitude of the data.
The question of depth of investigation is related to model resolution and to noise. It is not a straightforward question, since the thickness of the layer that needs to be resolved enters the discussion. For field conditions experienced in central Nebraska, we determined that inversion results below $60 \mathrm{~m}$ were unreliable for 100-m square loops of wire. For smaller (50-m) figure-eight loops, the reliable depth of investigation was interpreted to be about $30 \mathrm{~m}$. More sophisticated model appraisal would be welcome, as discussed below.

Unfortunately, the point-spread assessment does not provide information about equivalent models that fit the data or confidence in inverted parameters. The complex nature of the SNMR noise (fig. 14) makes model appraisal particularly trying. It is difficult to characterize the distribution of the noise, so stochastic realizations of simulated noise added to the predicted data coming out of the inversion cannot be re-inverted to assess variability of the inversion under observed noise conditions. Additional analysis of the noise could provide a more robust way to characterize the noise, allowing for this type of analysis.

\section{Aquifer Test Process Discussion}

Aquifer tests have been proven to be one of the most reliable and effective methods of obtaining hydraulic parameters from groundwater flow (Kruseman and de Ritter, 1990). Homogeneous isotropic aquifers occur very rarely in nature. So when determining groundwater flow in a heterogeneous anisotropic medium, the scientist or engineer must consider theoretical models based on assumptions, such as groundwater flow can be described by Darcy's Law, the aquifer has infinite areal extent, or groundwater flow is radial. Such assumptions, along with knowledge of the geologic medium, help produce reliable aquifer-test results that can, due to the nature of the aquifer-test assumptions, vary within an order of magnitude from actual values. In similar fashion, screen selection, length, and position in the aquifer can have effects similar to the results of the aquifer test. The assumptions chosen here and results they produce are within the acceptable range of industry standards. Consequently, all aquifer tests are designed, performed, and analyzed based on an understanding of the hydrogeology of the site.

In the case of aquifer tests for this study, great expense and effort went into understanding the hydrogeology prior to installation of the wells. As a result, this approach assured the best possible results from each aquifer test. The hydrogeology at each site, as mentioned in the hydrogeology section, consists of two distinct aquifers - an unconformable alluvial aquifer lying atop the bedrock Ogallala aquifer-separated by a leaky confining unit. The alluvial aquifer, and especially the Ogallala aquifer, are heterogeneous in all respects such as grain size, distribution of sediments, types of sediment, lithology (in the Ogallala), and aquifer thickness. Assumptions such as homogeneity, along with hydrologic reasoning, were used as required for the theoretical models to work with these 

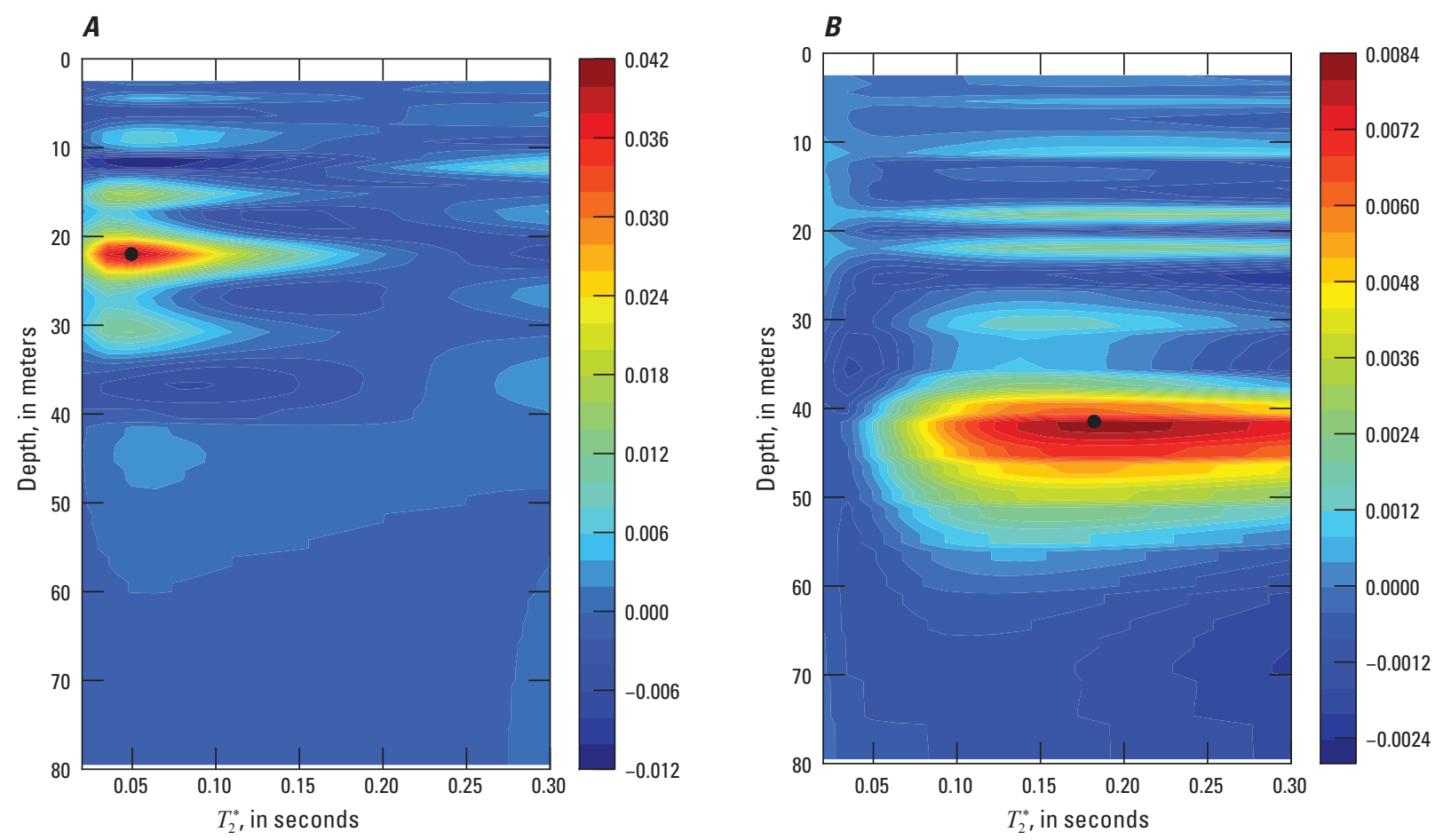

Figure 18. Two examples of the point-spread function of the SNMR kernel, plotted from data taken at site 58A. The black dot represents an input model of 100 percent water at that particular $T_{2}^{*}$ and depth bin. The colored plot is the output of the inversion of the sensitivity matrix, at the regularization level used in the final inversion. It can be seen that deeper areas in the model suffer from larger spreads, and therefore from lower resolution. These inversions did not include the log-barrier term, and small negative model values can be seen. This does not have a major impact on the point-spread function.

aquifers. Consequently, the results of the aquifer tests are not exact to nature but are considered very true and concordant, considering the conditions and necessary assumptions involving theoretical models and aquifers.

To quantify aquifer properties with aquifer tests, selection of an appropriate analytical solution is critical, as application of an incorrect solution invariably will bias results. Every analytical solution carries its own assumptions (such as those listed in table 2). Each assumption must be considered carefully and matched to local hydrogeologic conditions. In nature, perfectly confined aquifers occur far less frequently than leaky aquifers (Kruseman and de Ridder, 1990). Waterlevel responses from each aquifer test at sites $72 \mathrm{~A}$ and $58 \mathrm{~A}$ indicated the alluvial and Ogallala aquifers were separated by a leaky confining layer. The presence of a leaky confining layer between the two aquifers means the analytical solution must consider a leaky confining system, and few published solutions fit those criteria. Consequently, the Moench (1985) solution was selected for analysis of both Ogallala aquifer tests because the Ogallala is a leaky confining system in this part of the study area, as shown through the test results. An assumption of a confined system would have biased $\mathrm{T}$ results to higher levels in both Ogallala aquifer tests. In the case of site 58A the Moench (1985) solution was selected over other analytical methods (such as Hantush, 1960) by comparing residual versus simulated curves from the respective solutions. Moench (1985) was selected due to closeness of simulated curve matching, even though the Moench (1985) and Hantush (1960) methods gave similar results (T values of about $3.5 \times 10^{-3} \mathrm{~m}^{2} / \mathrm{s}$ for the Moench (1985) method, and $3.7 \times 10^{-3} \mathrm{~m}^{2} / \mathrm{s}$ for Hantush).

\section{Analysis of Electromagnetic Flowmeter Tests}

Described in this section are results from flow and fluidproperty logs collected at site 58A. Also included are comparisons of all flow and fluid-property logs to the previously described aquifer tests, including the flow and fluid-property logs collected at site 72A (Anderson and others, 2009). Flow and fluid-property logs were collected under ambient and quasi-steady-state pumping conditions in well OW58A-430 (table 5). The screen of OW58A-430 was open to multiple zones of the Tertiary units of the High Plains aquifer. Those multiple zones (fig. 19) contained varying hydraulic heads whose ambient measurements indicate a downward regional gradient from higher heads in the upper zones of the Ogallala (source) to lower heads in the lower of the High Plains aquifer (sink). Finer-grained units in the middle zones of the Ogallala may act as a semi-confining layer and restrict overall groundwater movement between the upper and lower zones.

Flow and fluid-property logs were collected in OW58A-430 under quasi-steady state pumping conditions while pumping at a rate of $22.3 \mathrm{~L} / \mathrm{min}$. The quasi-steady 


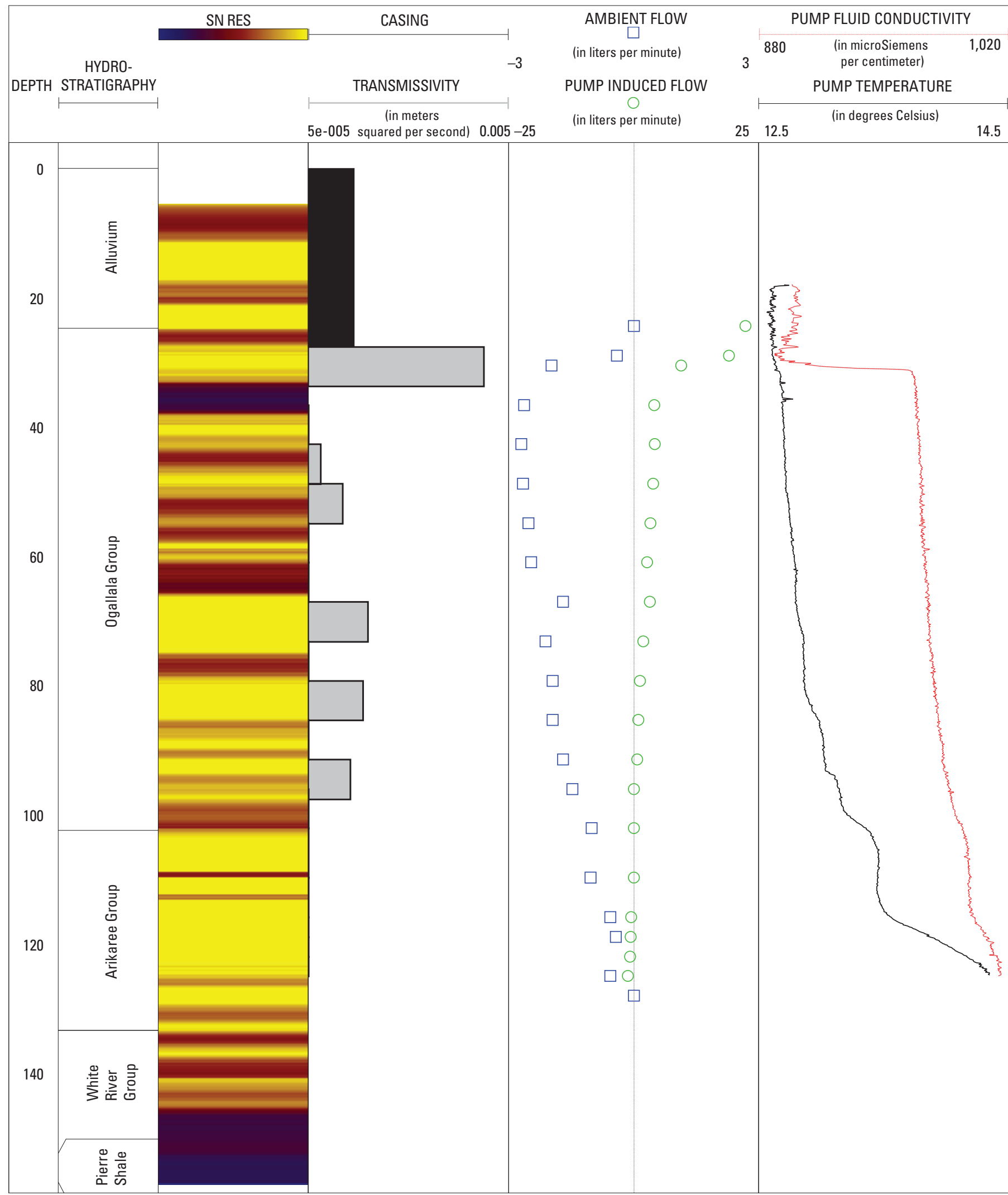

Scale 1:850

Figure 19. Composite of flow and fluid-property logs for well OW58A-430. [STRAT (hydrostratigraphic units); SN RES, short-normal resistivity — darker colors are less resistive, lighter colors are more resistive; CASING_black area indicates where blank casing was emplaced above the screened interval; ambient flow, negative values indicate downward flow, positive values indicate upward flow] 
state drawdown was $0.22 \mathrm{~m}$, which corresponds to a specific capacity of $101(\mathrm{~L} / \mathrm{min}) / \mathrm{m}$. The Tertiary units of the High Plains aquifer were subdivided into a series of zones based on the collected flow and fluid-property logs. Consistent with Andersen and others (2009), the upper zone of the Ogallala contributed much of the flow under pumping conditions - approximately 79 percent of the total flow (fig. 19). Other parts of the lower zone of the Ogallala contributed nearly zero to almost 6 percent of the total flow.

Quantification of T and $\mathrm{K}$ of discrete hydrostratigraphic zones can be determined using the proportions of the total $\mathrm{T}$ determined from the flowmeter results. Plotted in figure 20 are the estimated $\mathrm{K}$ values from the EM flowmeter for each hydrostratigraphic unit and the $\mathrm{K}_{\mathrm{r}}$ of each observation well in the Ogallala aquifer tests for site 58A. As noted in the Aquifer Tests section of this report, the total computed $\mathrm{T}$ of the Ogallala beneath site $58 \mathrm{~A}$ was $3.5 \times 10^{-3} \mathrm{~m}^{2} / \mathrm{s}$. The upper $6 \mathrm{~m}$ of the Ogallala had a computed T of $2.8 \times 10^{-3} \mathrm{~m}^{2} / \mathrm{s}$ and a hydraulic conductivity of $4.6 \times 10^{-4} \mathrm{~m} / \mathrm{s}$. At that interval, the $\mathrm{K}_{\mathrm{r}}$ estimated from the aquifer test was an order of magnitude lower $\left(5.3 \times 10^{-5} \mathrm{~m} / \mathrm{s}\right)$ than the $\mathrm{K}_{\mathrm{r}}$ of the flowmeter test. One possible reason for this is that the $\mathrm{K}_{\mathrm{r}}$ for the aquifer test at OW58A-E-110 may have been biased downward because of wellbore skin effects (Moench, 1985), where the interaction between the wellbore and the aquifer may have been reduced due to such factors as mud-invasion effects or bridging of sand filter pack near the screen. Consequently, a reduction in aquifer interaction would effectively reduce the estimated $\mathrm{K}_{\mathrm{r}}$ for the screened interval.

Flowmeter data indicate the lower zones of the

Ogallala had much lower $\mathrm{K}_{\mathrm{r}}$ and $\mathrm{T}$ compared to the upper zones (fig. 20). The flowmeter-derived $\mathrm{K}_{\mathrm{r}}$ values were generally concordant but less than those estimated from the aquifer test. One possible reason for this was that estimates for the flowmeter span the entire thickness of the aquifer and include zones of low T. In contrast, observation wells used for the aquifer test were generally screened in more transmissive zones. This "averaging" of the flowmeter data resulted in slightly smaller $\mathrm{K}_{\mathrm{r}}$ values for a given hydrostratigraphic interval.

Lateral heterogeneity of the Ogallala also may account for differences in the computed $\mathrm{K}_{\mathrm{r}}$ values. From the aquifer test, observation well OW58A-H-210 had an estimated $\mathrm{K}_{\mathrm{r}}$ of $4.2 \times 10^{-5} \mathrm{~m} / \mathrm{s}$ for the screened interval, which was slightly higher than the composite estimate of $3.5 \times 10^{-5} \mathrm{~m} / \mathrm{s}$ for the entire Ogallala section (table 6, Appendix). The test hole and borehole geophysical logs collected for the aquifer test indicated the 61- to 64-m screened interval primarily contains silt with some very fine-grained sandstone. In that interval, no flow was indicated in the flowmeter log data (OW58A-430) collected under pumping conditions (fig. 20). Consequently, an abrupt change in hydraulic properties may occur over a short lateral distance, resulting in discrepancies in the estimated $\mathrm{K}_{\mathrm{r}}$ values.

Flow and fluid-property logs were collected in 2007 from an observation well screened through the thickness of the alluvium and Ogallala (test well OW72A-430) and the production or pumping well. The flow and fluid-property logs collected under pumping conditions from both wells are concordant even though the wells were pumped at very different rates; test well OW72A-430 was pumped at $56.8 \mathrm{~L} / \mathrm{min}$, and the production well was pumped at $2,840 \mathrm{~L} / \mathrm{min}$. It should be noted that the position of the pump in the production well precluded the collection of logs above $41.2 \mathrm{~m}$ below land surface.

Anderson and others (2009) reported the alluvium and upper Ogallala contributed 70 percent of the T of the High Plains aquifer. The coarse-grained, weakly cemented sandstone beds of the middle Ogallala contributed 16 percent. Predominantly fine-grained units of the lower Ogallala contributed 4 percent of the total $\mathrm{T}$. The units near the base of the High Plains Aquifer, described by Anderson and others (2009) as the Arikaree Formation, contributed 8 percent of total $\mathrm{T}$. Other zones in that lower section contributed a negligible amount to total $\mathrm{T}$.

Using the composite $\mathrm{T}$ from the aquifer tests at site $72 \mathrm{~A}$ and the previously stated percentages from the EM flowmeter test, a quantitative comparison of $\mathrm{K}_{\mathrm{r}}$ can be made. A combined $\mathrm{T}$ of $7.2 \times 10^{-3} \mathrm{~m}^{2} / \mathrm{s}$ was computed for the composite alluvial and Ogallala aquifer tests. Dividing the $\mathrm{T}$ by the thickness for each unit will yield the $\mathrm{K}_{\mathrm{r}}$ for each hydrostratigraphic interval. Plotted in figure 21 are the estimated $\mathrm{K}$ from the EM flowmeter for each hydrostratigraphic unit and the $\mathrm{K}_{\mathrm{r}}$ of each observation well in the Ogallala aquifer tests for site 72A. Applying the same approach to the alluvial aquifer test results in the same $\mathrm{K}$ value; however, those results are included for comparison purposes in figure 21.

The $\mathrm{K}_{\mathrm{r}}$ estimates from the EM flowmeter are in general agreement with the results from the Ogallala aquifer test; the EM flowmeter estimates, however, were greater for observation wells in the upper zone of the Ogallala. The largest discrepancy occurs at 27.4-30.5 $\mathrm{m}$ where data from observation well OW72H-100 estimate a $\mathrm{K}_{\mathrm{r}}$ of $3.4 \times 10^{-5} \mathrm{~m} / \mathrm{s}$. The recorded lithologic and borehole geophysical logs indicated that the 27.4-30.5 m interval predominantly is fine to coarse sand. The EM flowmeter estimated the $\mathrm{K}_{\mathrm{r}}$ at the $22-30.5 \mathrm{~m}$ interval to be $1.9 \times 10^{-4} \mathrm{~m} / \mathrm{s}$, which is more typical of unconsolidated alluvial sands. The value of $3.4 \times 10^{-5} \mathrm{~m} / \mathrm{s}$ from observation well OW72H-100 was less than the composite solution of the Ogallala aquifer test of $3.9 \times 10^{-5} \mathrm{~m} / \mathrm{s}$. Given the fact that much of the middle and lower zones of the Ogallala included silt or well-consolidated, fine-grained sandstone intervals with relatively low $\mathrm{T}$, the hydraulic properties spanning the screened interval at observation well OW72H-100 may have changed abruptly over a short lateral distance.

Lateral heterogeneity was also noticed in the middle zone of the Ogallala as well. Observation wells OW72E-190 and OW72F-190 were screened at the same interval from $42.7-57.9 \mathrm{~m}$ below land surface. Values of $\mathrm{K}_{\mathrm{r}}$ for these observation wells are $1.5 \times 10^{-5} \mathrm{~m} / \mathrm{s}$ and $3.5 \times 10^{-5} \mathrm{~m} / \mathrm{s}$, respectively. The $\mathrm{K}_{\mathrm{r}}$ value from the EM flowmeter test was estimated at $7.4 \times 10^{-5} \mathrm{~m} / \mathrm{s}$. The lithologic and borehole log indicated interbedded fine- to medium-grained sand, with lesser amounts of silt. Although discrepancies exist, all values agree with published values for Ogallala sediments in Nebraska (Peckenpaugh and Dugan, 1983; Steele and Harvey, 2002). 


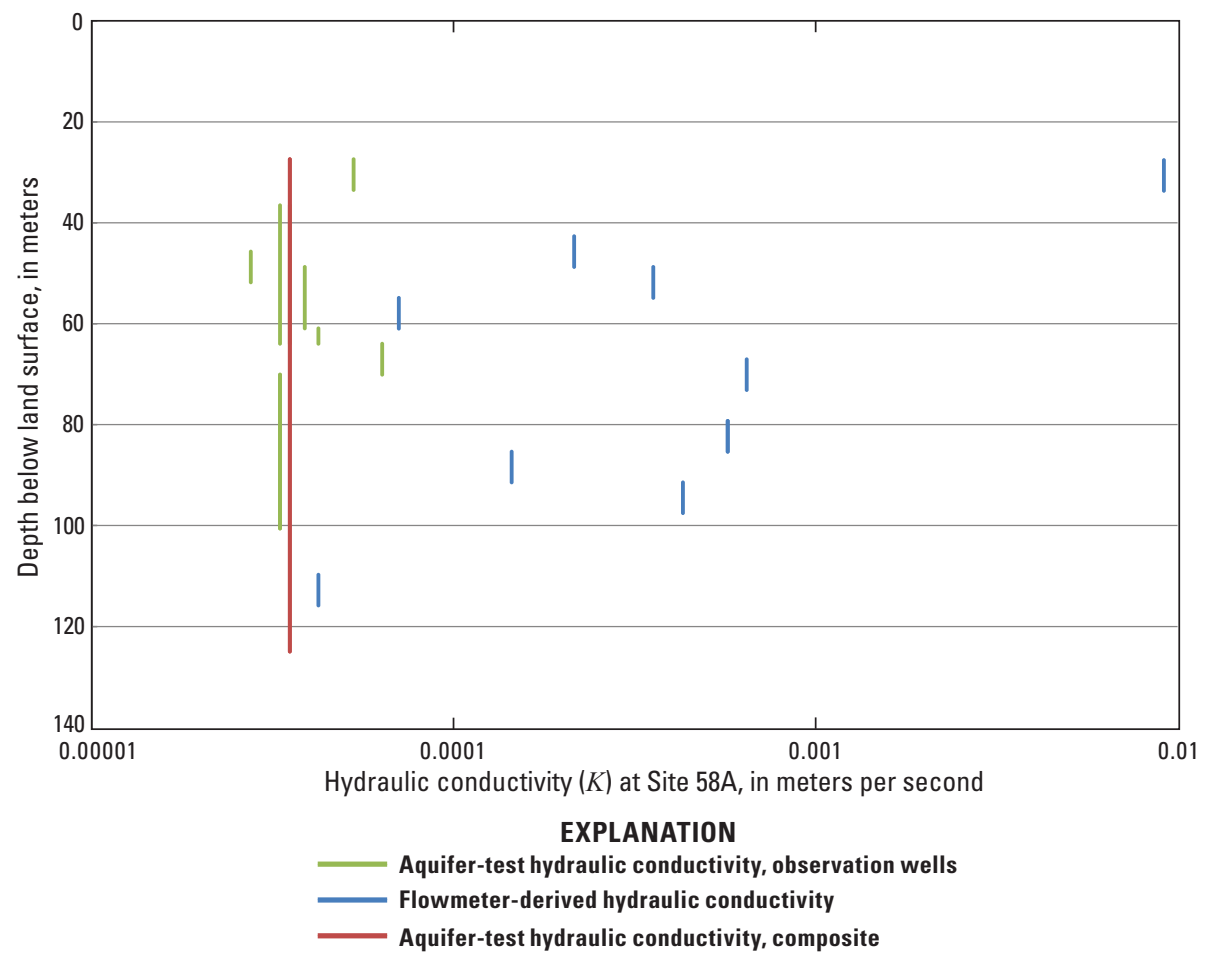

Figure 20. Flowmeter-derived hydraulic conductivities for individual hydrostratigraphic units, aquifer-test hydraulic conductivities for observations wells with screened intervals plotted against depth, and composite hydraulic conductivity from aquifer tests in the Ogallala Group at site $58 \mathrm{~A}$.

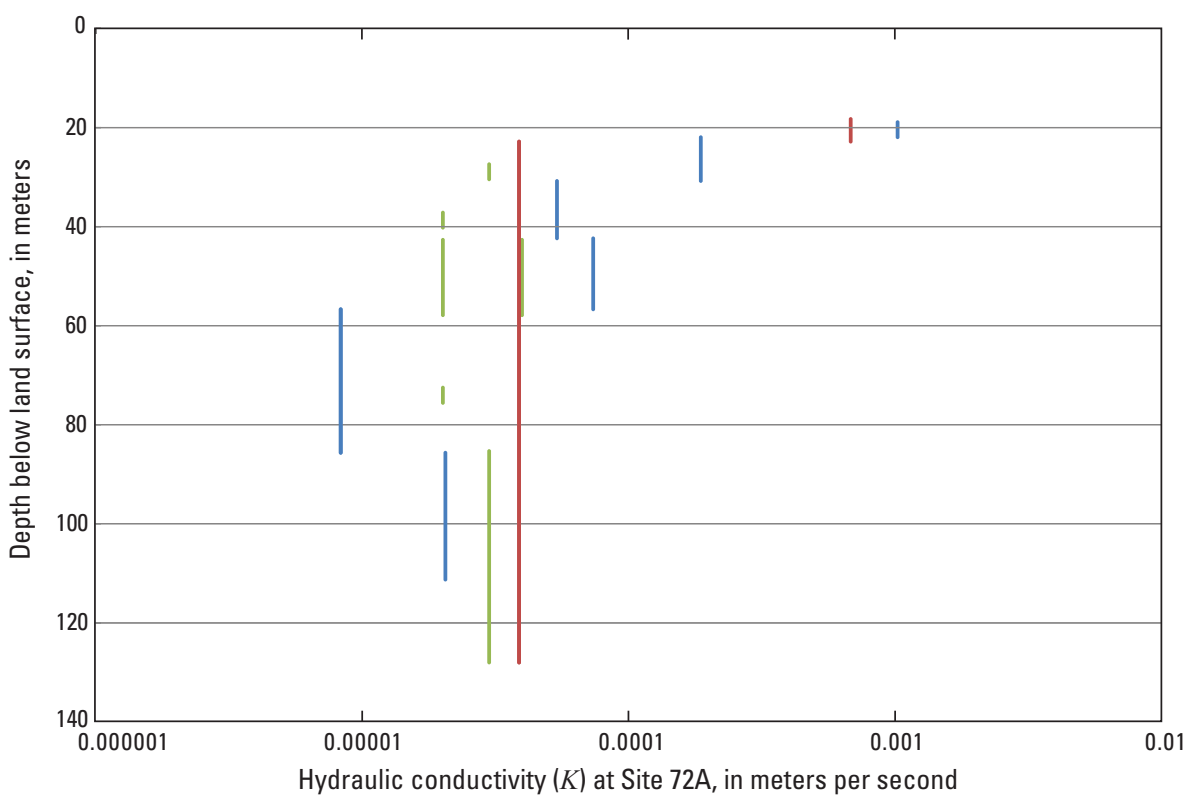

EXPLANATION

Aquifer-test hydraulic conductivity, observation wells

Flowmeter-derived hydraulic conductivity

Aquifer-test hydraulic conductivity, composite

Figure 21. Flowmeter-derived hydraulic conductivities for individual hydrostratigraphic units, aquifer-test hydraulic conductivities for individual screened intervals, and composite hydraulic conductivity from an aquifer test in the Ogallala Group at site 72A. 


\section{Surface NMR Inversions and Determination of the Cp Calibration Factor}

Surface NMR data were collected at sites 58A and $72 \mathrm{~A}$ using the Vista Clara Inc. GMR instrument between the spring of 2008 and the spring of 2010. Data were taken over the course of several years to establish repeatability of the data, to survey multiple locations within the same area, and to appraise multiple loop geometries and pulse sequences. Transmitter loops varying from $30 \mathrm{~m}$ to $150 \mathrm{~m}$ in diameter/ side were deployed and used FID, $T_{l}$, and spin echo pulses, all of varying pulse duration. In the analysis that follows, only the FID data are discussed. Although $T_{l}$ data have been shown to be less affected by magnetic media than other pulses, the long survey-acquisition time prevented us from collecting sufficiently dense data for analysis at all of our field sites. From a qualitative standpoint, the $T_{I}$ data appeared consistent with the aquifer characteristics. Additionally, important refinements to this pulse sequence (Walbrecker and others, 2011b) were developed after our field data campaign was complete. The spin-echo data can form a complimentary dataset as well, but the depth of investigation of that pulse sequence was not sufficient for our purposes.

After collecting and processing the data (using the methods of Walsh, 2008), the data were inverted using the scheme presented in the previous section of this report. The resulting depth vs. $T_{2}{ }^{*}$ image plots then needed comparison to the traditional aquifer tests. The task is less straightforward than it would seem as the aquifer tests generally report only a single value of $\mathrm{K}$ or transmissivity for each hydrostratigraphic unit. If the SNMR surveys are able to image the entire aquifer, it is possible to compare the SNMR transmissivity to the aquifer-test transmissivity, an approach taken by Plata and Rubio (2008) and Nielsen and others (2011). However, if the SNMR data do not image the entire aquifer, as in our case, that approach should be avoided, because the SNMR transmissivity is defined over a different interval than the aquifer-test transmissivity. For this reason we elected instead to compare $\mathrm{K}$ values across the methods. In our situation, this was a more logical choice. Both sites 58A and 72A were constructed with a large number of observation wells, and analysis of the tests produced estimates of $\mathrm{K}$ with greater depth resolution than many aquifer tests can produce. As the SNMR also provides depth resolution, this made for a much more natural comparison. Additionally, if only a few aquifer tests (or just one) will be used to calibrate SNMR inversions, this approach will yield a more robust estimate of the calibration factor $c_{p}$, as a larger number of data points are incorporated. We used the Kenyon (1997) variant of equation 19, which has been shown appropriate for dual-porosity sandstones (Plata and Rubio, 2008), and solved for the leading scalar $c_{p}$ factor. We constructed an over-determined linear system by simultaneously comparing all depths from the SNMR inversion that coincided with $K$ estimates from the aquifer tests. We then applied a least means square regression to calculate the $c_{p}$ factor that minimized the total RMS error. In contrast, comparing transmissivity, from a single aquifer test with one derived from SNMR, results in a single equation with one unknown.

\section{Site 58A}

At site 58A we used data from a 100-m square loop with a 40 -ms pulse-moment duration for our analysis. In general, the data quality at site 58A was excellent after applying noise cancellation (Walsh, 2008). Those data were acquired in the spring of 2010. The inverted section, along with the SNMRderived $\mathrm{K}$ and porosity, is shown in figure 22 .

\section{Site 72A}

Site $72 \mathrm{~A}$ was a more challenging field location. The presence of high-tension transmission lines as well as residential power lines and houses in the vicinity resulted in variable noise sources that could not be removed completely using the noise-cancelling reference-loop technique. Noise levels were significantly higher at this site compared to site $58 \mathrm{~A}$, and it was not always predictable when good SNMR data could be acquired. At times, SNMR data that were collected were unusable due to high noise levels. Still, usable data were collected on numerous occasions. In figure 23 an inversion from a 91-m square coil is presented along with SNMR-derived hydraulic conductivities and porosities.

To assess the repeatability of the inversions under changing conditions, we inverted and compared inversions at site 58A from a 91-m square-loop coil taken in 2009, and a $100-\mathrm{m}$ square-loop coil taken in 2010 . The two inversions (fig. 24) are in good agreement, suggesting reliable data repeatability.

\section{Application of Cp Factor to Previous Aquifer Tests}

There have been multiple aquifer tests completed in the Central Platte valley in the last 50 years whose data are publically available. The motivation for those tests has varied from aquifer characterization to studying the relationship between alluvial and deeper units and the interplay between fluvial and groundwater systems. We considered five of those previous aquifer tests and conducted SNMR surveys in the same general locations to determine if the SNMR results were consistent with the aquifer tests in the area. The test sites were Chapman West, Chapman South, Layher, Meyer, and MSEA, shown in table 3. More SNMR data were taken at two additional sites, but those datasets were corrupted due to infrastructure and were not invertible. 


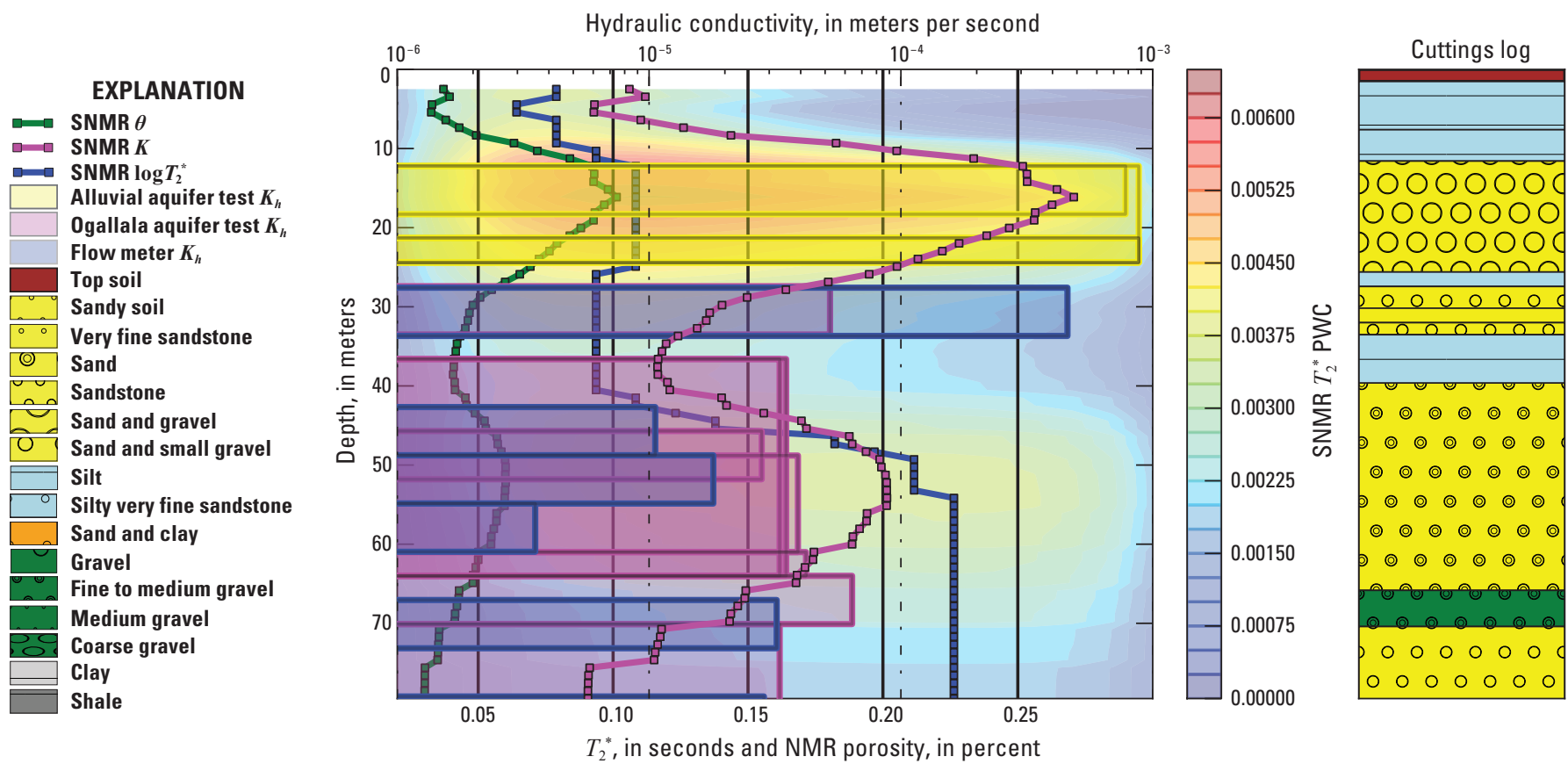

Figure 22. Results of surface nuclear magnetic resonance inversion at site 58A. The transparently colored bars represent the aquifer and flowmeter tests, and the solid lines show the SNMR-derived aquifer parameters. Symbols $K$ and $K_{h}$ show the surface nuclear magnetic resonance (SNMR) and horizontal aquifer test-derived hydraulic conductivities, respectively. The SNMR-derived porosity $(\theta)$ and logarithmic-mean $T_{2}^{*}$ parameters also are shown.

\section{EXPLANATION}

\begin{tabular}{|c|c|}
\hline$\square$ & SNMR $\theta$ \\
\hline$\square$ & SNMR $K$ \\
\hline$\square$ & SNMR $\log T_{2}^{*}$ \\
\hline & Alluvial aquifer test $K_{h}$ \\
\hline & Ogallala aquifer test $K_{h}$ \\
\hline & Flow meter $K_{h}$ \\
\hline & Top soil \\
\hline & Sandy soil \\
\hline 0 & Very fine sandstone \\
\hline () & Sand \\
\hline & Sandstone \\
\hline & Sand and gravel \\
\hline U & Sand and small gravel \\
\hline & Silt \\
\hline & Silty very fine sandstone \\
\hline & Sand and clay \\
\hline & Gravel \\
\hline & Fine to medium gravel \\
\hline & Medium gravel \\
\hline & Coarse gravel \\
\hline & Clay \\
\hline & Shale \\
\hline
\end{tabular}

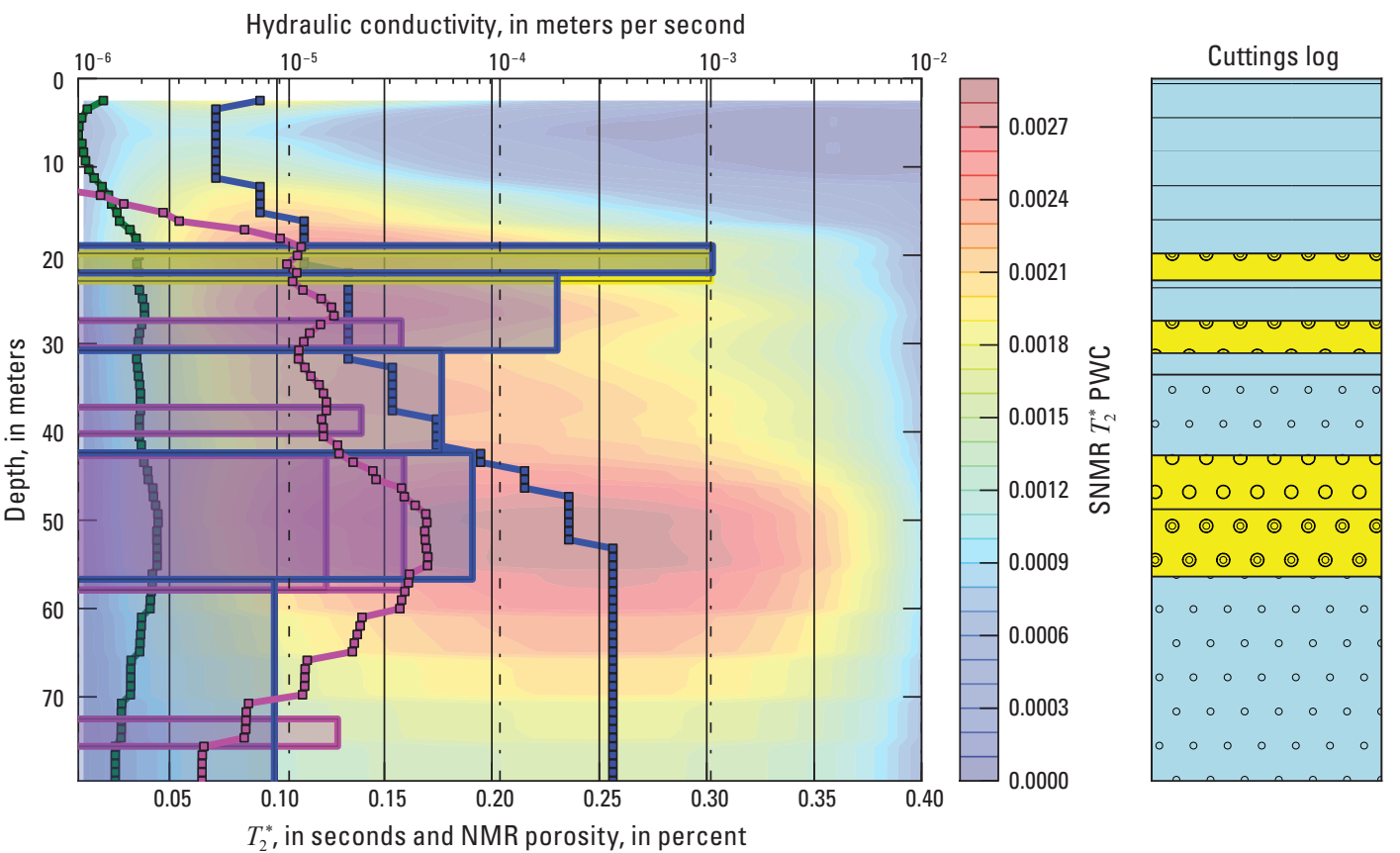

Figure 23. Results of Surface Nuclear Magnetic Resonance inversion at site 72A. The transparently colored bars represent the aquifer and flowmeter tests, and the solid lines show the SNMR-derived aquifer parameters. Symbols $K$ and $K_{h}$ show the surface nuclear magnetic resonance (SNMR) and horizontal aquifer test-derived hydraulic conductivities, respectively. The SNMR-derived porosity $(\theta)$ and logarithmic-mean $T_{2}^{*}$ parameters are also shown. 

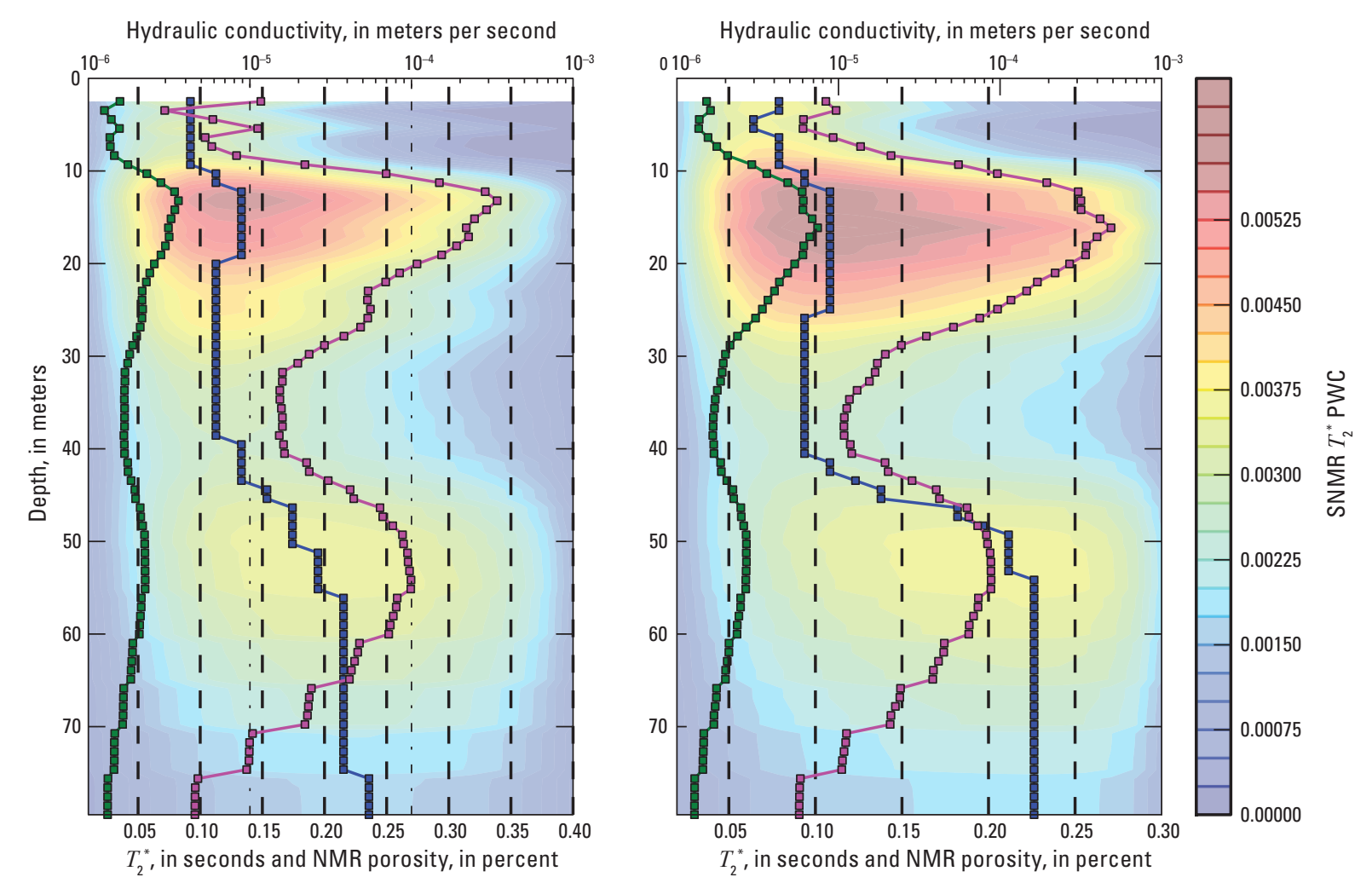

EXPLANATION

$\square \operatorname{SNMR} \theta \quad \square \operatorname{SNMR} K \quad$ SNMR $\log \bar{T}_{2}^{*}$

Figure 24. Comparison of inversions at site 58A from 2009 (left) and 2010 (right). The solid lines show the surface nuclear magnetic resonance-derived aquifer parameters. Symbol $K$ represents the surface nuclear magnetic resonance-derived hydraulic conductivity. The SNMR-derived porosity $(\theta)$ and logarithmic-mean $T_{2}^{*}$ parameters are also shown.

Our approach was to treat these sites as a regional test deployment. The same survey configuration and geometry were used at each site. The goal was to see how well the SNMR method performed in this type of "production" mode. Most of the aquifer tests concentrated on the shallow parts of the alluvial aquifer, so it was decided to use a relatively small (44-m) figure-eight transmitter loop. That type of transmitter rejects a large amount of common-mode noise (Trushkin and others, 1994). This survey configuration is a safe choice when ambient noise levels are not known; the downside is that the depth of investigation is significantly reduced. In this situation we feel that it was a prudent choice. Results of each of the SNMR inversions are discussed below, as is each individual aquifer test, including location and number of observation wells, as well as the goals of each test.

Table 3. Dates of data acquisition, Central Platte Natural Resources District, Nebr.

\begin{tabular}{lcc}
\hline \multicolumn{1}{c}{ Site } & Aquifer test date & SNMR acquisition \\
\hline 58A & $11 / 2009$ & $3 / 2008-3 / 2010$ \\
$72 \mathrm{~A}$ & $11 / 2007$ & $3 / 2008-3 / 2010$ \\
Chapman West & $7 / 2005$ & $4 / 2010$ \\
Chapman South & 2005 & $4 / 2010$ \\
Meyer & $9 / 1962$ & $4 / 2010$ \\
Layher & Spring 1993 & $4 / 2010$ \\
MSEA & $11 / 1991$ & $4 / 2010$ \\
\hline
\end{tabular}

None of these five aquifer tests were as comprehensive as those at sites $58 \mathrm{~A}$ and $72 \mathrm{~A}$, making the task of validation somewhat vague. In every case, cuttings logs also were recorded and are presented along with inversion results. At several sites, no observation wells were placed in areas where the SNMR indicated the largest porosities and hydraulic conductivities. In areas lacking observation-well coverage, the cuttings logs become the only way to validate and verify the SNMR data.

\section{Chapman West}

The Chapman West aquifer test was completed near Chapman, Nebr. (fig. 1), within the Platte River alluvial valley. The driller's log indicates a layer of alluvial sand and gravel at depths of 11.6 to $24.3 \mathrm{~m}$, that overlies a layer of clay. Four observation wells were completed in zones as shallow as $12.1 \mathrm{~m}$ to as deep as $18.2 \mathrm{~m}$ (fig. 25; table 7, Appendix). Across those intervals hydraulic conductivities ranged from $0.9 \times 10^{-3}$ to $1.2 \times 10^{-3} \mathrm{~m} / \mathrm{s}$ (fig. 25 ; table 6 ).

The SNMR data at Chapman West were fair in quality; the estimated noise bias was $16.7 \mathrm{nV}$, and the standard deviation of the late time was estimated at $34 \mathrm{nV}$. The smallest amplitude pulse moments contained the largest portion of the signal, so most of the water content was expected to be shallow. The 


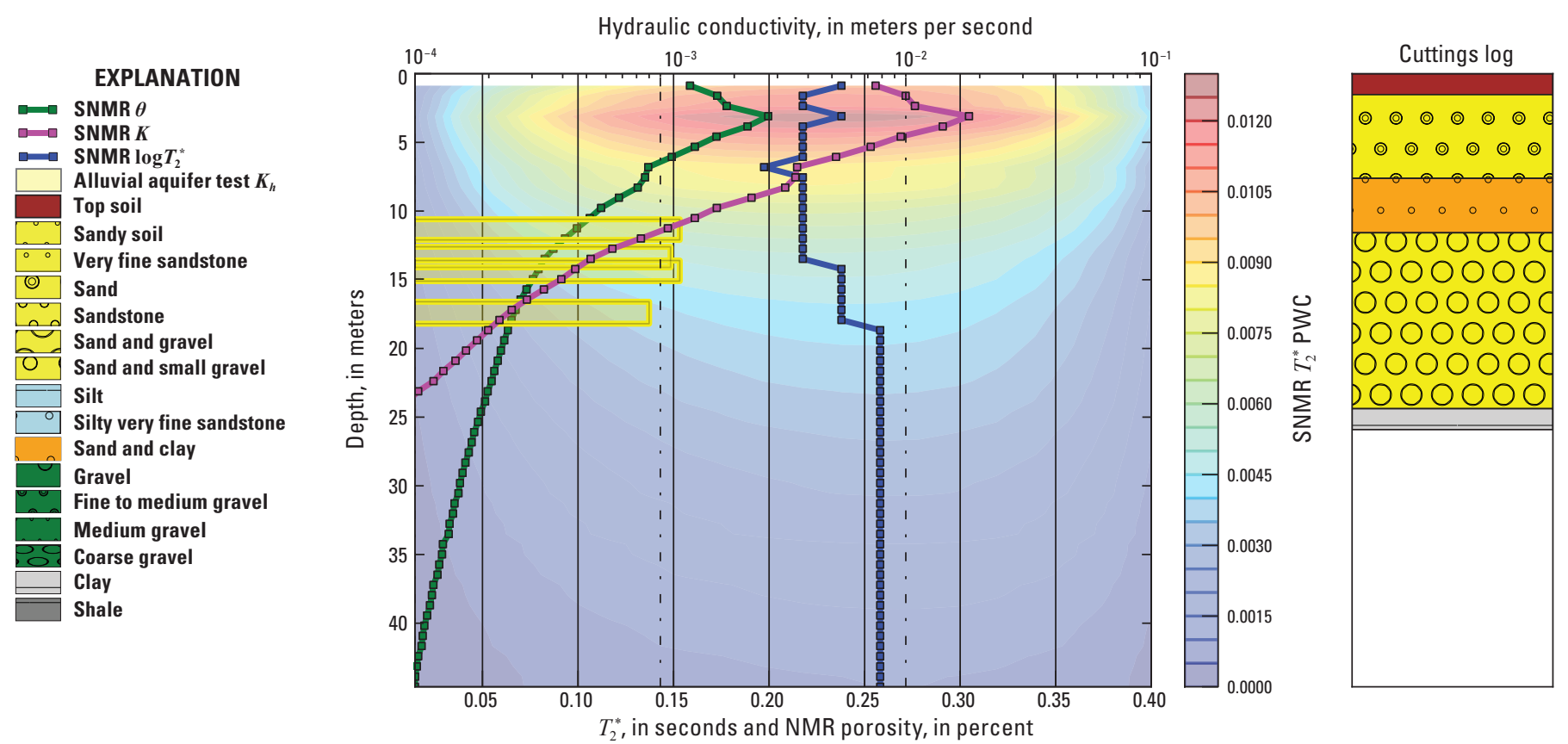

Figure 25. Inversion result for the Chapman West site, Nebraska. The transparent bars represent the aquifer and flowmeter tests, and the solid lines show the surface nuclear magnetic resonance-derived aquifer parameters. The $K$ and $K_{h}$ show the surface nuclear magnetic resonance (SNMR) and horizontal aquifer test-derived hydraulic conductivities, respectively. The SNMR-derived porosity $(\theta)$ and logarithmic-mean $T_{2}^{*}$ parameters also are shown.

inversion result (fig. 25) suggests that most of the water at this site is in the top few meters, specifically around $4 \mathrm{~m}$ in depth. The total water content falls off with depth about where cuttings logs show a sand and clay wedge, fining towards the clay unit at about $25 \mathrm{~m}$ depth.

\section{Chapman South}

The Chapman South aquifer test was completed near Chapman, Nebr. (fig. 1), within the Platte River alluvial valley. The driller's log indicates a layer of alluvial sand and gravel from 4.5 to $26 \mathrm{~m}$. Three observation wells were completed in the alluvium in two separate depths from approximately 11 to $12 \mathrm{~m}$ and 16 to $18 \mathrm{~m}$ below land surface (fig. 26). Hydraulic conductivity ranged from $1.1 \times 10^{-3}$ to $1.3 \times 10^{-3} \mathrm{~m} / \mathrm{s}$ (fig. 26 ; table 7, Appendix).

The SNMR data at Chapman South were of good quality, with estimated noise bias at $17 \mathrm{nV}$, and the standard deviation of the late time at $21 \mathrm{nV}$. The inversion shows the majority of water between 5 and $25 \mathrm{~m}$, which is in excellent agreement with the cuttings logs. The $K$ estimates from the SNMR are somewhat larger than those determined by the aquifer test. It can be seen, however, that this aquifer test did not have extensive coverage.

\section{Meyer}

The Meyer aquifer test was completed in 1931 near the city of Grand Island, Nebr. (fig. 1), using 80 shallow monitoring wells and piezometers. Although a test hole indicated the site is underlain by more than $30 \mathrm{~m}$ of alluvial sand and gravel, screened intervals for the observation wells ranged from 2.6 to $6.7 \mathrm{~m}$ below land surface, focusing on the shallow alluvial aquifer (fig. 27). Piezometers were driven into the ground to a desired depth and were open to the formation through the bottom of the piezometer. Further detail regarding aquifer test design and data collection can be found in Wenzel (1936) and Wenzel and Fishel (1942). Chen (1998) reevaluated the data collected from 22 of the 80 monitoring wells (table 7, Appendix) and estimated hydraulic conductivities that ranged from $1.0 \times 10^{-3}$ to $1.6 \times 10^{-3} \mathrm{~m} / \mathrm{s}$ (fig. 27 , table 7, Appendix).

The SNMR data from Meyer were of fair quality, with an estimated noise bias and standard deviation of 20 and $31 \mathrm{nV}$, respectively. The low-amplitude pulse moments contained the largest signal amplitudes, but larger pulse moments have signal as well. The inversion (fig. 27) is consistent with the data and shows a peak of water content at about 3 meters, but with significant $K$ zones as deep as 30 meters. A peak in the SNMR $K$ at 24 meters is consistent with gravel at that depth in the cuttings logs. The hydraulic conductivities near the observation wells are in good agreement with those returned by the aquifer test.

\section{Layher}

The Layher aquifer test was completed in 1993 by the U.S. Department of Interior Bureau of Reclamation (Robert Kutz, written commun., 1993). As indicated by the test-hole $\log$ (fig. 28), $2 \mathrm{~m}$ of clay are underlain by $20 \mathrm{~m}$ of 

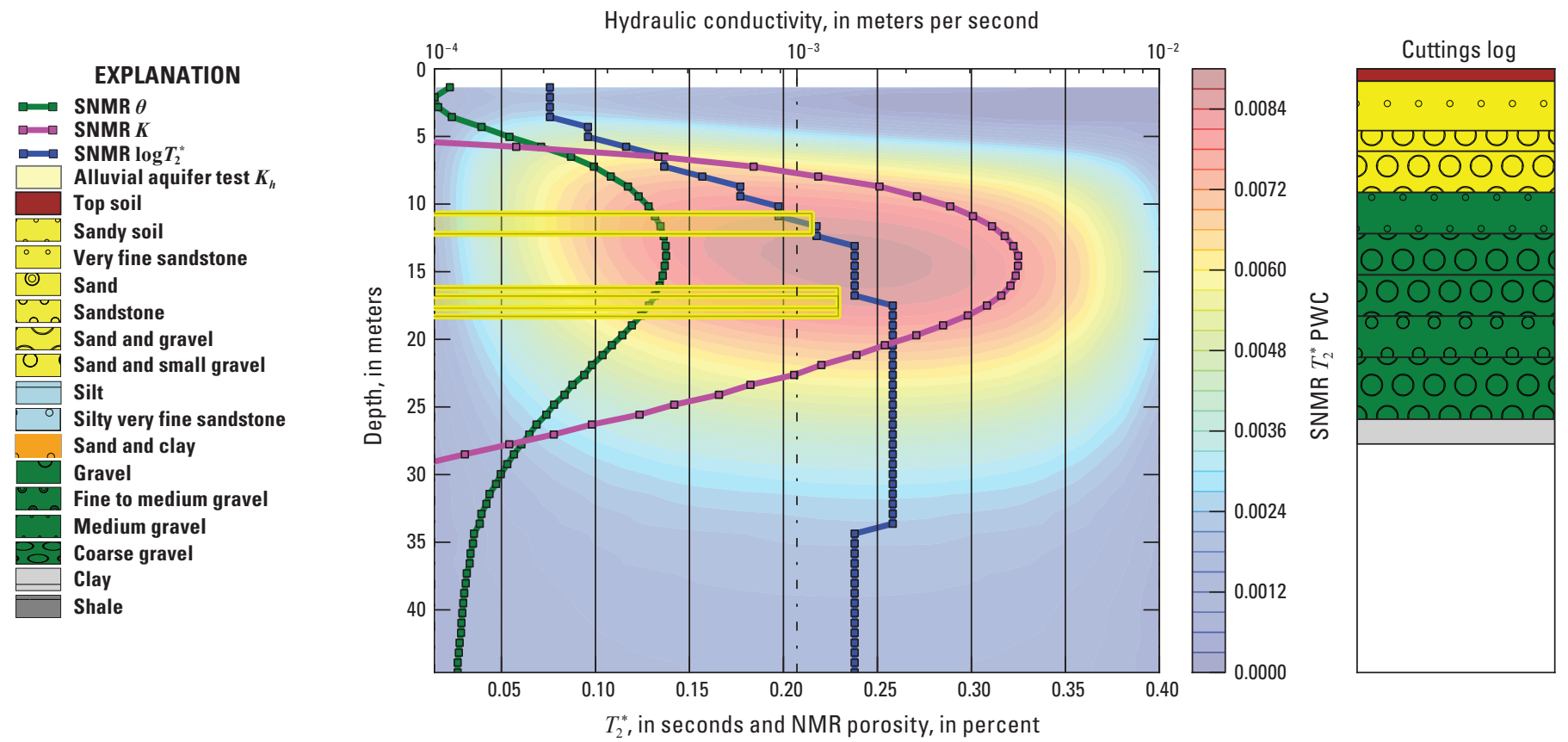

Figure 26. Inversion result from the Chapman South site, Nebraska. The transparent bars represent the aquifer and flowmeter tests, and the solid lines show the SNMR-derived aquifer parameters. Symbols $K$ and $K_{h}$ show the surface nuclear magnetic resonance (SNMR) and horizontal aquifer test-derived hydraulic conductivities, respectively. The SNMR-derived porosity $(\theta)$ and logarithmic-mean $T_{2}^{*}$ parameters also are shown.

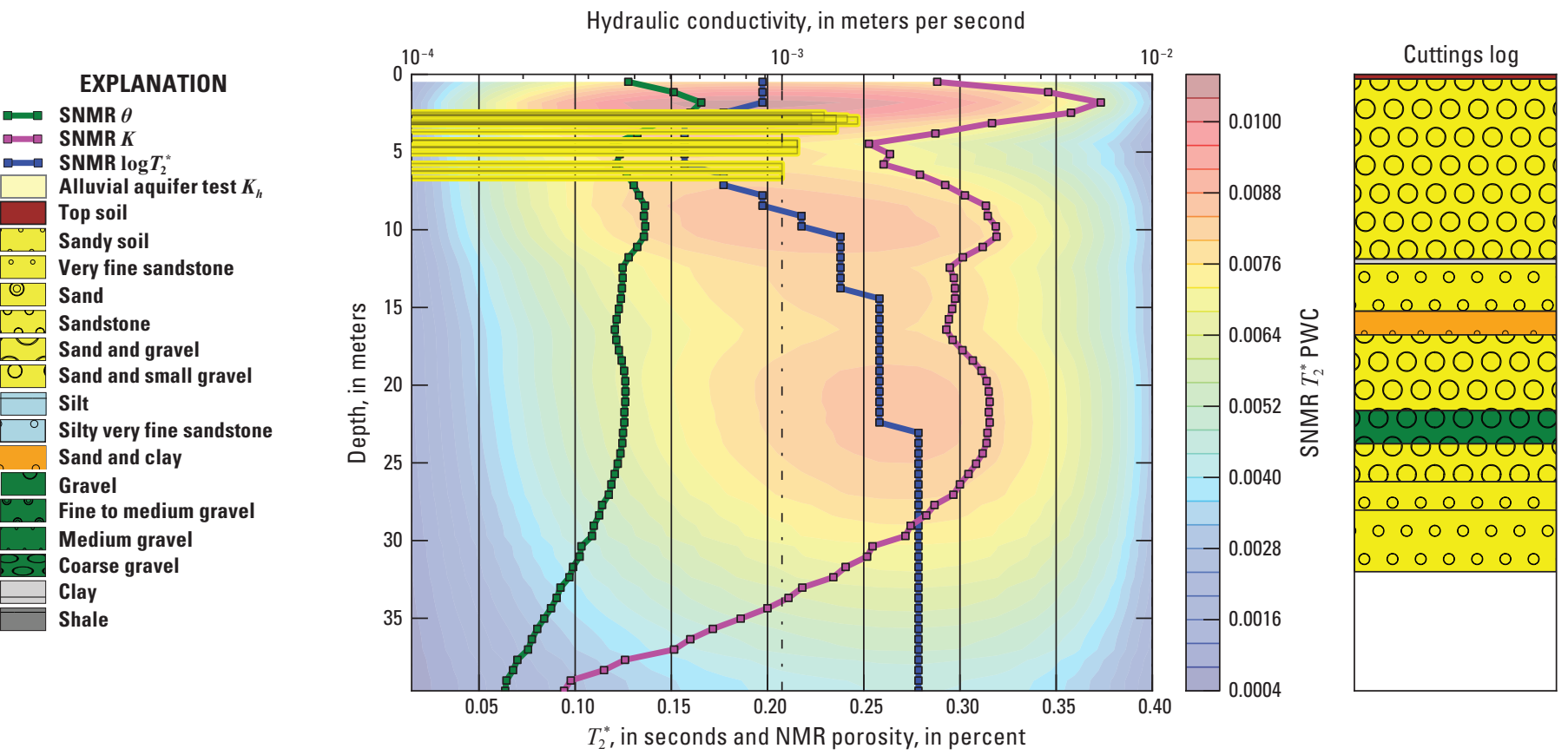

Figure 27. Inversion result from the Meyer site, Nebraska. Transparent bars represent the aquifer and flowmeter tests, and the solid lines show the surface nuclear magnetic resonance-derived aquifer parameters. Symbols $K$ and $K_{h}$ show the surface NMR results and horizontal aquifer test-derived hydraulic conductivities, respectively. The surface NMR-derived porosity $(\theta)$ and logarithmic-mean $T_{2}^{*}$ parameters also are shown. 


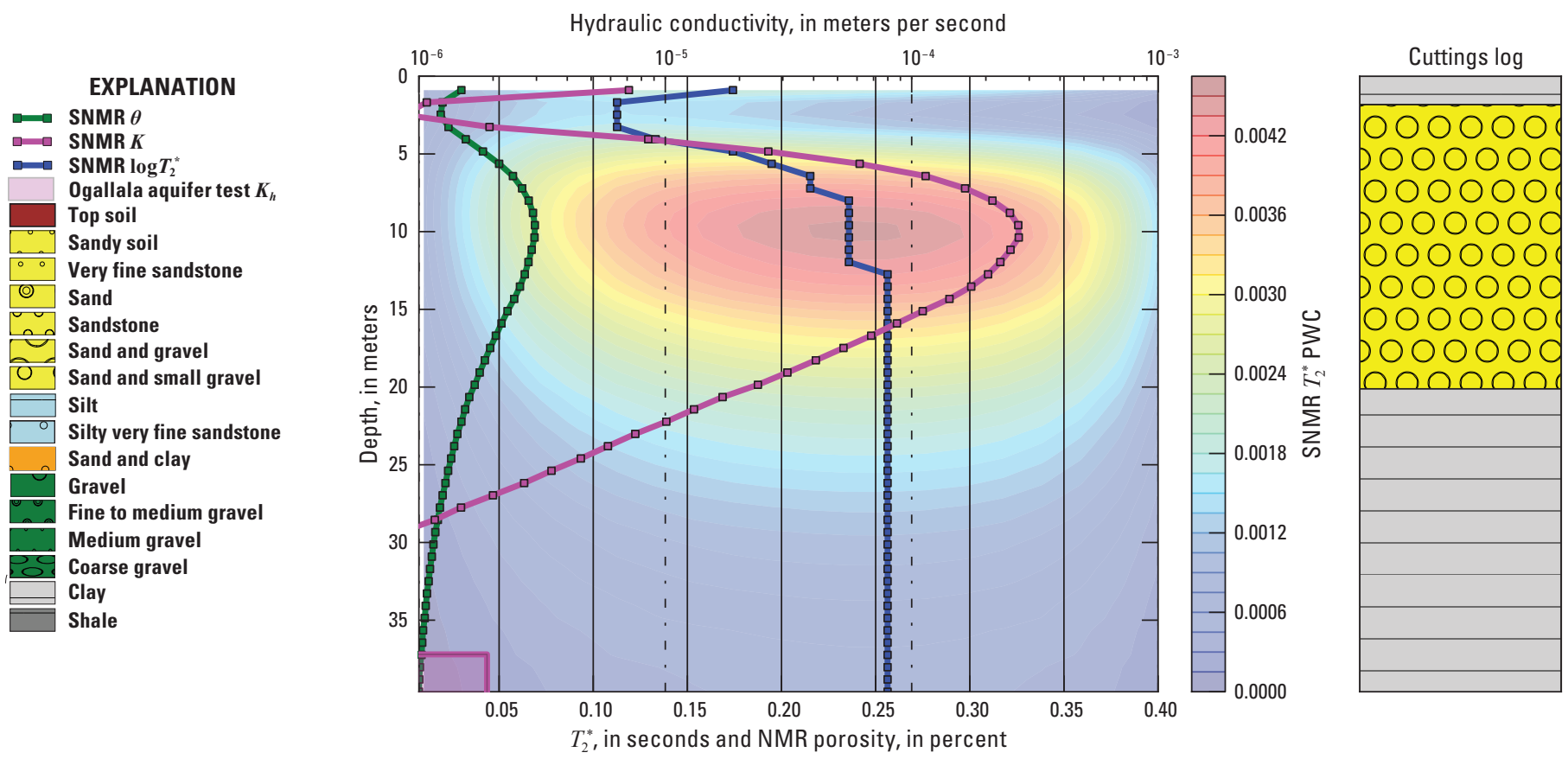

Figure 28. Inversion result from the Layher site, Nebraska. Transparent bars represent the aquifer and flowmeter tests, and the solid lines show the surface nuclear magnetic resonance-derived aquifer parameters. Symbols $K$ and $K_{h}$ show the surface NMR results and horizontal aquifer test-derived hydraulic conductivities, respectively. The surface NMR-derived porosity $(\theta)$ and logarithmic-mean $T_{2}^{*}$ parameters also are shown.

sand and gravel. The only observation well within the SNMR depth of investigation was completed in a 20 -m-thick layer of clay and silt that separates sand and gravel from the Ogallala Group. As a result, hydraulic properties of the shallow alluvial aquifer have not been quantified as were other sites. The low- $K$ silt and clay separating alluvium from Ogallala rock units was estimated to be $1.9 \times 10^{-6} \mathrm{~m} / \mathrm{s}$ (fig. 28 , table 7 , Appendix). For this aquifer test, the placement of the screened intervals makes for a difficult comparison.

The data at Layher were low noise, with an estimated noise bias of $8 \mathrm{nV}$, with a late-time standard deviation of $8 \mathrm{nV}$ as well. As stated above, there are no $K$ estimates within the depth of investigation of this SNMR loop. The inversion, shown in figure 28, is consistent with the cuttings logs in the area and with other local known sand units.

\section{Management Systems Evaluation Area (MSEA)}

The Management Systems Evaluation Area (MSEA) aquifer test was completed southwest of the city of Shelton, Nebr., at the University of Nebraska MSEA (fig. 1). McGuire and Kilpatrick (1998) reported completion of two aquifer tests (in 1991 and 1992; table 7, Appendix) estimating the aquifer properties of the underlying alluvial aquifer above a 3-m-thick clay layer. Screened intervals spanned from 5.5 to $18 \mathrm{~m}$ below land surface. Estimated hydraulic conductivity values ranged from $1.1 \times 10^{-3}$ to $1.3 \times 10^{-3} \mathrm{~m} / \mathrm{s}$ (fig. 29; table 7, Appendix).
Data quality at MSEA was fair, and the data contained many noise spikes. The noise bias was estimated at $22 \mathrm{nV}$, and the late time had a standard deviation of $21 \mathrm{nV}$. However, the inversion at this site is in good agreement with the aquifer test. As shown in figure 29, the gravel aquifer from 4 to 16 meters was well-characterized with the surface NMR, and the hydraulic conductivity estimates are in good agreement with the aquifer test.

\section{Discussion}

The surface nuclear magnetic resonance method should be adopted as a valuable tool to aid in characterizing and understanding the hydrogeologic framework in the Platte River valley of central Nebraska. It could also be deployed in different terrains and locations, but such use would require additional calibration. Having two carefully constructed and thorough aquifer tests at sites $58 \mathrm{~A}$ and $72 \mathrm{~A}$ allowed for calibration of the SNMR data using a minimum number of aquifer tests. The fact that our approach to calibration, while different from those presented by Plata and Rubio (2008) and Nielsen and others (2011), was capable of producing consistent estimates of hydraulic properties, is encouraging. For aquifers that extend beyond the depth of investigation of SNMR, or if only a limited number of very comprehensive aquifer tests are available, our approach may be the more attractive one. It appears that a single 

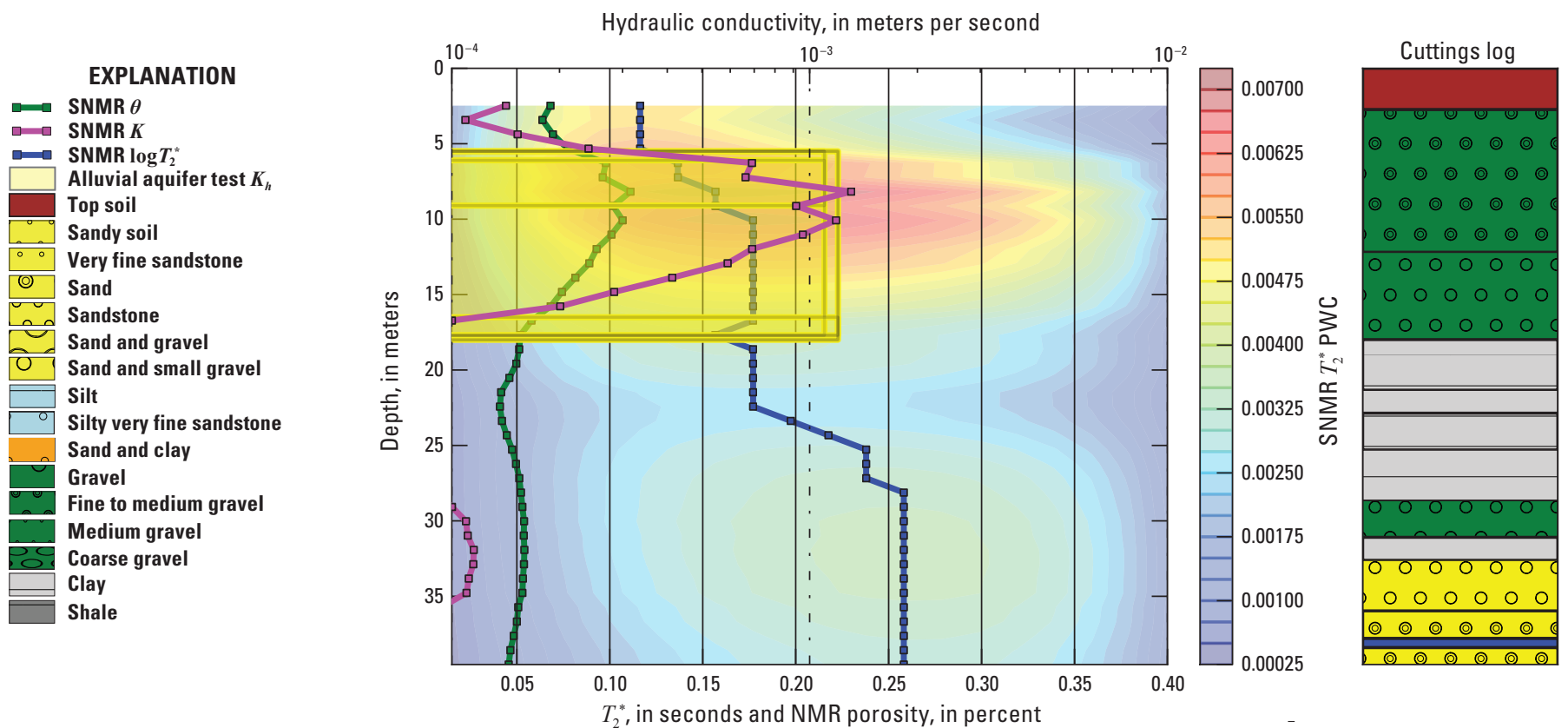

Figure 29. Inversion result from the Management Systems Evaluation Area (MSEA) site, Nebraska. The transparent bars represent the aquifer and flowmeter tests, and the solid lines show the surface nuclear magnetic resonance-derived aquifer parameters. Symbols $K$ and $K_{h}$ show the surface NMR and horizontal aquifer test-derived hydraulic conductivities, respectively. The surface NMR-derived porosity $(\theta)$ and logarithmic-mean $T_{2}^{*}$ parameters also are shown.

aquifer test could be sufficient, before deploying SNMR instruments in a new area, to thoroughly investigate the hydrologic setting. Surface NMR-derived estimates of $K$ at Sites OW58A and OW72A were within the range provided by the flowmeter and aquifer tests. The uncertainty of these tests is difficult to quantify, so that the variance between them stands as the only gauge of traditional testing confidence. The fact that the SNMR data are repeatable between years also is important and highlights the fact that the SNMR method can be used in resourcemanagement applications.

Our validation through the blind application of the $c_{p}$ factor from sites OW58A and OW72A to previously performed aquifer tests was also encouraging. The SNMR results are in general agreement with the aquifer tests in the blind applications. Those instances where there are disparities generally can be attributed to aquifer-test design or placement. The fact that we were able to make estimates of $K$ over a large area is particularly promising. On one hand, it seems unfortunate that the 'historical' aquifer tests were not all designed in a way that allowed for direct or complete comparison with the SNMR. On the other hand, this fact highlights the utility of SNMR. Aquifer tests are expensive, and SNMR can be used to fill in existing coverage and to add detail to incomplete or sparse aquifer tests.

While the results are promising, it is important to recognize the limitations of SNMR. The SNMR inversions did struggle to resolve thin layers of high $K$; this is especially evident at sites 58A and 72A. The SNMR method also is limited in regard to depth of investigation. Noise also can be a significant limitation for SNMR.
Groundwater managers in the CPNRD anticipate integrating SNMR information into their groundwater models. The CPNRD is responsible for managing groundwater use over 8,500 square kilometers, and fully determining aquifer characteristics over such a large area using aquifer tests would be cost-prohibitive. Surface NMR could provide coverage economically over that large area, however. The SNMR also could be used in critical but poorly understood areas, to map out changing aquifer characteristics. The CPNRD anticipates integrating SNMR-derived hydraulic conductivities as inputs into their regional groundwater models.

\section{Suggestions for Future Studies}

This research focused on the application of the SNMR technique and the development of a new inversion method to quantify aquifer properties in the Platte River valley. It also investigated supporting data and techniques such as borehole flowmeter logs and surface transient electromagnetic (TEM) soundings in order to begin development of proper techniques and procedures for use of that tool. Quantifying aquifer properties using SNMR requires the calculation of a $c_{p}$ factor specific to an area. As the technology continues to be applied in this or other studies, we would suggest that scientists consider the following approaches or procedures.

Application of the approach described in this study requires a good regional hydrogeologic framework and at least one fully characterized study site where aquifer properties have been quantified, typically with multi-well aquifer tests. As discussed previously in this report, due to the expense, 
many aquifer tests may not characterize adequately the entire thickness of the aquifer of interest. Therefore, it may be necessary to select a new site or sites by reviewing available hydrogeologic information and/or collecting additional data (test-hole drilling, TDEM, or other techniques).

As with traditional aquifer tests, once a site is selected, a test hole is drilled and logged. We suggest collection of borehole geophysical data beyond the standard suite of logs (resistivity, gamma, electromagnetic induction, and caliper $\operatorname{logs}$ ) to include flow and fluid-property logs. Those logs provide a more detailed look at various flow zones within an aquifer as compared to aquifer tests alone and prove useful in evaluating SNMR inversion results. Additionally, we suggest the collection of borehole magnetometer data which will help determine the appropriate dephasing window used for inversion of the SNMR data. A recently developed borehole NMR system (Vista Clara Inc., 2012) provides estimates of the hydraulic conductivity (K) and can aid in interpretation of SNMR data by providing an independent measurement of $T_{2}$, the NMR transverse spin-spin relaxation-time constant. Because borehole NMR data are collected "down hole," that tool is not limited to a depth of investigation, and deeper portions of aquifers can be investigated.

Once a reference site has been adequately characterized and SNMR data collected, a calibration factor $\left(c_{p}\right)$ used in relating SNMR inversions and aquifer test results can be calculated with an appropriate form of equation 19. All depths from the SNMR inversion can be compared to estimates of hydraulic conductivity from the aquifer tests or other borehole logs. A least-mean-square regression can be used to calculate the $c_{p}$ factor that minimizes total RMS error. Additional SNMR soundings collected within the same geologic terrane can then be used to quantify aquifer properties and to evaluate the effectiveness of the $c_{p}$ calibration factor. Unsatisfactory performance of the $c_{p}$ factor should prompt evaluation of the collected SNMR data and/or consideration of the need for additional reference sites.

As SNMR begins to be applied in other locations across the United States and the world, other geologic terranes will be characterized with reference sites. To allow other scientists to take advantage of the advancing technology, we propose that such additional reference sites could be added to a database relating SNMR soundings with aquifer properties.

\section{Summary}

Surface nuclear magnetic resonance (SNMR) is a noninvasive geophysical method that measures a signal directly related to the water in the subsurface. This allows for low-cost quantitative estimates of hydraulic parameters. In actual practice, additional factors influence the signal, complicating interpretation. The U.S. Geological Survey, in cooperation with the Central Platte Natural Resources District (CPNRD), and funded in part by the Nebraska Environmental Trust, evaluated whether hydraulic parameters derived from SNMR data could provide valuable data for input into groundwater models used for evaluating water-management practices. Two calibration sites in Dawson County, Nebr., (sites 58A and 72A) were chosen based on previous detailed hydrogeologic and geophysical investigations. At each site, SNMR data were collected, and derived parameters were compared with results from four carefully designed constant-discharge aquifer tests previously conducted at the same sites. In addition, comparisons were made with borehole electromagnetic (EM) flowmeter tests at sites 58A and 72A (Anderson and others, 2009). Also presented in this report are comparisons of SNMR inversions collected where additional aquifer tests were completed in the CPNRD. The purpose of this report is to compare collected SNMR data to the results from four aquifer tests completed at sites $58 \mathrm{~A}$ and $72 \mathrm{~A}$.

The two primary hydrostratigraphic units underlying the CPNRD are the Ogallala and alluvial deposits. The Ogallala underlies the western part of the CPNRD and is the principal hydrogeologic unit in the High Plains aquifer system. The Ogallala is a poorly sorted mixture of sand, silt, clay, and gravel. The Ogallala generally is unconsolidated or weakly consolidated but contains layers of sandstone cemented by calcium carbonate. Where sufficient saturated deposits are present in the CPNRD, the alluvial deposits form a primary aquifer largely because of their widespread distribution, shallow depth, and their ability to yield sufficient groundwater supplies to high-capacity wells.

Surface NMR is a promising geophysical technique for non-invasively estimating hydraulic conductivity and total subsurface water. The advantage over other geophysical methods is that the SNMR response is directly related to liquid water in the subsurface. This allows for quantitative estimates of hydraulic parameters. Surface NMR does present challenges, however, as the method suffers under low signal-tonoise conditions. The SNMR signal is further complicated by electrical and magnetic properties of the subsurface. Building on work by Irons and others (2010), we present a novel modeling and inversion framework for SNMR that incorporates these effects. This approach is unique in its ability to model the dynamics of the magnetic property effects. The inversion is also compressive and has good numerical properties.

Four aquifer tests of 192-hr duration were conducted at sites $58 \mathrm{~A}$ and $72 \mathrm{~A}$; $96-\mathrm{hr}$ of pumping immediately followed by $96-\mathrm{hr}$ of water-level recovery. Sixteen observation wells, nine at site $58 \mathrm{~A}$ and seven at site $72 \mathrm{~A}$, were open to the Ogallala. Fourteen of those 16 observation wells were open only to the Ogallala and were used for aquifer-test data collection to characterize the hydraulic properties of the Ogallala. Results of the aquifer tests indicate that with respect to aquifer type (alluvial or Ogallala), horizontal hydraulic conductivity $\left(\mathrm{K}_{\mathrm{r}}\right)$ at sites $58 \mathrm{~A}$ and $72 \mathrm{~A}$ were similar. Values of $\mathrm{K}_{\mathrm{r}}$ in the alluvial aquifers at both sites, were at least an order of magnitude larger than values of $\mathrm{K}_{\mathrm{r}}$ in the Ogallala aquifers. Composite analysis, looking at the aquifer as a whole, of the alluvial aquifer indicates $\mathrm{K}_{\mathrm{r}}$ values of $8.5 \times 10^{-4} \mathrm{~m} / \mathrm{s}$ at site $58 \mathrm{~A}$ and $1.0 \times 10^{-3} \mathrm{~m} / \mathrm{s}$ at site $72 \mathrm{~A}$. Composite analysis of the Ogallala at each site shows $\mathrm{K}_{\mathrm{r}}$ values ranging from $3.5 \times 10^{-5}$ to $3.9 \times 10^{-5} \mathrm{~m} / \mathrm{s}$ at sites $58 \mathrm{~A}$ and $72 \mathrm{~A}$, respectively. 
Flow and fluid-property logs were collected in OW58A-430 under quasi-steady state pumping conditions. Consistent with Andersen and others (2009), the upper zone of the Ogallala contributed much of the flow under pumping conditions - approximately 79 percent of the total flow. Other portions of the lower zone of the Ogallala contributed between nearly zero to almost 6 percent of the total flow.

At sites $72 \mathrm{~A}$ and 58A, SNMR data were taken over the course of several years to establish repeatability of the measurements, to survey multiple locations within the same area, and to appraise multiple-survey loop geometries and pulse sequences. At site 58 we used data from a 100-m square loop with a 40-ms pulse-moment duration for our analysis. In general, the data quality at site 58 was excellent after applying noise cancellation. Site 72A was a more challenging field location, where the presence of both high-tension transmission lines as well as residential power lines and houses in the vicinity resulted in variable noise sources that were not completely removable using the noise-cancelling reference-loop technique. There were cases where the SNMR data that were collected were unusable due to high noise levels. Still, usable data were collected on numerous occasions.

Sites 58A and 72A further were used as reference sites where a calibration factor $\left(c_{p}\right)$ factor could be determined and used in the Kenyon equation. The $c_{p}$ factor was estimated by simultaneously comparing all depths from the SNMR inversion that coincided with hydraulic conductivity estimates from the aquifer tests. A least-mean-square regression was used to calculate the $c_{p}$ factor that minimized the total RMS error.

There have been multiple aquifer tests completed in the Central Platte valley in the last 50 years with data publically available. None of those aquifer tests were as comprehensive as sites $58 \mathrm{~A}$ and $72 \mathrm{~A}$, making the task of validation somewhat vague. In every case, cuttings logs were also recorded and are presented along with the inversion results. At several sites, no observation wells were placed in areas where the SNMR indicated the largest porosities and hydraulic conductivities. In areas lacking coverage of observation wells, the cuttings logs become the only way to validate and verify the SNMR data.

Our validation through the blind application of the $c_{p}$ factor from sites $58 \mathrm{~A}$ and $72 \mathrm{~A}$ to previously performed aquifer tests is encouraging. The SNMR results are in general agreement with the aquifer tests in the blind applications. Disparities between SNMR and aquifer tests can be generally attributed to aquifer test design or placement. The fact that we were able to make hydraulic conductivity estimates over a large area is particularly promising. On the one hand, it seems unfortunate the "historical" aquifer tests were not all designed in a way that allows for direct or complete comparison with the SNMR. On the other hand, this fact highlights the utility of SNMR. Aquifer tests are expensive, and SNMR can be used to fill in existing coverage and add detail to incomplete and sparse aquifer tests. This makes the data collected from the SNMR useful in groundwater models provided the data are properly collected and analyzed.

\section{References Cited}

Abragam, A., 1961, The principles of nuclear magnetism: Oxford, International Series of Monographs on Physics, Clarendon Press, 599 p.

Abraham, J.D., Cannia, J.C., Bedrosian, P.A., Johnson, M.R., Ball, L.B., and Sibray, S.S., 2011a, Airborne electromagnetic mapping of the base of aquifer in areas of western Nebraska: U.S. Geological Survey Scientific Investigations Report 2011-5219, 42 p.

Abraham, J.D., Bedrosian, P.A., Asch, T.H., Ball, L.B., Cannia, J.C., Phillips, J.D., and Lackey, Susan, 2011b, Evaluation of geophysical techniques for the detection of paleochannels in the Oakland area of eastern Nebraska as part of the Eastern Nebraska Water Resource Assessment: U.S. Geological Survey Scientific Investigations Report 2011-5228, 40 p.

Anderson, J.A., Morin, R.H., Cannia, J.C., and Williams, J.H., 2009, Geophysical log analysis of selected test holes and wells in the High Plains aquifer, Central Platte River basin, Nebraska: U.S. Geological Survey Scientific Investigations Report 2009-5033, 16 p.

Auken, E., and Nebel, K., 2001, Getting started with SiTEM and Semdi: Aarhus, Denmark, University of Aarhus HydroGeophysics Group, 22 p., available at $h t t p: / / w w w . a a r h u s g e o . c o m /$ files/papers/sitem_semdi.pdf/.

Ball, L.B., Kress, W.H., Steele, G.V., Cannia, J.C., and Andersen, M.A., 2006, Determination of canal leakage potential using continuous resistivity profiling techniques, Interstate and Tri-State Canals, western Nebraska and eastern Wyoming, 2004: U.S. Geological Survey Scientific Investigations Report 2006-5032, 53 p.

Barrett, R., Berry, M, Chan, T.F., Demmel, J., Donato, J., Dongarra, J., Eijkhout, V., Pozo, R., Romine, C., and van der Vorst, H., 1994, Templates for the solution of linear systems - Building blocks for iterative methods ( $2 \mathrm{~d}$ ed.): Philadelphia, Society for Industrial and Applied Mathematics [SIAM], $107 \mathrm{p}$.

Bloch, F., 1946, Nuclear induction: Physical Review, v. 70, p. $460-474$.

Braun M., Hertrich, M., and Yaramanci, U., 2005, Study on complex inversion of magnetic resonance sounding signals: Near Surface Geophysics, v. 3, p. 155-163.

Brownstein, K.R., and Tarr, C.E., 1979, Importance of classical diffusion in NMR studies of water in biological cells: Physical Review A, v. 19, p. 2446-2453.

Calvetti, D., Lewis, B., Reichel, L., and Sgallari, F., 2004, Tikhonov regularization with nonnegativity constraint: Electronic Transactions on Numerical Analysis, v. 18, p. 153-173. 
Cannia, J.C., Woodward, D., and Cast, L.D., 2006, Cooperative Hydrology Study [COHYST] hydrostratigraphic units and aquifer characterization report: Lincoln, Nebraska Department of Natural Resources, 96 p., accessed December 2010, at http://cohyst.dnr.ne.gov/document/ dc012hydro_aquifer_022406.pdf.

Carney, C.P., 2008, Groundwater flow model of the central model unit of the Nebraska Cooperative Hydrology Study (COHYST) area: Lincoln, Nebraska Department of Natural Resources, 87 p., accessed December 2010, at http://cohyst. dnr.ne.gov/adobe/dc012CMU_GFMR_081224.pdf.

Carr, H.Y., and Purcell, E.M., 1954, Effects of diffusion on free precession in nuclear magnetic resonance experiments: Physical Review, v. 94, p. 630-638.

Center for Advanced Land Management Information Technologies, 2007, 2005 Nebraska land use map: Lincoln, Univ. of Nebraska, [CALMIT data], accessed December 9, 2010, at http://www.calmit.unl.edu/2005landuse/statewide.shtml.

Chen, X., 1998, Assessment of hydraulic properties in an unconfined alluvial aquifer near Grand Island, Nebraska: Journal of the American Water Resources Association, v. 34, no. 3, p. 603-616.

Chen, X., Goeke, J.W., Ayers, J.F., and Summerside, S.E., 2003, Observation well network design for pumping tests in unconfined aquifers: Journal of the American Water Resources Association, v. 39, no. 1, p. 17-32.

Chen, X., Yin, Y., Goeke, J.W., and Diffendal, R.F., Jr., 2005, Vertical movement of water in a High Plains aquifer induced by a pumping well: Environmental Geology, v. 47, no. 7, p. 931-941.

Condon, S.M., 2005, Geologic studies of the Platte River, south-central Nebraska and adjacent areas-Geologic maps, subsurface study, and geologic history: U.S. Geological Survey Professional Paper 1706, 63 p.

Condra, G.E., and Reed, E.C., 1943, The geological section of Nebraska: Nebraska Geological Survey (Conservation and Survey Division, University of Nebraska-Lincoln) Bulletin, v. 14, p. 82.

Darton, N.H., 1898, Underground waters of a portion of southeastern Nebraska: U.S. Geological Survey Water Supply and Irrigation Paper 12, $56 \mathrm{p}$.

Darton, N.H., 1905, Preliminary report on the geology and underground water resources of the central Great Plains: U.S. Geological Survey Professional Paper 32, 433 p.

Diffendal, R.F., Jr., 1991, Geologic map showing configuration of the bedrock surface, North Platte 1 degree $\times$ 2 degrees Quadrangle, Nebraska: U.S. Geological Survey Miscellaneous Investigations Series Map I-2277, 1 sheet, scale 1:250,000.
Dlugosch, R., Müeller-Petke, M., Günther, T., Costabel, S., and Yaramanci, U., 2011, Assessment of the potential of a new generation of surface nuclear magnetic resonance instruments: Near Surface Geophysics, v. 9, no. 2, p. $169-178$.

Ernst, R., Bodenhausen, G., and Wokaun, A., 1990, Principles of nuclear magnetic resonance in one and two dimensions: Oxford, International Series of Monographs on Chemistry, Clarendon Press, 610 p.

Farrar, T., and Becker, E., 1971, Pulse and Fourier transform NMR - Introduction to theory and methods: New York, Academic Press, 107 p.

Fenneman, N.M., and Johnson, D.W., 1946, Physiographic divisions of the conterminous United States: U.S. Geological Survey Special Map Series, scale 1:7,000,000.

Gev, I., Goldman, M., Rabinovich, B., Rabinovich, M., and Issar, A., 1996, Detection of the water level in fractured phreatic aquifers using nuclear magnetic resonance (NMR) geophysical measurements: Journal of Applied Geophysics, v. 34 , no. 4 , p. $277-282$.

Grunewald, E., and Knight, R., 2011, The effect of pore size and magnetic susceptibility on the surface NMR relaxation parameter $T_{2}^{*}$ : Near Surface Geophysics, v. 9, no. 2, p. 169-178.

Guillen, A., and Legchenko, A., 2002, Inversion of surface nuclear magnetic resonance data by an adapted Monte Carlo method applied to water resource characterization: Journal of Applied Geophysics, v. 50, nos. 1-2, p. 193-205.

Gutentag, E.D., Heimes, F.J., Krothe, N.C., Luckey, R.R., and Weeks, J.B., 1984, Geohydrology of the High Plains aquifer in parts of Colorado, Nebraska, New Mexico, Oklahoma, South Dakota, Texas, and Wyoming: U.S. Geological Survey Professional Paper 1400-B, 63 p.

Hahn, E.L., 1950, Spin echoes: Physical Review, v. 80, p. 580-594.

Hansen, P.C., 1992, Analysis of discrete ill-posed problems by means of the L-curve: Society for Industrial and Applied Mathematics [SIAM] Review, v. 34, p. 561-580.

Hantush, M.S., 1960, Modification of the theory of leaky aquifers: Journal of Geophysical Research, v. 65, no. 11, p. 3713-3725.

Hertrich, M., Braun, M., and Yaramanci, U., 2005, Magnetic resonance soundings with separated transmitter and receiver loop: Near Surface Geophysics, v. 3, p. 131-144.

Hobza, C.M., Asch, Theodore, and Bedrosian, P.A., 2011, Hydrostratigraphic interpretation of test-hole and surface geophysical data, Upper Loup River basin, Nebraska, 2008 to 2010: U.S. Geological Survey Open-File Report 2011-1289, 60 p. (Also available online at $h t t p: / / p u b s . u s g s . g o v / o f / 2011 / 1289 /$ ).

HydroSOLVE, Inc., 2011, AQTESOLV: Reston, Va., HydroSOLVE, Inc., version 4.50.002, [aquifer-test analytical software], accessed April 2011, at http://www.aqtesolv.com. 
Irons, T., Li, Y., and McKenna, J.R., 2010, Frequency-domain surface nuclear magnetic resonance forward modeling on an adaptive octree mesh: Society of Exploration Geophysicists Technical Program Expanded Abstracts, v. 29, p. 3935-3939.

Jackson, J. D., 1998, Classical electrodynamics (3d ed.): New York, Wiley, 808 p.

Johnson, A.I., 1967, Specific yield-Compilation of specific yields for various materials: U.S. Geological Survey WaterSupply Paper 1662-D, 74 p.

Kenyon, W., 1997, Petrophysical principles of applications of NMR logging: The Log Analyst, v. 38, no. 2, p. 21-43.

Kenyon, W., Day, P., Straley, C., and Willemsen, J., 1988, A three-part study of NMR longitudinal relaxation properties of water-saturated sandstones: Society of Petroleum Engineers Formation Evaluation, v. 3, no. 3, p. 622-636.

Kleinberg, R., Kenyon, W., and Mitra, P., 1994, Mechanism of NMR relaxation of fluids in rock: Journal of Magnetic Resonance, Series A, v. 108, no. 2, p. 206-214.

Knight, R., Grunewald, E., Irons, T., Dlubac, K., Song, Y., Bachman, H.N., Grau, B., Walsh, D., Abraham, J.D., and Cannia, J.C., 2012, Field experiment provides ground truth for surface nuclear magnetic resonance measurement: Geophysical Research Letters, v. 39, [letter] L03304, 7 p.

Kollet, S.J., 2003, Stream-aquifer interactions under pumping conditions in an unconfined aquifer considering threedimensional flow, aquifer heterogeneity, and anisotropy: Lincoln, University of Nebraska-Lincoln, Ph.D. dissertation, $336 \mathrm{p}$.

Kollet, S.J., and Zlotnik, V.A., 2003, Stream depletion predictions using pumping test data from a heterogeneous streamaquifer system [a case study from the Great Plains, USA]: Journal of Hydrology, v. 281, no. 1-2: p. 96-114.

Konikow, L.F., and Bredehoeft, J.D., 1992, Ground-water models cannot be validated: Advances in Water Resources, v. 15 , no. 1 , p. 7583 .

Kruseman, G.P., and de Ridder, N.A., 1990, Analysis and evaluation of pumping test data, with assistance from J.M. Verweij ( $2 \mathrm{~d}$ ed.): Wageningen, The Netherlands, International Institute for Land Reclamation and Improvement, Publication 47, $377 \mathrm{p}$.

Legchenko, A., and Valla, P., 1998, Processing of surface proton magnetic resonance signals using non-linear fitting: Journal of Applied Geophysics, v. 39, no. 2, p. 77-83.

Legchenko, A., and Valla, P., 2002, A review of the basic principles for proton magnetic resonance sounding measurements: Journal of Applied Geophysics, v. 50, p. 3-19.

Legchenko, A., and Valla, P., 2003, Removal of power-line harmonics from proton magnetic resonance measurements: Journal of Applied Geophysics, v. 53, no. 23, p. 103-120.
Legchenko, A., Baltassat, J-M., Beauce, A., and Bernard, J., 2002, Nuclear magnetic resonance as a geophysical tool for hydrogeologists: Journal of Applied Geophysics, v. 50, nos. 1-2, p. 2-46.

Legchenko, A., Baltassat, J-M., Bobachev, A., Martin, C., Robain, H., and Vouillamoz, J-M., 2004, Magnetic resonance sounding applied to aquifer characterization: Ground Water, v. 42, no. 3, p. 363-373.

Legchenko, A., Clément, R., Garambois, S., Maury, E., Mic, L-M., Laurent, J-P., Desplanque, C., and Guyard, H., 2011, Investigating water distribution in the Luitel Lake peat bog using MRS, ERT and GPR: Near Surface Geophysics, v. 9, no. 2, p. 201-209.

Legchenko, A., Descloitres, M., Bost, A., Ruiz, L., Reddy, M., Girard, J-F., Sekhar, M., Mohan Kumar, M.S., and Braun, J-J., 2006, Resolution of MRS applied to the characterization of hard-rock aquifers: Ground Water, v. 44, no. 4, p. 547-554.

Legchenko, A., Vouillamoz, J-M., and Roy, J., 2010, Application of the magnetic resonance sounding method to the investigation of aquifers in the presence of magnetic materials: Geophysics, v. 75, no. 6, p. 91-100.

Legchenko, A.V., and Shushakov, O.A., 1998, Inversion of surface NMR data: Geophysics, v. 63, no. 1, p. 75-84.

Levitt, M., 2001, Spin dynamics-Basics of nuclear magnetic resonance: New York, John Wiley \& Sons, 744 p.

Li, Y., and Oldenburg, D., 2000, 3-D inversion of induced polarization data: Geophysics, v. 65, no. 6, p. 1931-1945.

Lohman, S.W., 1972, Ground-water hydraulics: U.S. Geological Survey Professional Paper 708, 70 p.

Lugan, A.L., and Wenzel, L.K., 1938, Geology and groundwater resources of south-central Nebraska, with special reference to the Platte River valley between Chapman and Gothenburg: U.S. Geological Survey Water-Supply Paper 779, $242 \mathrm{p}$.

McGuire, V.L., and Kilpatrick, J.M., 1998, Hydrogeology in the vicinity of the Nebraska management systems evaluation area [MSEA] site, central Nebraska: U.S. Geological Survey Water-Resources Investigations Report 97-4266, $25 \mathrm{p}$.

Moench, A.F., 1985, Transient flow to a large-diameter well in an aquifer with storative semiconfining layers: Water Resources Research, v. 21, no. 8, p. 1121-1131.

Moench, A.F., 1997, Flow to a well of finite diameter in a homogeneous, anisotropic water-table aquifer: Water Resources Research, v. 33, no. 6, p. 1397-1407.

Mohnke, O., and Yaramanci, U., 2002, Smooth and block inversion of surface NMR amplitudes and decay times using simulated annealing: Journal of Applied Geophysics, v. 50, no. 12 , p. 163-177. 
Mohnke, O., and Yaramanci, U., 2005, Forward modeling and inversion of MRS relaxation signals using multi-exponential decomposition: Near Surface Geophysics, p. 165-185.

Mohnke, O., and Yaramanci, U., 2008, Pore-size distributions and hydraulic conductivities of rocks, derived from magnetic resonance sounding relaxation data using multi-exponential decay-time inversion: Journal of Applied Geophysics, v. 66 , nos. 3-4, p. 73-81.

Molz, F.J., and Young, S.C., 1993, Development and application of borehole flowmeters for environmental assessment: The Log Analyst, v. 34, no. 1, p. 13-23.

Müeller-Petke, M., and Yaramanci, U., 2010, QT inversionComprehensive use of the complete surface NMR data set: Geophysics, v. 75, no. 4, p. WA199-WA209.

Müeller-Petke, M., Hiller, T., Herrmann, R., and Yaramanci, U., 2011, Reliability and limitations of surface NMR assessed by comparison to borehole NMR: Near Surface Geophysics, v. 9, no. 2, p. 123-134.

National Oceanic and Atmospheric Administration, 2010, Climatological data annual summary, 2009: National Climatic Data Center, accessed December 9, 2010, at http://gis.ncdc.noaa.gov/website/ims-cdo/sod/viewer.htm.

Nielsen, M.T., Hagensen, T., Chalikakis, K., and Legchenko, A., 2011, Comparison of transmissivities from MRS and pumping tests in Denmark: Near Surface Geophysics, v. 9, p. 211-223.

Ostdiek, A., 2009, The integrated management planning process: Lincoln, Nebr., Nebraska Department of Natural Resources, Water Matters, no. 1, 4 p., accessed December 10, 2010, at http://www.dnr.state.ne.us/IWM/ WaterMatters/WaterMatters_No1.pdf.

Paillet, F.L., 2000, A field technique for estimating aquifer parameters using flow log data: Ground Water, v. 38 , no. 4 , p. $510-521$.

Parker, R.L., 1977, Understanding inverse theory: Annual Review, Earth and Planetary Science Letters, vol. 5, p. 35-64.

Payne, J.D., and Teeple, A.P., 2011, Time-domain electromagnetic soundings collected in Dawson County, Nebraska, 2007-09: U.S. Geological Survey Data Series 581, 46 p.

Peckenpaugh, J.M., and Dugan, J.T., 1983: Hydrology of parts of the Central Platte and Lower Loup Natural Resources Districts, Nebraska: U.S. Geological Survey WaterResources Investigations Report 83-4219, 125 p.

Peterson, S.P., 2007, Groundwater flow model of the eastern model unit of the Nebraska Cooperative Hydrology Study (COHYST) area: Lincoln, Nebr., Nebraska Department of Natural Resources, 80 p., accessed December 2010, at http:// cohyst.dnr.ne.gov/adobe/dc012EMU_GFMR_090507.pdf.
Plata, J.L., and Rubio, F.M., 2008, The use of MRS in the determination of hydraulic transmissivity-The case of alluvial aquifers: Journal of Applied Geophysics, v. 66, nos. 3-4, p. 128-139.

Radi, T., 2005, Zeitreihenauswertung von NMR messungen im Erdmagnetfeld., [presented at] Protokoll über das 21[st] Kolloquium "Elektromagnetische Tiefenforschung:" Deutsche Geophysikalische Gesellschaft e.V., [unpaginated].

Reed, E.C., and Dreeszen, V.H., 1965, Revision of the classification of the Pleistocene deposits of Nebraska: Nebraska Geological Survey Bulletin 23, 65 p.

Schwartz, F.W., and Zhang, H., 2003, Fundamentals of ground water: New York, John Wiley and Sons, 583 p.

Seevers, D., 1966, A nuclear magnetic method for determining the permeability of sandstones, in Annual Logging Symposium, Tulsa, Okla., USA, May 8-11, 1996, Transactions: Ann Arbor, Mich., Society of Petrophysicists and Well-Log Analysts, Paper L, 14 p.

Semenov, A.G., 1987, NMR hydroscope for water prospecting, in Seminar on Geotomography, Hyderabad, Proceedings: Hyderabad, Indian Geophysical Union, Expanded Abstracts, p. 66-67.

Shushakov, O.A., and Fomenko, V., 2004, Surface NMR relaxation and echo of aquifers in geomagnetic field: Applied Magnetic Resonance, v. 25, p. 599-610.

Shushakov, O.A., 1996a, Groundwater NMR in conductive water: Geophysics, v. 61, no. 4, p. 998-1006.

Shushakov, O.A., 1996b, Surface NMR measurement of proton relaxation times in medium to coarse-grained sand aquifer: Magnetic Resonance Imaging, v. 14, no. 78, p. $959-960$.

Stanton, G.P., Kress, W.H., Hobza, C.M., and Czarnecki, J.B., 2003, Possible extent and depth of salt contamination in ground water using geophysical techniques, Red River aluminum site, Stamps, Arkansas, April 2003: U.S. Geological Survey Water-Resources Investigations Report 03-4292, $35 \mathrm{p}$.

Steele, G.V., 1994, Groundwater levels in response to precipitation events, central Nebraska, 1987-1992: unpub. master's thesis, Lincoln, University of Nebraska-Lincoln, 183 p.

Steele, G.V., and Harvey, F.E., 2002, Use of water chemistry, isotopes, and chlorofluorocarbons to investigate the sources of ground water beneath Loup City, central Nebraska, 2000: U.S. Geological Survey Water-Resources Investigations Report 02-4049, 43 p.

Strehl, S., 2006, Development of strategies for improved filtering and fitting of SNMR-signals: Berlin, Germany, Technical University of Berlin, Master's thesis, 103 p. Available at http://www.geophysik.tu-berlin.de/fileadmin/a36321500/ Diplomarbeiten/Strehl.pdf, accessed August 13, 2012. 
Swinehart, J.B., and Diffendal, R.F., 1989, Geology, in Bleed, A.S., and Flowerday, C.A., eds., An atlas of the Sand Hills: Lincoln, Nebr., University of Nebraska-Lincoln Conservation and Survey Division Resource Atlas, no. 5a, p. 29-42.

Swinehart, J.B., Souders, V.L., DeGraw, H.M., and Diffendal, R.F., Jr., 1985, Cenozoic paleogeography of western Nebraska, in Flores, R.M., and Kaplan, S.S., eds., Cenozoic paleogeography of the west-central United States, Denver, Colo., Rocky Mountain Paleogeography Symposium 3: Tulsa, Society of Economic Paleontologists and Mineralogists, p. 209-229.

Todd, D.K., and Mays, L.W., 2005, Groundwater Hydrology (3d ed.): New York, John Wiley and Sons, 636 p.

Torrey, H.C., 1956, Bloch equations with diffusion terms: Physical Review, v. 104, p. 563-565.

Trushkin, D.V., Shushakov, O.A., and Legchenko, A.V., 1994, The potential of a noise-reducing antenna for surface NMR groundwater surveys in the earth's magnetic field: Geophysical Prospecting, v. 42, no. 8, p. 855.

U.S. Geological Survey, 2010, The Platte River Program-A USGS Priority Ecosystems Program: U.S. Geological Survey, accessed December 2010, at http://ne.water.usgs.gov/ platte/index.html.

University of Nebraska-Lincoln, Conservation and Survey Division, 2010, Nebraska test-hole database: Lincoln, Nebr., University of Nebraska-Lincoln, Conservation and Survey Division data, accessed December 2010 at http://snr.unl.edu/data/geologysoils/NebraskaTestHole/ NebraskaTestHoleIntro.asp/.

University of Nebraska-Lincoln, Conservation and Survey Division, 1998, Ground water atlas of Nebraska (2d ed.): Lincoln, Nebr., University of Nebraska-Lincoln, Conservation and Survey Division Resource Atlas, no. 4a, 44 p.

Valla, P., and Legchenko, A., 2002, One-dimensional modeling for proton magnetic resonance sounding measurements over an electrically conductive medium: Journal of Applied Geophysics, v. 50, nos. 1-2, p. 217-229.

Vista Clara Inc., 2012, Javelin Microhole/Slimhole NMR logging: Mukilteo, Wash., Vista Clara Inc., accessed April 26, 2012, at http://vista-clara.com/instruments_javelin.html.

Waite, H.A. and others, 1949, Progress report on the geology and ground-water hydrology of the lower Platte River valley, Nebraska, with a section on The chemical quality of the ground water, by H.A. Swensen: U.S. Geological Survey Circular 20, $211 \mathrm{p}$.

Walbrecker, J.O., Hertrich, M., and Green, A.G., 2009, Accounting for relaxation processes during the pulse in surface NMR data: Geophysics, v. 74, no. 6, p. G27-34.
Walbrecker, J.O., Hertrich, M., and Green, A.G., 2011a, Offresonance effects in surface nuclear magnetic resonance: Geophysics, v. 76, no. 2, p. G1-12.

Walbrecker, J.O., Hertrich, M., Lehmann-Horn, J.A., and Green, A.G., 2011b, Estimating the longitudinal relaxation time T1 in surface NMR: Geophysics, v. 76, no. 2, p. F111-122.

Walsh, D.O., 2008, Multi-channel surface NMR instrumentation and software for 1D/2D groundwater investigations: Journal of Applied Geophysics, v. 66, nos. 3-4, p. 140-150.

Ward, S.H., and Hohmann, G.W., Electromagnetic theory of geophysical applications, in Nabighian, M.N., ed., Electromagnetic methods in applied geophysics: Tulsa, Society of Exploration Geophysicists Investigations in Geophysics, v. 1, chap. 4, p. 131-308.

Weeks, J.B., and Gutentag, E.D., 1988, Region 17, High Plains, in Back, W., Rosenshein, J.S., and Seaber, P.R., eds., Hydrogeology, the geology of America: Boulder, Colo., Geological Society of America, v. O-2, p. 157-164.

Weeks, J.B., Gutentag, E.D., Heimes, F.J., and Luckey, R.R., 1988, Summary of the High Plains Regional Aquifer-system analysis in parts of Colorado, Kansas, Nebraska, New Mexico, Oklahoma, South Dakota, Texas, and Wyoming: U.S. Geological Survey Professional Paper 1400-A, 30 p.

Weichman, P. B., Lavely, E.M., and Ritzwoller, M.H., 2000, Theory of surface nuclear magnetic resonance with applications to geophysical imaging problems: Physical Review E, V. 62, no. 1, p. 1290-1312.

Weichman, P.B, Lun, D.R., Ritzwoller, M.H., and Lavely, E.M., 2002, Study of surface nuclear magnetic resonance inverse problems: Journal of Applied Geophysics, v. 50, nos. 1-2, p. 129-147.

Wenzel, L.K., 1936, The Thiem method for determining permeability of water-bearing materials and its application to the determination of specific yield - Results of investigations in the Platte River valley, Nebraska: U.S. Geological Survey Water-Supply Paper 679-A, 206 p.

Wenzel, L.K., and Fishel, V.C., 1942, Methods for determining permeability of water-bearing materials, with special reference to discharging-well methods, with a section on Direct laboratory methods and bibliography on permeability and laminar flow: U.S. Geological Survey Water-Supply Paper 887, 192 p.

Yaramanci, U., Lange, G., and Knodel, K., 1999, Surface NMR within a geophysical study of an aquifer at Haldensleben, Germany: Geophysical Prospecting, vol. 47, p. 923-943.

Zimmerman, R.A., Gibby, W.A., and Carmody, R.F., 2000, Neuroimaging: New York, Springer, 1642 p. 


\section{Appendix}

Table 4. Depth, screened interval, screen slot, and radial distance of observation wells from respective production wells, Dawson County, Nebr.

[All distances in meters unless indicated; water level at start of each test was about 3.66 meters below land surface at site 58A and about 12.8 meters below land surface at site 72A; r, radial distance; diameter of production wells, 40.6 centimeters; diameter of observation wells, 5.1 centimeters]

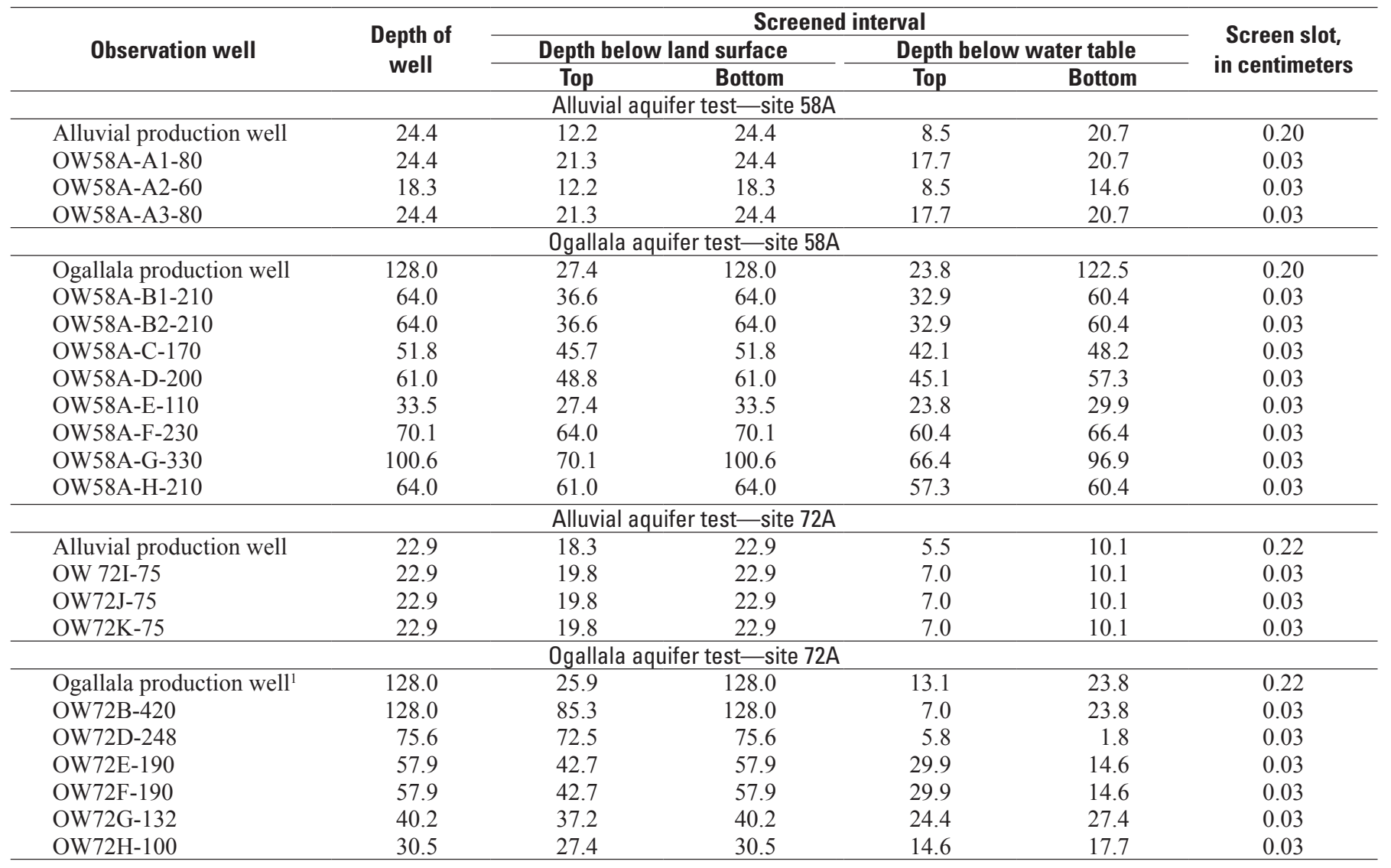

${ }^{1}$ Depth of production well actually is 131.1 meters. However, the bottom 3 meters is in the lower confining unit.

Table 5. Depth, screened interval, screen slot, and radial distance of fully screened observation wells from respective production wells, Dawson County, Nebr.

[All distances in meters unless indicated; water level at start of each test was about 3.66 meters below land surface at site 58A and about 12.8 meters below land surface at site $72 \mathrm{~A}$; cm, centimeters; shaded cells indicate screened interval open to alluvial deposits]

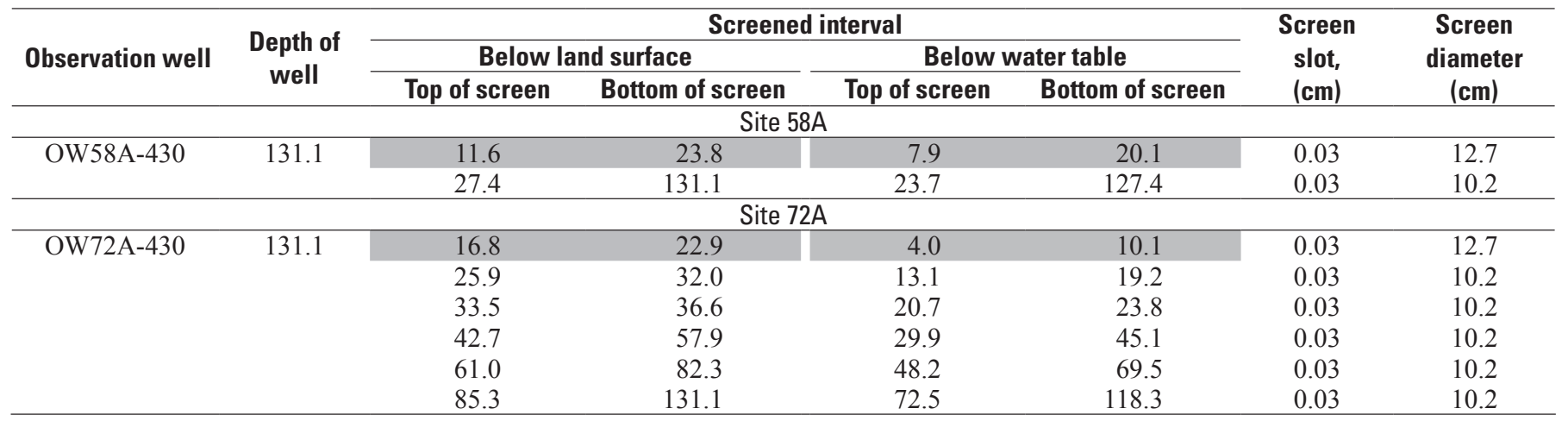


Table 6. Results of aquifer-test analyses, sites 58A and 72A, Dawson County, central Nebraska, 2008 and 2010.

[Symbols and abbreviations: $\mathrm{r}$, radius in meters; $\mathrm{m}^{2} / \mathrm{s}$, meters squared per second; $\mathrm{m} / \mathrm{s}$, meters per second; L/min, liters per minute; --, not applicable]

$\begin{array}{cccccc}\text { Well } & \begin{array}{c}\text { Distance from } \\ \text { pumped well }\end{array} & \begin{array}{c}\text { Transmissivity } \\ (\mathrm{r})\end{array} & \begin{array}{c}\text { Hydraulic } \\ \text { conductivity } \\ \left(\mathrm{m}^{2} / \mathrm{s}\right)\end{array} & \begin{array}{c}\text { Specific storage } \\ \text { (dimensionless) }\end{array} & \begin{array}{c}\text { Specific yield } \\ \text { (dimensionless) }\end{array}\end{array}$

Alluvial aquifer test; site $58 \mathrm{~A}$ - aquifer thickness 21.9 meters-discharge $5,700 \mathrm{~L} / \mathrm{min}$

\begin{tabular}{|c|c|c|c|c|c|}
\hline Alluvial composite test & -- & $1.8 \times 10^{-2}$ & $8.5 \times 10^{-4}$ & $1.2 \times 10^{-3}$ & $1.4 \times 10^{-1}$ \\
\hline OW58A-A1-80 & 8.2 & $1.9 \times 10^{-2}$ & $8.8 \times 10^{-4}$ & $1.0 \times 10^{-3}$ & $1.3 \times 10^{-1}$ \\
\hline OW58A-A3-80 & 18.3 & $1.8 \times 10^{-2}$ & $8.8 \times 10^{-4}$ & $8.0 \times 10^{-4}$ & $1.4 \times 10^{-1}$ \\
\hline Ogallala composite test & -- & $3.5 \times 10^{-3}$ & $3.5 \times 10^{-5}$ & $8.0 \times 10^{-4}$ & -- \\
\hline OW58A-B1-210 & 8.2 & $3.4 \times 10^{-3}$ & $3.5 \times 10^{-5}$ & $5.0 \times 10^{-4}$ & -- \\
\hline OW58A-B2-210 & 14.0 & $3.2 \times 10^{-3}$ & $3.3 \times 10^{-5}$ & $5.0 \times 10^{-4}$ & -- \\
\hline OW58A-E-110 & 14.3 & $5.2 \times 10^{-3}$ & $5.2 \times 10^{-5}$ & $1.0 \times 10^{-4}$ & -- \\
\hline OW58A-F-230 & 14.9 & $6.0 \times 10^{-3}$ & $6.4 \times 10^{-5}$ & $3.0 \times 10^{-4}$ & -- \\
\hline OW58A-G-330 & 8.8 & $3.2 \times 10^{-3}$ & $3.3 \times 10^{-5}$ & $2.0 \times 10^{-3}$ & -- \\
\hline OW58A-H-210 & 20.7 & $4.0 \times 10^{-3}$ & $4.2 \times 10^{-5}$ & $2.0 \times 10^{-3}$ & -- \\
\hline \multicolumn{6}{|c|}{ Alluvial aquifer test; site 72A - aquifer thickness 4.6 meters_-discharge $800 \mathrm{~L} / \mathrm{min}$} \\
\hline Alluvial composite test & -- & $3.1 \times 10^{-3}$ & $1.0 \times 10^{-3}$ & $5.5 \times 10^{-5}$ & $1.7 \times 10^{-2}$ \\
\hline Ogallala composite test & -- & $4.1 \times 10^{-3}$ & $3.9 \times 10^{-5}$ & $2.1 \times 10^{-3}$ & -- \\
\hline OW72B-420 & 18.7 & $3.5 \times 10^{-3}$ & $3.4 \times 10^{-5}$ & $8.6 \times 10^{-4}$ & -- \\
\hline OW72D-248 & 18.9 & $1.8 \times 10^{-3}$ & $1.7 \times 10^{-5}$ & $1.9 \times 10^{-3}$ & -- \\
\hline OW72E-190 & 19.2 & $1.6 \times 10^{-3}$ & $1.5 \times 10^{-5}$ & $3.3 \times 10^{-4}$ & -- \\
\hline OW72F-190 & 13.1 & $3.7 \times 10^{-3}$ & $3.5 \times 10^{-5}$ & $2.3 \times 10^{-3}$ & -- \\
\hline OW72G-132 & 8.3 & $2.3 \times 10^{-3}$ & $2.2 \times 10^{-5}$ & $1.8 \times 10^{-3}$ & -- \\
\hline OW72H-100 & 13.4 & $3.5 \times 10^{-3}$ & $3.4 \times 10^{-5}$ & $1.4 \times 10^{-3}$ & -- \\
\hline
\end{tabular}


Table 7. Primary investigator, reference date, site, well identifier, aquifer thickness, screened interval below land surface, and hydraulic conductivity of observation wells at selected aquifer-test sites in the Central Platte Natural Resources District, Nebr.

[All distances in meters; depths are depth below land surface datum; hydraulic conductivity in meters per second; open pipe suggested for wells having same depth for top and bottom of screen; UNL/USGS, University of Nebraska-Lincoln and U.S. Geological Survey; USGS, U.S. Geological Survey; MSEA, Management Systems Evaluation Area]

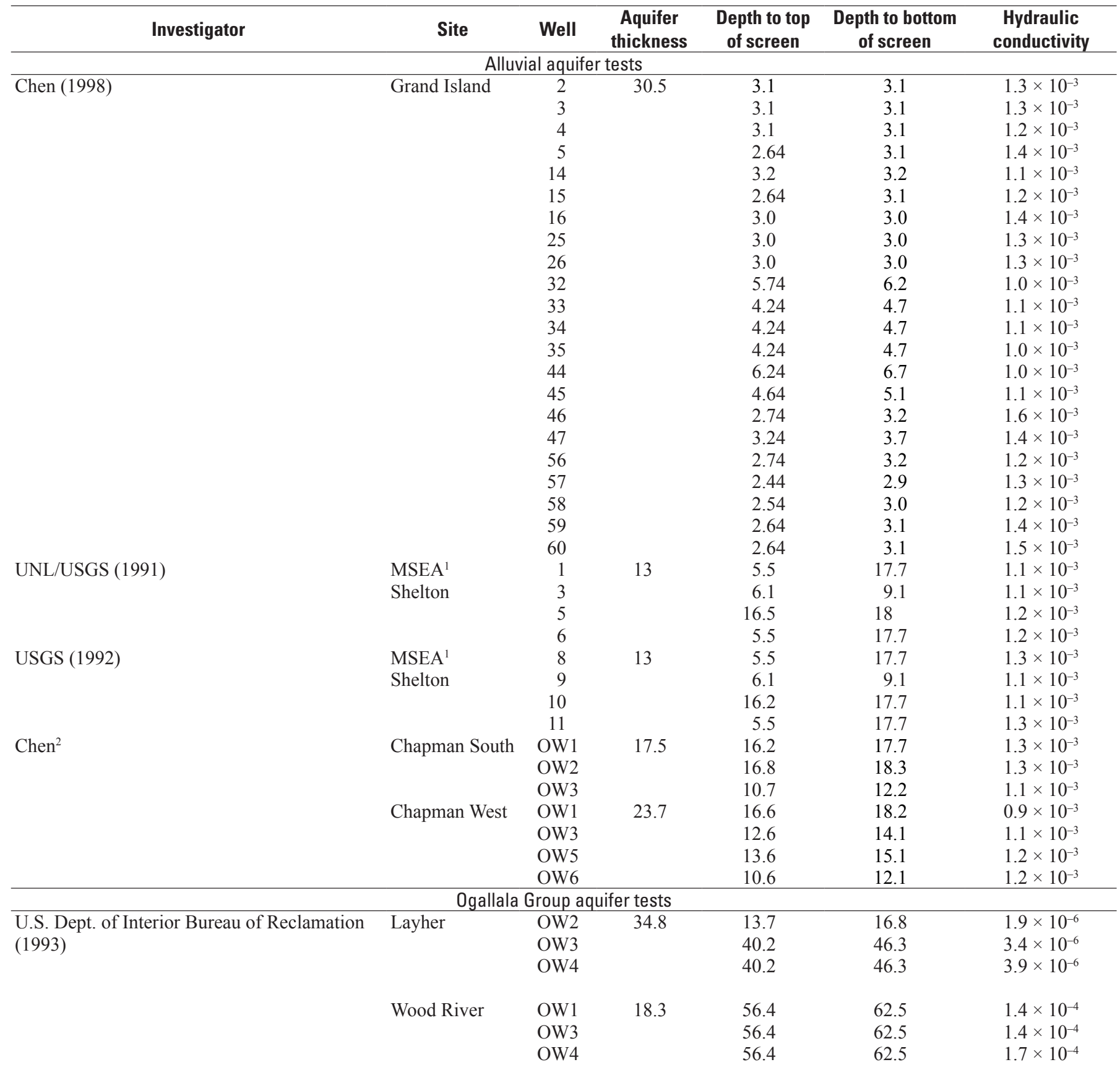


Table 7. Primary investigator, reference date, site, well identifier, aquifer thickness, screened interval below land surface, and hydraulic conductivity of observation wells at selected aquifer-test sites in the Central Platte Natural Resources District, Nebr.-Continued

[All distances in meters; depths are depth below land surface datum; hydraulic conductivity in meters per second; open pipe suggested for wells having same depth for top and bottom of screen; UNL/USGS, University of Nebraska-Lincoln and U.S. Geological Survey; USGS, U.S. Geological Survey; MSEA, Management Systems Evaluation Area]

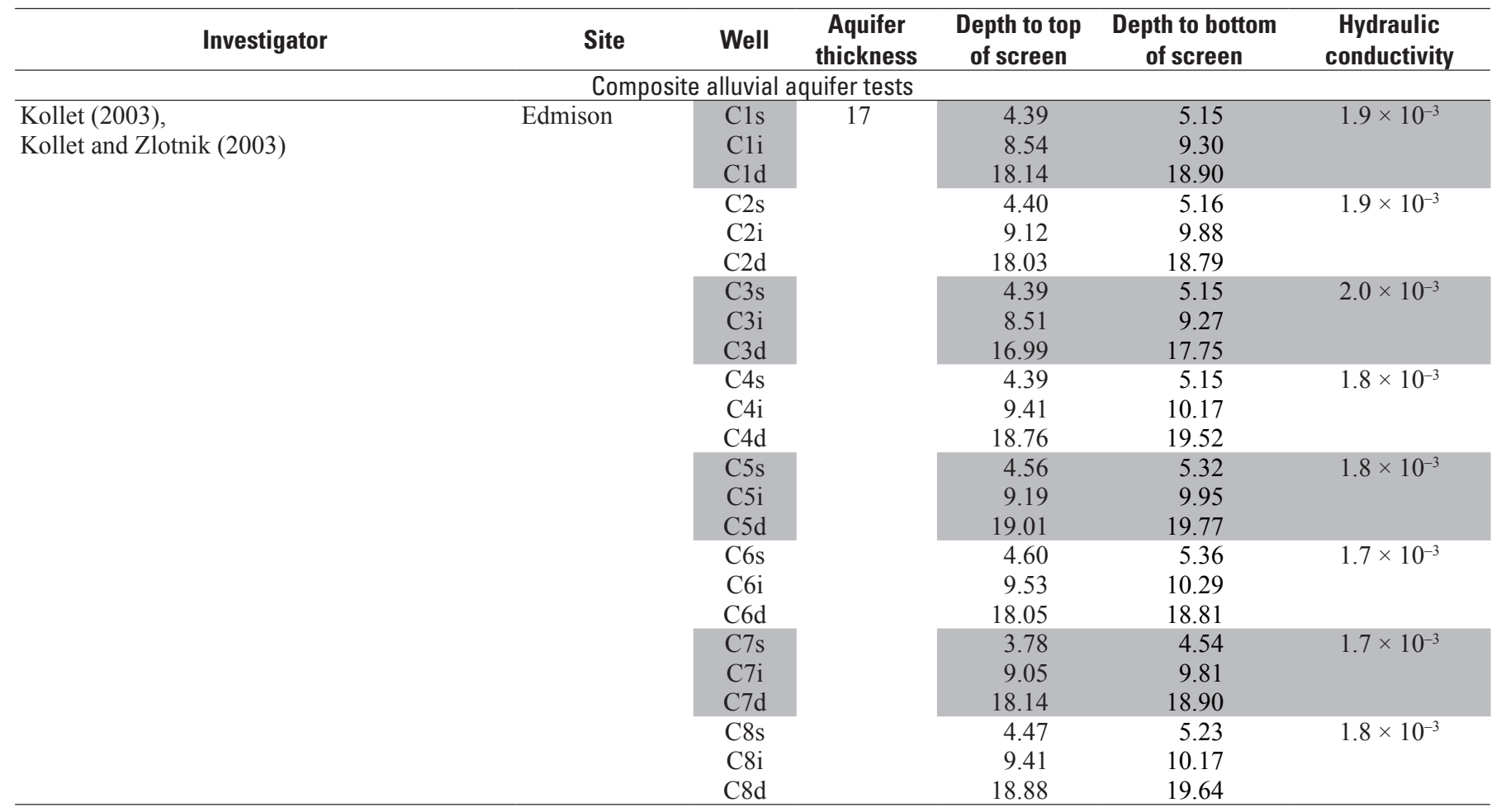

${ }^{1}$ McGuire, V.L., and Kilpatrick, J.M., 1998.

${ }^{2}$ Xun-hong Chen, University of Nebraska-Lincoln, 2005, written commun.

Publishing support provided by:

Denver Publishing Service Center, Denver, Colorado

For more information concerning this publication, contact:

Center Director, USGS Crustal Geophysics and Geochemistry Science Center Box 25046, Mail Stop 964

Denver, C0 80225

(303) 236-1312

Or visit the Crustal Geophysics and Geochemistry Science Center Web site at: http://crustal.usgs.gov/

This publication is available online at: http://pubs.usgs.gov/sir/2012/5189/ 
